Portland State University

PDXScholar

Civil and Environmental Engineering Master's

Project Reports

Fall 2020

\title{
Rapid Repair of Seismically Vulnerable Bridge Columns Following Earthquake Induced Damage
}

Gregory H. Norton

Portland State University

Follow this and additional works at: https://pdxscholar.library.pdx.edu/cengin_gradprojects

Part of the Structural Engineering Commons

Let us know how access to this document benefits you.

\section{Recommended Citation}

Norton, Gregory H., "Rapid Repair of Seismically Vulnerable Bridge Columns Following Earthquake Induced Damage" (2020). Civil and Environmental Engineering Master's Project Reports. 54.

https://doi.org/10.15760/CCEMP.52

This Project is brought to you for free and open access. It has been accepted for inclusion in Civil and Environmental Engineering Master's Project Reports by an authorized administrator of PDXScholar. Please contact us if we can make this document more accessible: pdxscholar@pdx.edu. 
RAPID REPAIR OF SEISMICALLY VULNERABLE BRIDGE COLUMNS FOLLOWING EARTHQUAKE INDUCED DAMAGE

BY

Gregory H. Norton

A research project report submitted in partial fulfillment of the requirement for the degree of

\author{
MASTER OF SCIENCE \\ IN \\ CIVIL AND ENVIRONMENTAL ENGINEERING
}

Project Advisor:

Peter Dusicka

Portland State University

(C) 2020 


\section{ACKNOWLEDGMENTS}

This report and Master of Science in Civil and Environmental Engineering project is based upon research conducted for the Oregon Department of Transportation (ODOT), whose support is gratefully acknowledged.

I would like to thank my advisor, Dr. Peter Dusicka, for his guidance and support throughout my time at Portland State University, as well as the opportunity to work as a research assistant in the iSTAR Laboratory. I would also like to acknowledge my undergraduate advisor, Dr. Kelly Clifton, for her encouragement to further my education through graduate school.

I would like to recognize the iSTAR staff, graduate students, and undergraduate students for their help with this research project. Ilya Palnikov, AKM Golam Murtuz, Aaron Smith, Patrick McCoy, Evgeny Hadji, Heyi Feng and Bradley Sharpshair, thank you for the countless hours you spent working on this research project.

Lastly, I would like to thank my family for their endless support throughout my undergraduate and graduate studies at Portland State University. I could not have done it without you. 


\section{ABSTRACT}

The Cascadia Subduction Zone (CSZ) earthquake has a high probability of occurrence within our lifetime, threatening bridges across the Pacific Northwest. Damage is expected to be geographically spread throughout the region and will have a nearly simultaneous impact on transportation through several important corridors. While bridge repair and replacement will ultimately be needed, priority will be placed on resuming mobility such that repairs will need to be implemented quickly. In an effort to anticipate this need, a repair method is being developed for rapid repair with the goal of achieving semi-permanent installation that also considers the different bridge damage states for future earthquakes. The proposed repair involves encasing the damaged column in a steel jacket which is then anchored to the foundation through easily replaceable ductile fuse hold-downs. The design objective is to isolate all inelastic strains to the hold-downs thus creating a low-damage solution.

Full-scale cyclic tests were conducted to investigate the cyclic performance on substandard column-to-foundation specimens. The proposed repair was applied to the damaged column and the specimen was then re-tested using the cyclic loading that is representative of CSZ demands. The experiments validated the design goal of achieving restored or controlled strength, while also exhibiting no additional damage and self-centering behavior. The experiments have shown the potential of this methodology to rapidly repair earthquake damaged columns with a relatively generic approach. 


\section{TABLE OF CONTENTS}

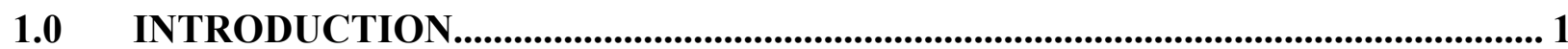

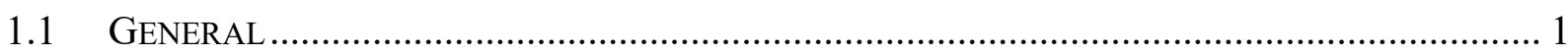

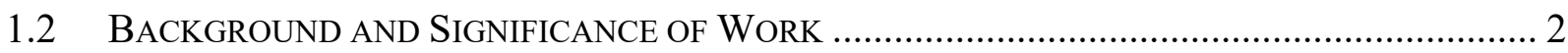

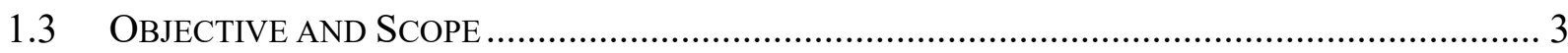

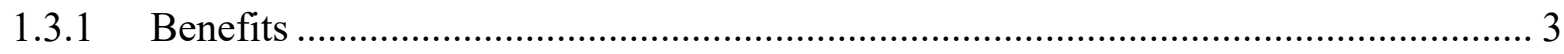

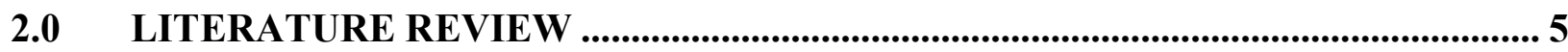

2.1 EarthQuake Damage to Reinforced Concrete Bridge Columns ............................ 5

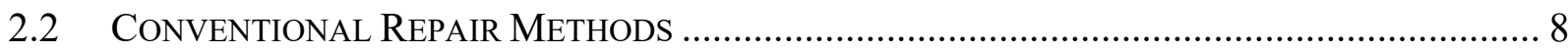

2.2.1 Seismic Repair of Reinforced Concrete Bridge Columns: Review of Research

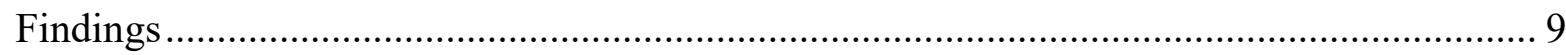

2.3 Dissipative Controlled Rocking with Self-Centering......................................... 11

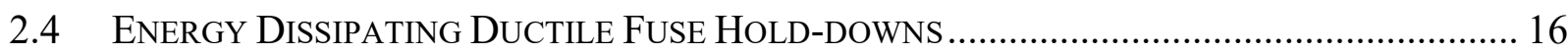

3.0 AS-BUILT COLUMN-TO-FOUNDATION TEST SPECIMEN AND RESULTS .. 19

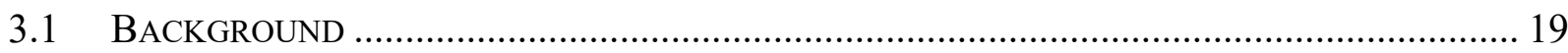

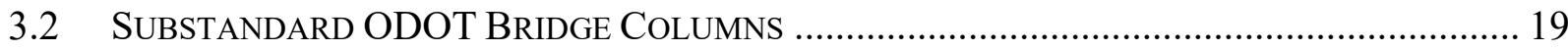

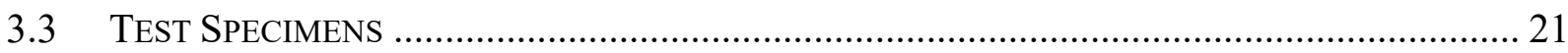

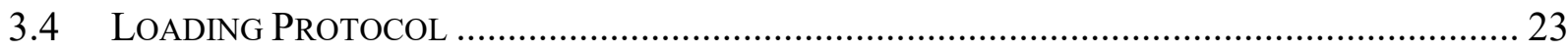

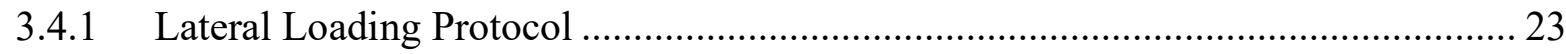

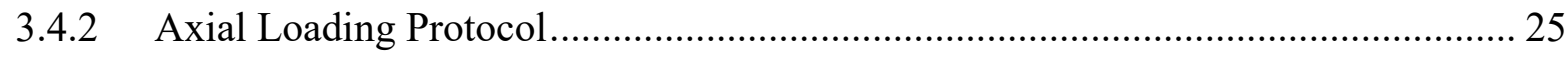

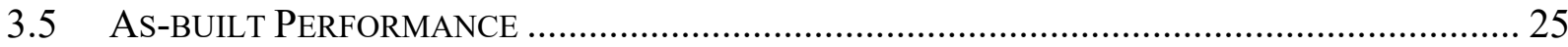

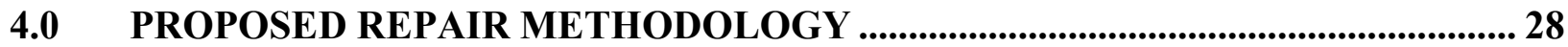




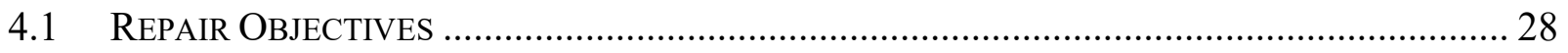

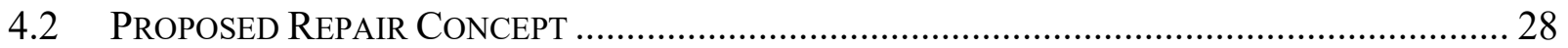

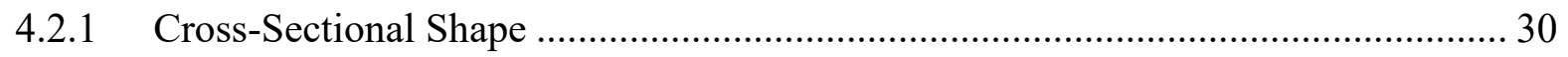

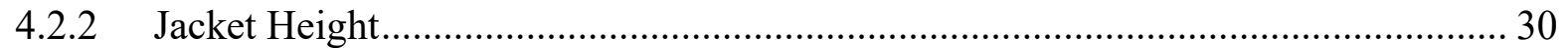

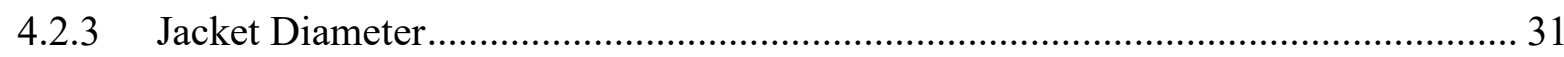

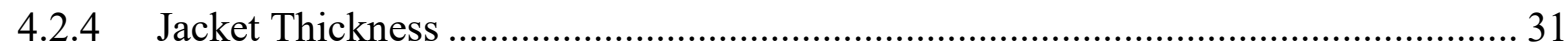

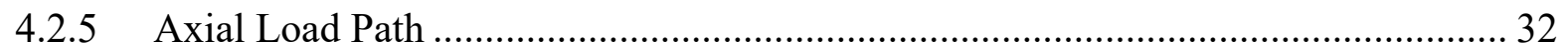

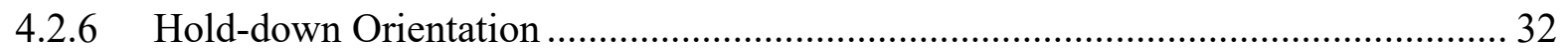

4.3 Analytical Predictions and Initial Design Philosophy ......................................... 33

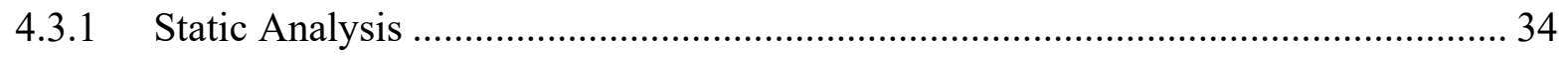

4.3.2 Pushover Analysis............................................................................................ 36

5.0 EXPERIMENTAL VALIDATION ............................................................................. 39

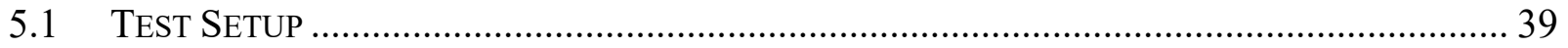

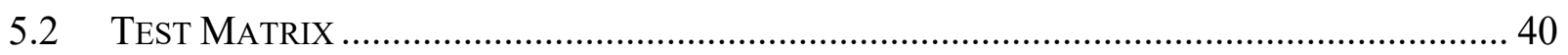

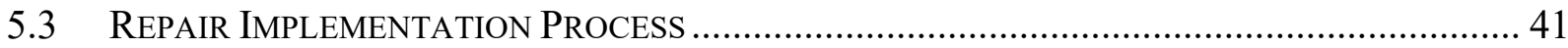

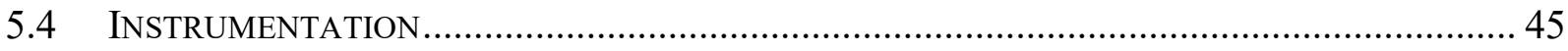

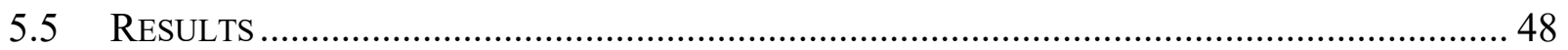

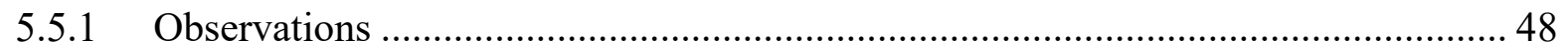

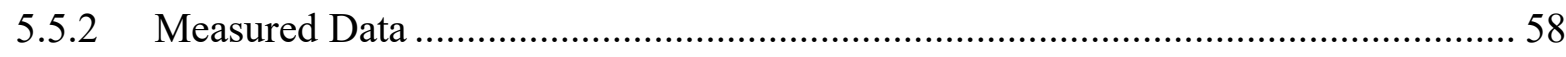

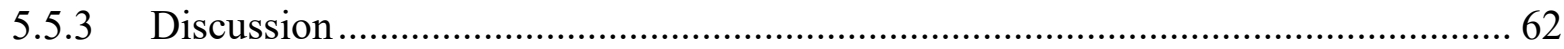

6.0 CONCLUSIONS ……......................................................................................................... 71

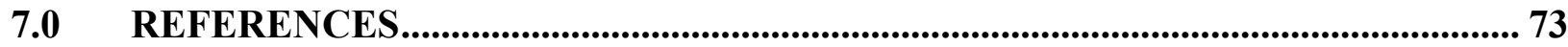




\section{LIST OF TABLES}

Table 3.1: As-built test specimen details (Murtuz, Dusicka, \& Schumacher, 2020)................. 21

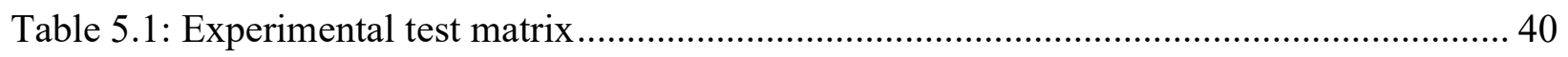

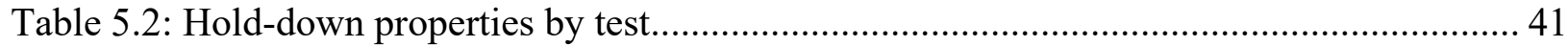

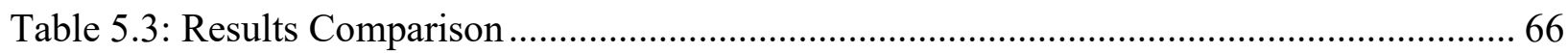




\section{LIST OF FIGURES}

Figure 2.1: (a) Column shear failure, (b) Column flexural failure and collapse, 1994 Northridge earthquake (Priestley, Seible, \& Calvi, 1996)

Figure 2.2: (a) Lap splice failure, 1989 Loma Prieta earthquake, (b) Mid-height failure, 1995

Kobe earthquake (Priestley, Seible, \& Calvi, 1996) ………………………............... 8

Figure 2.3: Prototype bridge: (a) longitudinal profile, (b) transverse section (Mashal, Palermo, \&

Chegini, 2014) 13

Figure 2.4: Low damage system configuration and expected response (Mashal, Palermo, \&

Chegini, 2014)

Figure 2.5: Precast Bridge Columns with 10mm steel jackets (Mashal, Palermo, \& Chegini,

2014) 14

Figure 2.6: (a) Energy dissipating reduced bar, (b) Column base plate (Mashal, Palermo, \&

Chegini, 2014) 15

Figure 2.7: Testing configuration (Mashal, Palermo, \& Chegini, 2014) 15

Figure 2.8: (a) Lower rocking interface, (b) Upper rocking face (Mashal, Palermo, \& Chegini, 2014) 16

Figure 2.9: (a) UFP dissipator located between flexibly based shear walls in a composite building (Kelly, Skinner, \& Heine, 1972), (b) UFP's in an energy dissipating hold-down on a rocking CLT shear wall (Smith, 2019) 17

Figure 2.10: (a) UFP Geometry (Palnikov, 2017), (b) UFP shear couple (Baird, Smith, Palermo,

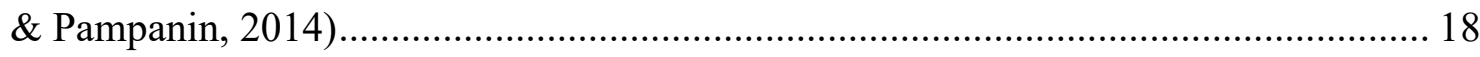

Figure 3.1: Typical substandard ODOT bridge column (Murtuz, Dusicka, \& Schumacher, 2020) 
Figure 3.2: (a) Column cross sectional details (Section A-A), (b) Tie bar details, (c) ColumnFoundation longitudinal section details (d) Foundation cross section details (Murtuz,

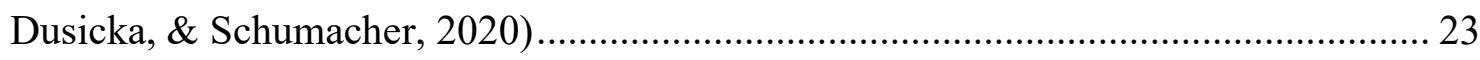

Figure 3.3: Comparison of subduction zone and conventional loading protocols (Bazaez \&

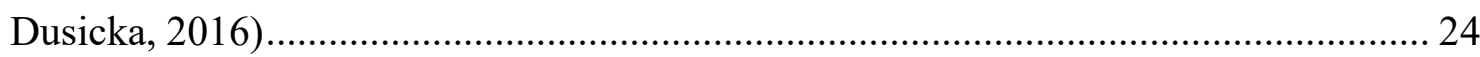

Figure 3.4: Axial Loading Protocol (Murtuz, Dusicka, \& Schumacher, 2020)............................ 25

Figure 3.5: As-build damage progression (specimen SVF\#8) .................................................... 26

Figure 3.6: As-built performance of substandard column (a) specimen SVF\#8, (b) specimen

LVF\#8 (Murtuz, Dusicka, \& Schumacher, 2020) ………………………………….... 27

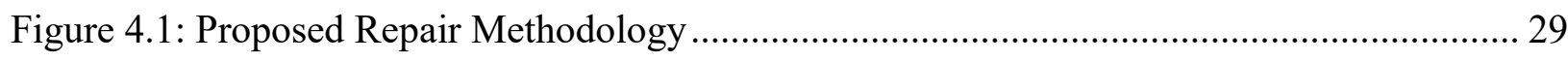

Figure 4.2: FHWA steel shell recommendations (Buckle, et al., 2006) …………………........... 31

Figure 4.3: Hold-down orientations (a) corner orientation (b) face orientation ............................ 33

Figure 4.4: Forces about the rocking edge (a) corner orientation (b) face orientation .................. 35

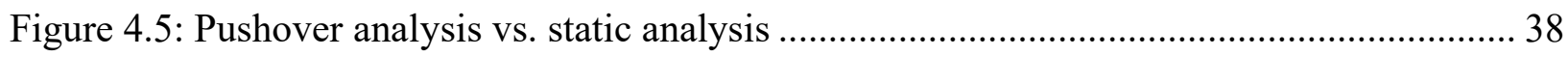

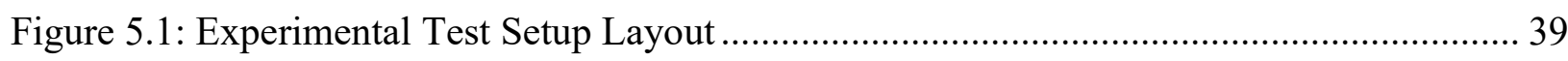

Figure 5.2: Repair Methodology (a) elevation view (b) section view ........................................ 42

Figure 5.3: Prototype Repair Sequence ………………………………………………...... 43

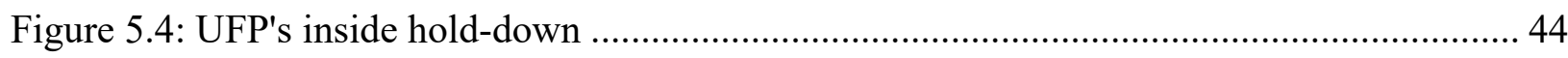

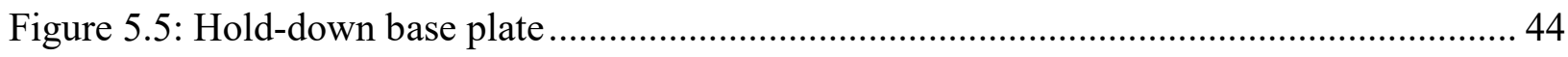

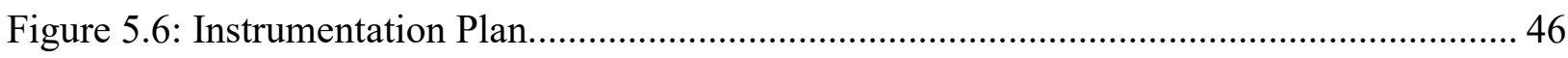

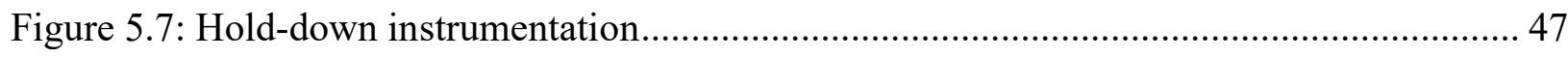

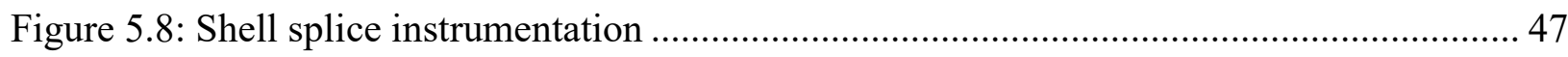

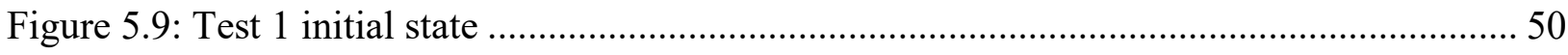




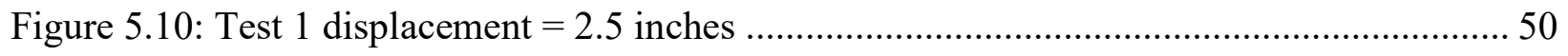

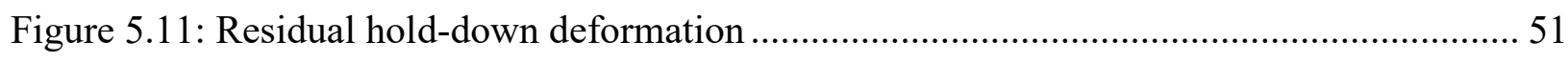

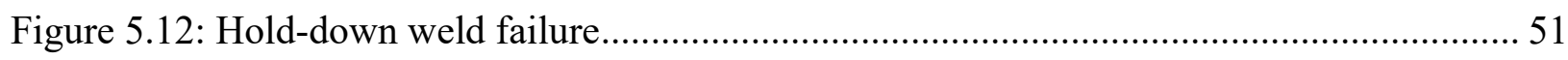

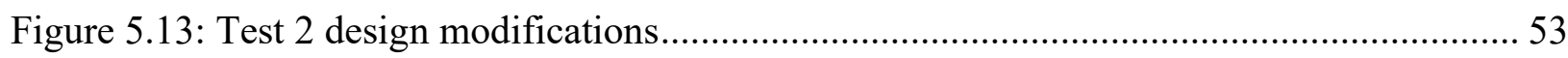

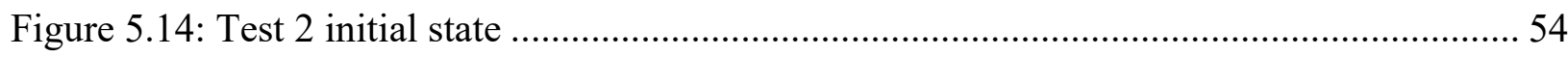

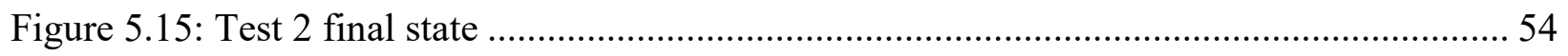

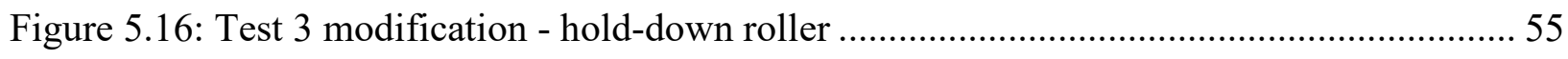

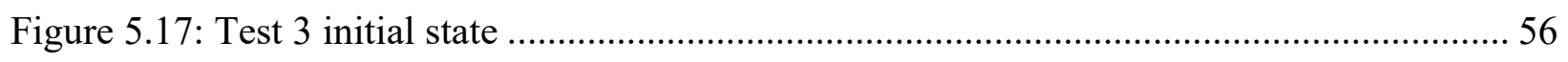

Figure 5.18: Hold-down rollers before/after test ...................................................... 56

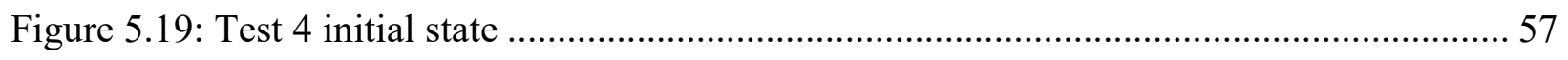

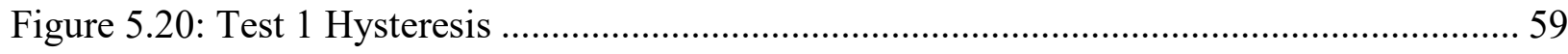

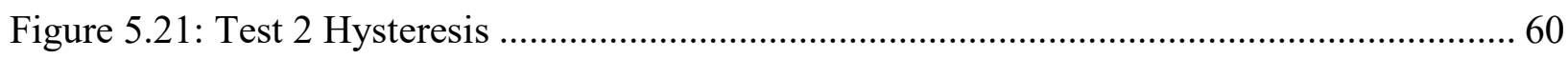

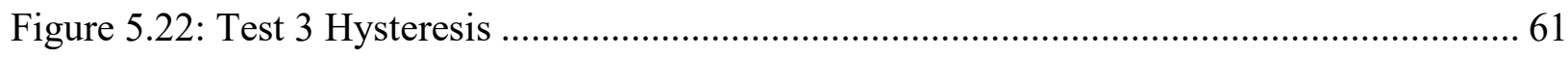

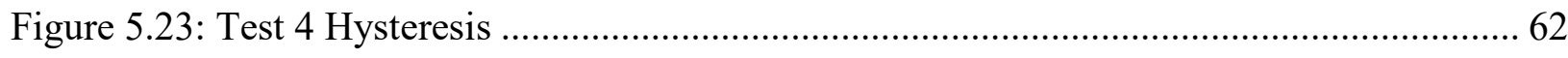

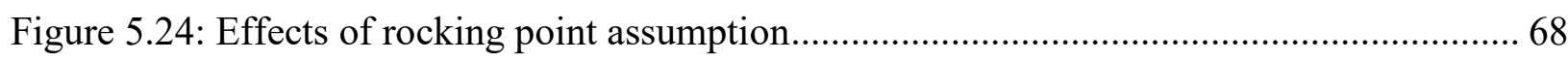

Figure 5.25: rocking point distance to edge of column, corner orientation ............................. 69

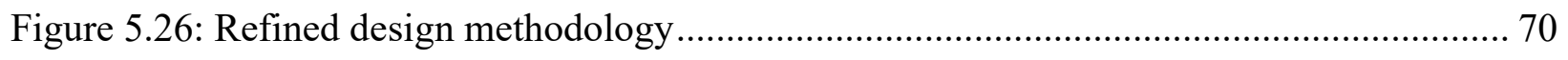




\subsection{INTRODUCTION}

\subsection{General}

Seismic retrofit or replacement of the entire ODOT vulnerable bridge inventory is unlikely in the foreseeable future, leaving us with a large bridge inventory of seismically vulnerable bridges. Simultaneously, the Cascadia Subduction Zone (CSZ) earthquake has a high probability of occurrence within our lifetime ( $\sim 30 \%$ in next 50 years). One of the major issues facing the transportation infrastructure during and following CSZ earthquake is not necessarily the magnitude of shaking at any particular site alone, but the vast and varied damage that will be distributed throughout the state. Damage is expected to be geographically spread and have a nearly simultaneous impact on transportation West of I-5 up and down the state. Significant aftershocks are expected for months to possibly years. Variability in intensity across the state combined with the actual individual bridge responses will mean that the extent of damage throughout the inventory will vary from minor to significant.

Bridge repair in lieu of replacement will be needed following the CSZ earthquake. Priority will be placed on resuming mobility such that repairs will need to be implemented quickly and in many cases expected to remain for the useful life of the bridge as not all damaged bridges would be slated for replacement. In an effort to anticipate this need, a strategy is required for having a rapid repair methodology in place prior to the CSZ earthquake hitting our region. Ideally, this would be a strategy that will allow for rapid repair with the goal of achieving semi-permanent installation that also considers resiliency for future earthquakes including aftershocks. 


\subsection{Background and Significance of Work}

Seismically substandard bridges in Oregon are typically characterized by multicolumn bridge bents, which can develop damage in the columns, in the foundations and in the bent beams. The damage can range from rebar yielding and concrete cracks to more severe lap-splice pull-out or longitudinal rebar buckling and fracture. Yet, the collapse mechanism continues to rely on the component's ability to carry gravity loads. Numerous bent and column experiments along with observations from post-earthquake reconnaissance have shown that collapse is not inevitable just because the lateral system is damaged. Despite severe degradation of the lateral strength in specific areas, bridges can continue to carry design level gravity loads as the gravity structure can remain relatively damage free.

Conventional repair methods aim to restore strength to the damage zones, such as repairing of cracked concrete and encasing the column in concrete jacket, steel jacket, or FRP wrap. This may be appropriate for cases of low damage, whereby the steel cage remains largely intact. However, more involved procedures are needed for cases of loss of lap splice, buckled or fractured rebar or merely loss of confidence at the remaining low cycle fatigue capacity for subsequent earthquakes. Past research had focused on coupling the rebar in various ways for continuity prior to the encasement or wrap. While effective at restoring the column, there are three significant issues with these approaches: a) restoring rebar continuity is labor intensive resulting in lengthy and potentially costly repairs, b) the affected area can be damaged again in an aftershock requiring new significant repairs, and c) encasing results in higher stiffness and strength that would likely shift failures to other parts of the bridge under future earthquake demands.

An alternative post-earthquake repair method is proposed that can be rapidly implemented and that also has the potential for increasing the resilience for future shaking. The method utilizes 
externally mounted brackets, which are secured to the non-damaged parts of the bent. The brackets can be fabricated shortly following the earthquake from standard drawings or prefabricated and stockpiled for common geometries. Researchers at Portland State University (PSU) have developed a similar concept as retrofit of slender equipment support structures and a similar approach has also been proposed for new precast $\mathrm{ABC}$ bridge construction in New Zealand (Palermo \& Mashal, 2012). The proposed repair measure would be best suited for bents that had significant damage and not lost gravity capacity, which is expected to encompass a majority of bridges statewide.

Damage outside of the columns is possible for vulnerable bridges types in Oregon and repairing for strength in those components can be relatively conventional. The difficulty is in repairing for ductility and providing future resiliency, which this rapid approach could offer.

\subsection{Objective and Scope}

The proposed research aims to develop, design, and validate a practical post-earthquake repair methodology that can be rapidly implemented and that incorporates low damage earthquake resilience for future shaking. The effectiveness of existing repair methods will be reviewed whilst considering rapid installation and susceptibility to future earthquake damage. These will be contrasted to the proposed concept that utilizes the external collar with ductile fuses. In order to evaluate the proposed repair method, damaged components of a typical bent will be repaired and experimentally evaluated in the laboratory.

\subsubsection{Benefits}

Restoring mobility following CSZ earthquake is an important consideration for ODOT in order to restore not just life routes following CSZ earthquake, but also the rest of the network in 
order to reach communities in need. The damage will be vast and the need to repair and restore the network functionality quickly will be high. The benefit to ODOT also relates directly to cost as the anticipated research product introduces a new tool in the repair toolbox, a tool that has the potential to be simpler to implement and significantly more resilient than conventional methods alone.

The validation portion of the proposed research can leverage test specimens that are already slated to be constructed and damaged at PSU as part of an ongoing project on bridge seismic performance criteria. These specimens are of bent sub-assemblies, thereby incorporating not just column, but also key parts of the foundation and bent beam. The damaged specimens from that project can therefore be used to apply the proposed repair strategy, maintaining realistic boundary conditions and anticipated damage states. 


\subsection{LITERATURE REVIEW}

To develop a suitable repair methodology, it is necessary to understand the damage that a typical reinforced concrete bridge column experiences during an earthquake. The first subsection of this literature review describes common failure modes of reinforced concrete bridge columns and provides observations from past earthquakes and previous experimental research. Furthermore, this literature review covers previous research and findings relevant to the repair of earthquake damaged columns, dissipative controlled rocking, and energy dissipating ductile fuses. Applicable sources relating to column retrofit are also mentioned, as there are many similarities between column repair methods and column retrofit methods.

\subsection{Earthquake Damage to Reinforced Concrete Bridge Columns}

In Seismic Design and Retrofit of Bridges, Priestley et al. (1996) describes common failure modes and deficiencies of reinforced concrete bridge columns. Priestley claims that most common deficiencies are a direct result of an inadequate design philosophy, called the elastic design philosophy, that was widely accepted and used prior to the 1970's. Failures are classified as either flexural strength and ductility failures or shear failures. Figure 2.1(a) and (b) are examples of a flexural failure and a shear failure, respectively. Both of these examples were from the 1994 Northridge earthquake. 


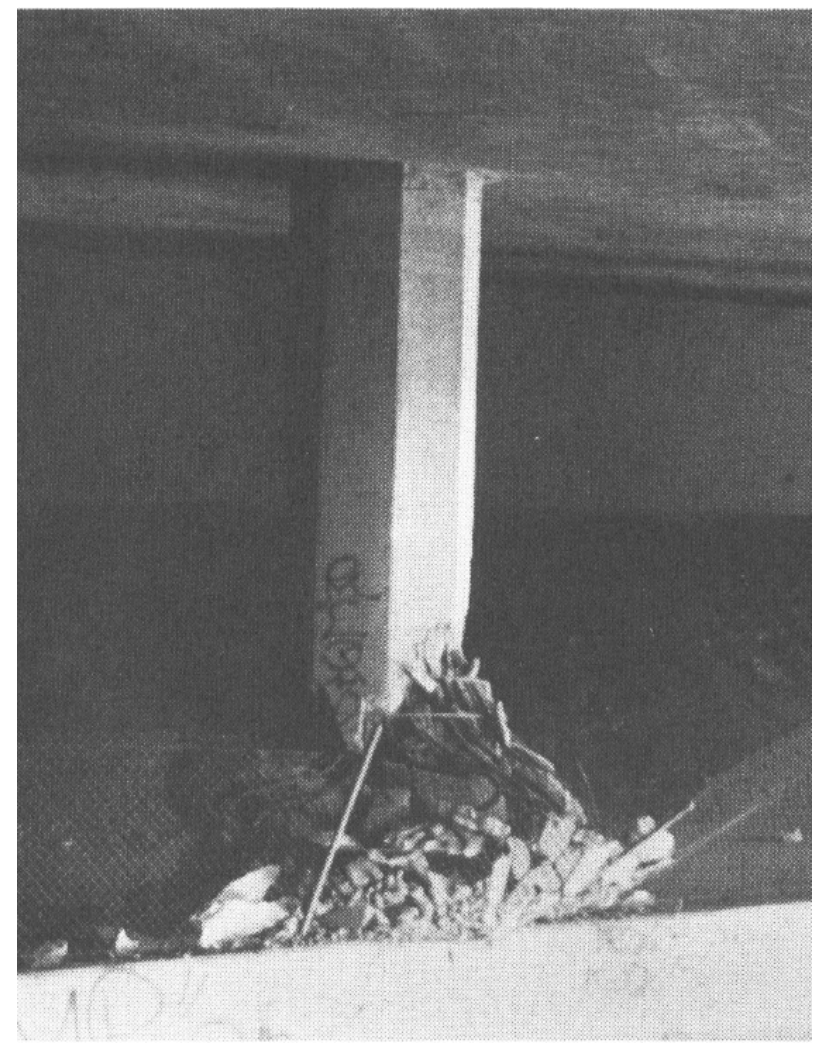

(a)

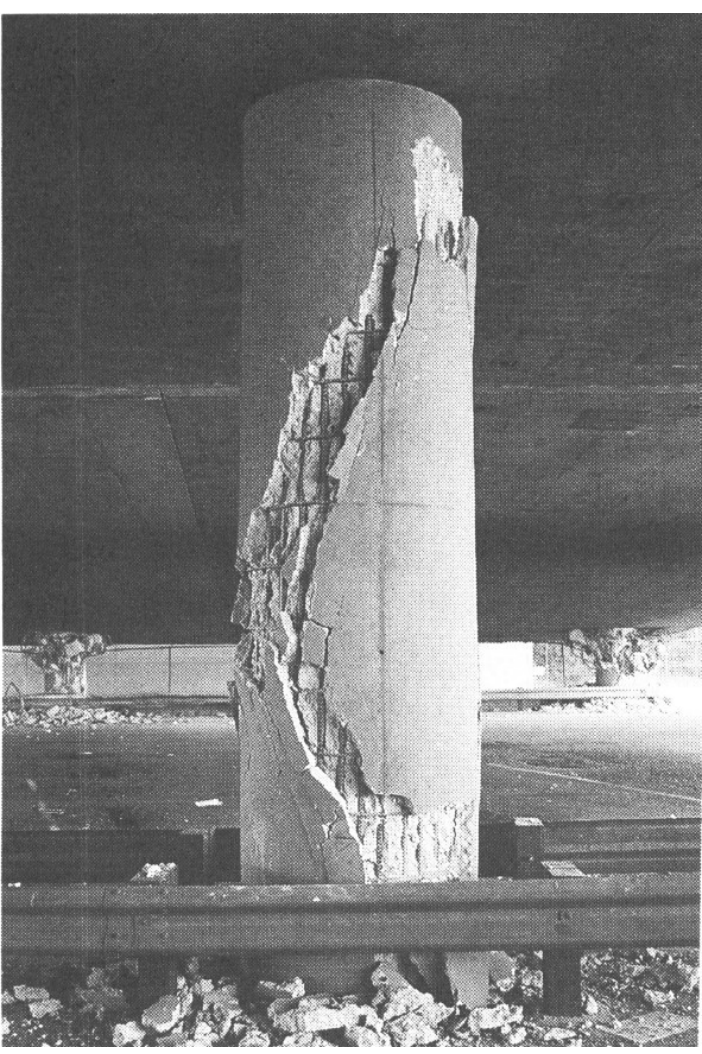

(b)

Figure 2.1: (a) Column shear failure, (b) Column flexural failure and collapse, 1994 Northridge earthquake (Priestley, Seible, \& Calvi, 1996)

Flexural and ductility failures can generally be attributed to four common deficiencies: (1) inadequate flexural strength, (2) undependable column flexural strength, (3) inadequate flexural ductility, and (4) premature termination of column reinforcement.

(1) Inadequate Flexural Strength - Historically, bridge designers have drastically underestimated the seismic forces that are expected in reinforced concrete bridge columns. Priestley et al. (1996) claims that it was common for bridges in California to be designed for seismic lateral loads that are around $6 \%$ of the typical gravity loads. Now it is thought that these loads are greater than $100 \%$ of the gravity load. 
(2) Undependable Column Flexural Strength - Inadequate development length of lap splices is commonly found in reinforced concrete bridge columns. Furthermore, these lap splices often reside at the top and bottom of the column, where seismic loading produces large flexural forces. Priestley et al. (1966) has found lap splice lengths as short as 20 bar diameters to be common in California. Inadequate development length prevents reinforcing bars from reaching their design levels, causing the column flexural design strength to be undependable. An example of lap splice failure from the 1989 Loma Prieta earthquake is shown in Figure 2.2(a).

(3) Inadequate Flexural Ductility - Reinforced concrete bridges often have inadequate flexural ductility. Again, this is a result of the elastic design philosophy in which the idea of plastic hinging did not exist. The current design philosophy is to allow reinforced concrete bridge columns to undergo inelastic deformation, dissipating energy through plastic hinging action. Columns that are not well confined (i.e. columns with large transverse reinforcement spacing) often suffer from inadequate flexural ductility because as they experience inelastic flexural deformations, the crushing and degradation of concrete quickly infiltrated the core concrete of the column.

(4) Premature Termination of Column Reinforcement - Mid-height flexural failures have been attributed to premature termination of the longitudinal reinforcing bars. Priestley et al. (1996) found that a series of columns that failed in the 1995 Kobe earthquake had $33 \%$ of the longitudinal rebar terminate at $20 \%$ of the column height. The plastic hinge formed above this termination, where the flexural strength was less, causing a flexural-shear failure at midheight. The failed column is shown in Figure 2.2(b). 


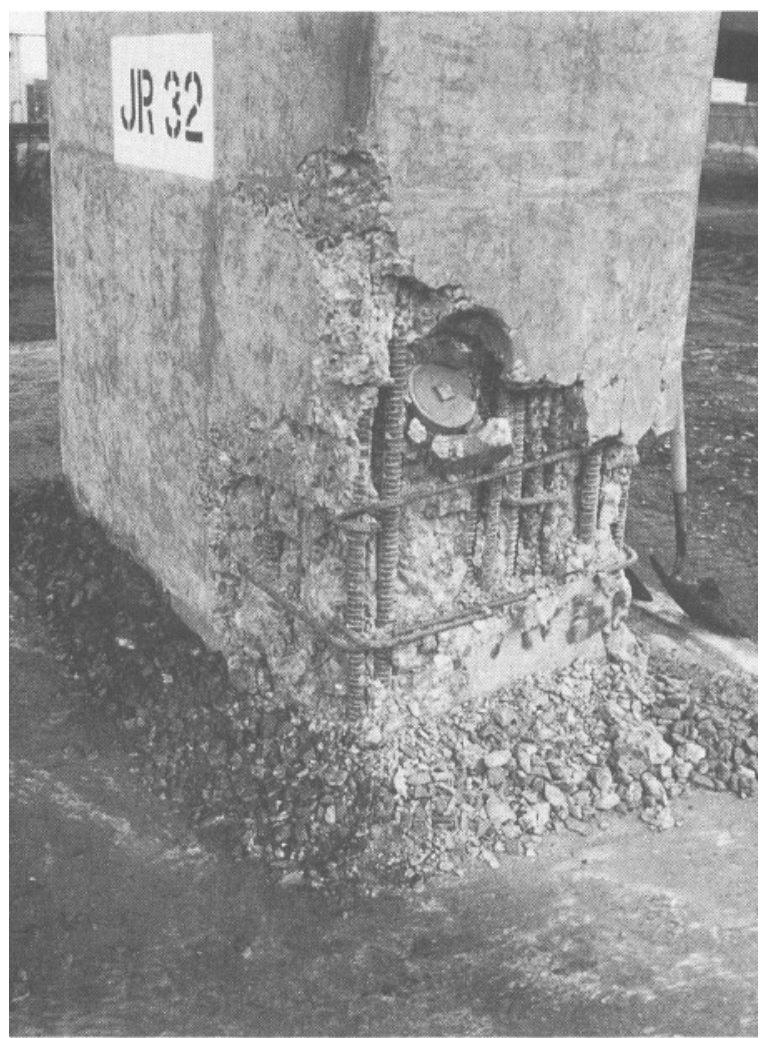

(a)

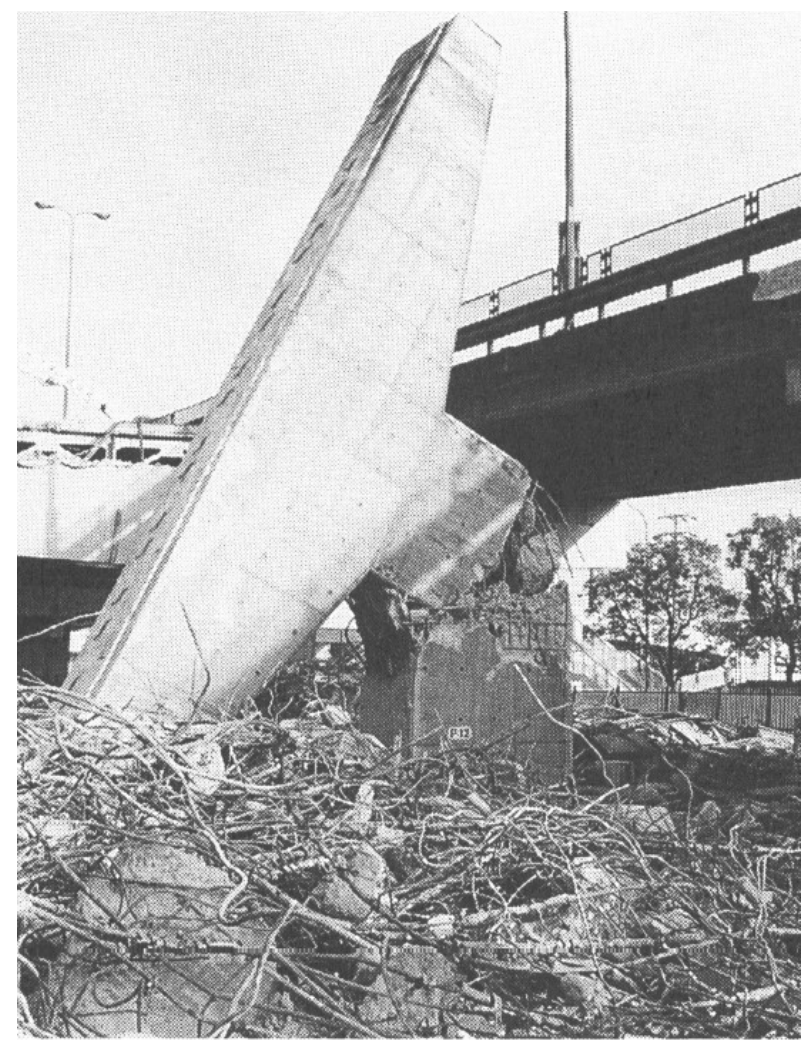

(b)

Figure 2.2: (a) Lap splice failure, 1989 Loma Prieta earthquake, (b) Mid-height failure, 1995 Kobe earthquake (Priestley, Seible, \& Calvi, 1996)

Priestley et al. (1997) also found shear failures to be common in reinforced concrete columns. The 1971 San Fernando earthquake, the 1994 Northridge earthquake and the 1995 Kobe earthquake all provided examples of reinforced concrete bridge columns that failed in shear. Shear reinforcement in older columns often consists of No. 4 bars spaced at 12 inches. This size and spacing is found in columns with a large range of demand requirements causing Priestley to speculate that shear strength considerations were often neglected by bridge designers.

\subsection{Conventional Repair Methods}

Conventional repair approaches aim to restore a damaged column to some degree of its original strength and stiffness. Repair methods have been the focus of numerous research projects 
for many decades. For reinforced concrete bridge columns, the most common repair methods involve the application of a reinforced concrete jacket, a steel jacket, or a fiber-reinforced polymer jacket (D.E. Lehman, 2001). These methods are compared and evaluated in an article published in the American Society of Civil Engineering's Journal of Bridge Engineering. The article compiles the research findings from over 20 studies on the repair of reinforced concrete bridge columns (He, Yang, \& Sneed, 2015). The following subsection will summarize the findings of this article titled, "Seismic Repair of Reinforced Concrete Bridge Columns: Review of Research Findings."

\subsubsection{Seismic Repair of Reinforced Concrete Bridge Columns: Review of Research}

\section{Findings}

The authors of the study, "Seismic Repair of Reinforced Concrete Bridge Columns: Review of Research Findings," summarize various research that was conducted on bridge column retrofit and repairs (He, Yang, \& Sneed, 2015). The authors state the major challenge with repair of damaged columns is estimating the residual capacity of the damaged structure. Bridge columns are designed as the primary source of energy dissipation during seismic activity for bridges. Many bridges built in the 70 s are inadequately detailed and are expected to require significant require after major seismic events.

The researchers summarize repair techniques for various damage types including: flexural and shear cracking, longitudinal reinforcement yielding, cover spalling, crushing of the diagonal compression strut, yielding of the transverse reinforcement, longitudinal bar buckling, spiral fracture, and longitudinal bar fracture. Repair of RC Bridge Columns without Fractured Longitudinal Bars generally could be accomplished by injecting cracks, replacing damaged concrete, and strengthening column. Another method is reinforced concrete jackets which requires 
enlarging the columns cross section. Steel Jackets have also been used to repair bridge columns without longitudinal bar fractures. Steel jacket installation includes casting new concrete to restore the cross section, installing steel jacket, and filling the gap between the jacket and column with grout. The authors state that research has shown that steel jacketing repair enhances strength and ductility compared to as-built structure.

FRP jackets could also be used to repair damaged bridge columns where the fibers could be oriented in different orientations to achieve different responses from the FRP. Fibers oriented in the hoop direction improve shear performance while fibers oriented along the length of the column mainly improve flexural strength of the column. The authors state that tests have been performed with scaled columns that were repaired with epoxy injections and FRP jackets, test results indicated restoration of initial stiffness and increase in ductility compared to the as-built column.

Similarly, the authors also summarize research conducted on repairing reinforced bridge columns with fractured longitudinal bars. Longitudinal bar fracture occurs due to high ductility demands in flexural-dominant RC columns. Repair techniques include connecting fractured bars with couplers, placing new longitudinal bars anchored in footing with enlarged cross section, and applying externally bonded longitudinal reinforcement.

Based on the compilation of studies, the authors draw conclusions for the repair methods. For reinforced concrete columns without longitudinal bar fracture the academics determined that the repair methods are able to restore or even enhance performance compared to as-built columns. The repair methods included passive confinement though RC, steel, or FRP jacketing. Active confinement included SMA, steel jacketing, and FRP jacketing. The authors state that jackets may 
alter the stiffness of the column resulting in a change in dynamic response. According to the researchers, $\mathrm{RC}$ jackets are time consuming and required specialty equipment for construction.

For RC columns with fractured longitudinal bars, the authors state that mechanical coupler repairs show successful strength and ductility recovery. Also, increasing the RC column region with well anchored bars showed successful column response. The researchers state that the larger cross section may result in changes in structural behavior. Other repair methods shift the location of the plastic hinge zone from the region previously damaged by the results indicate that this decreases ductility because the new region must undergo large rotations to achieve the same ductility. The authors state that most of the methods require a lot of time and are not suited for rapid repair. The researchers state that external FRP bars have been attempted as a rapid repair method and some repair methods may result in a lower limit state performance.

\subsection{Dissipative Controlled Rocking with Self-Centering}

Conventional structures depend on inelastic deformation of primary structural members to dissipate energy in seismic events leaving structural damage at critical locations. Even structures that are compliant with modern building codes are expected to have structural damage to primary elements such as columns, beams, and shear walls (Chancellor, Eatherton, Roke, \& Akbas, 2014). The seismic design philosophy of reinforced concrete bridge columns relies on the inelastic response of the structure to occur within plastic hinge regions that are expected to form at the top and/or bottom of reinforced concrete columns leading to significant structural damage which will require repair after an earthquake (Palermo \& Pampanin, 2005).

Dissipative controlled rocking (DCR) is a concept that eliminates inelastic deformations in primary structural elements during seismic events. Instead, inelastic deformations are isolated to 
energy dissipating ductile fuses. The result is a low damage structure that will require minimal repairs after an earthquake. The concept has been proposed and experimentally implemented on steel braced frames (Eatherton, et al., 2014), cross-laminated timber shear walls (Smith, 2019), and pre-cast concrete bridge bents (J. Stanton, 2014) (Mashal, Palermo, \& Chegini, 2014).

Mashal et al. (2014) experimentally investigated the concept of DCR for accelerated bridge construction. The results from quasi-static cyclic testing of half-scale precast column-to-footing specimens with external energy dissipators showed that DCR is a viable option for creating low damage bridge columns (Mashal, Palermo, \& Chegini, 2014).Prototype development, design detailing, construction, assembly, and experimental testing of two half-scale fully precast bridge bents are discussed in the paper. Shown in Figure 2.3 is the prototype bridge used for the detailing of the specimen components. The first specimen is a "ABS High Damage" specimen with grouted ducts and member socket connections (MSC). The ABS High Damage solution is expected to have plastic hinge formation, residual displacement, and require repair or replacement after an earthquake. The grouted ducts and member socket connections have a similar concept to "Highways for Life" bents which have not been experimentally tested. While testing the ABC High Damage Emulative specimen spalling occurred in the four expected plastic hinge regions. The specimen emulated behavior of cast-in-plate bride construction. 


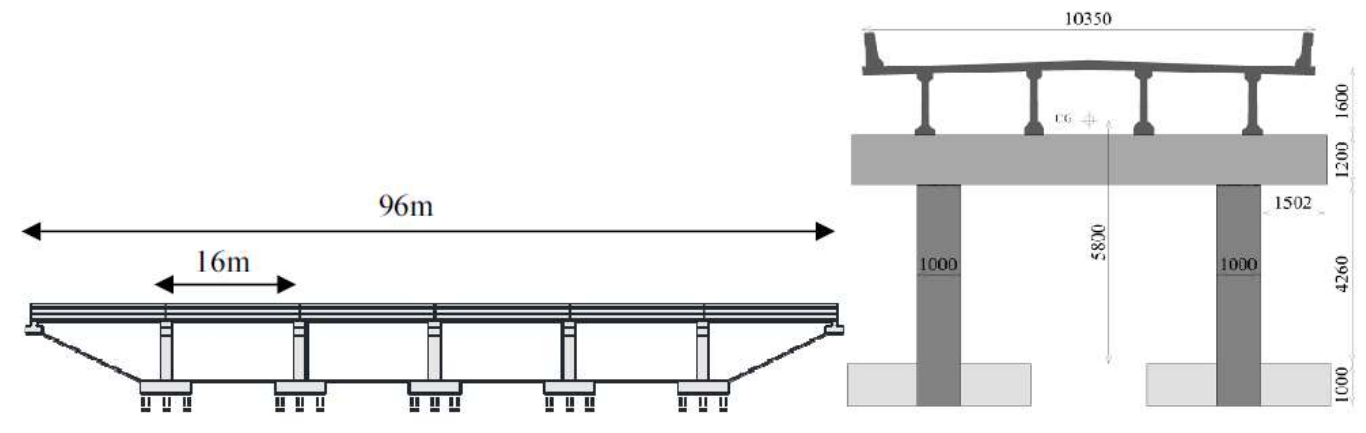

(a)

(b)

Figure 2.3: Prototype bridge: (a) longitudinal profile, (b) transverse section (Mashal, Palermo, \& Chegini, 2014)

The second specimen referred to "ABC Low Damage" in this paper is a dissipative controlled rocking (DCR) bent with self-centering and external dissipaters. The connections are designed to be low damage and have replaceable energy dissipaters. The proposed configuration and system response are shown in Figure 2.4. The selected dimensions and properties reflected typical highway bridge pier support structures for low to medium span bridges in New Zealand.

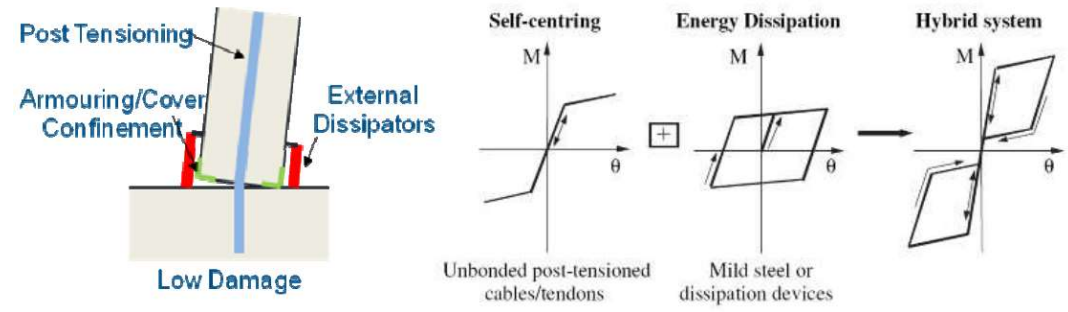

Figure 2.4: Low damage system configuration and expected response (Mashal, Palermo, \& Chegini, 2014)

An identical second specimen was constructed but the connection was replaced with a hybrid connection. The hybrid connection consists of a combination of post-tensioning with external replaceable dissipaters. The system provides self-centering with minimal permanent deformation and damping thought the hysteretic devices this system is referred to as "ABC Low Damage Bent." The expected ABS Low Damage Bent hysteresis is flag shaped with no structure permanent 
structure drift. The ABC Low Damage Bent was designed using the outline procedures in NZCS PRESS Design Handbook In order to prevent concrete spalling at the ends of the precast columns, $10 \mathrm{~mm}$ steel jackets were installed. Shown in Figure 2.5 are the bridge columns with the steel jacketing. The steel shells connected to the concrete column core through welded studs. For the low damage system, the steel shell length was based on similar cast-in-place and member socket connection column plastic hinge length, a length of $500 \mathrm{~mm}$ was used.

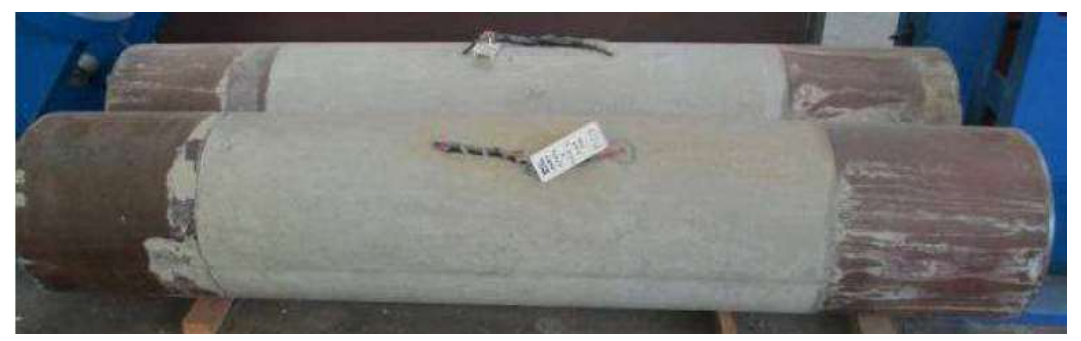

Figure 2.5: Precast Bridge Columns with 10mm steel jackets (Mashal, Palermo, \& Chegini, 2014)

Plates were installed on the rocking interfaces of the footing and under the cap beam. Also, a shear key was used to transfer shear force and prevent excessive sliding at the base interface. Tapped holes in the steel plate allow for attaching the hysteretic devices to the foundation plate. The plate was bolted into the existing foundation allows high stresses due to rocking to be distributed on the footing. The plate design included tapped holes for installation of the base plate. Brackets on the steel shell allowed for attaching the hysteretic devices to the column. The hysteretic device designed by the researchers is a steel bar with a reduced cross-section, the reduced section is incased in a steel tube to prevent buckling while maintaining similar tensile and compressive capacity. The proposed hysteretic device is shown in Figure 2.6(a). Shown in Figure 2.6(b) is the installed base plate and column shear key. 


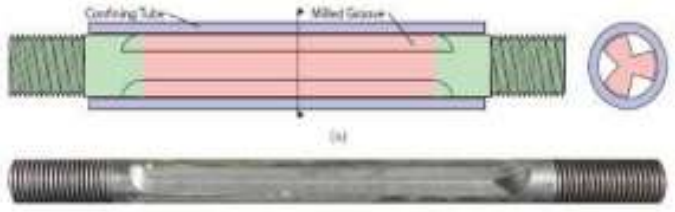

(a)

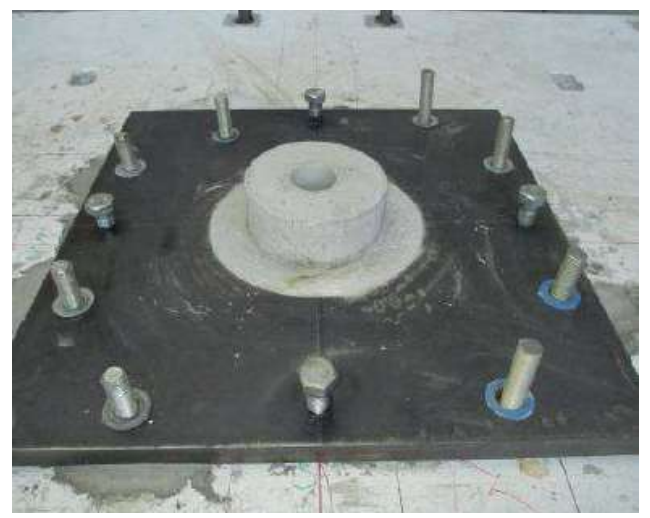

(b)

Figure 2.6: (a) Energy dissipating reduced bar, (b) Column base plate (Mashal, Palermo, \& Chegini, 2014)

The assembled bridge bent is shown in Figure 2.7 where the footing, column and bent cap are post-tensioned using Macalloy running through the center of the precast columns. Two hydraulic actuators were used to control lateral and gravity forces during the experiment. The foundation base plate, steel column shell, device brackets, and hysteretic energy dissipaters are shown for the bottom and top column interface in Figure 2.8.

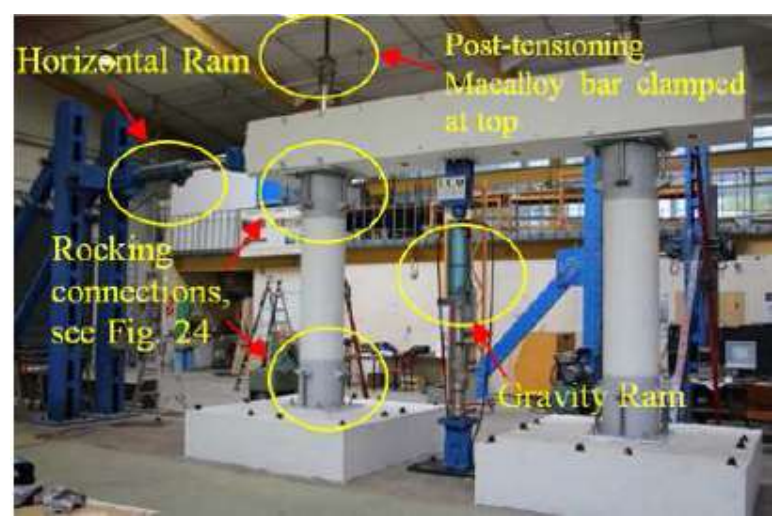

Figure 2.7: Testing configuration (Mashal, Palermo, \& Chegini, 2014) 


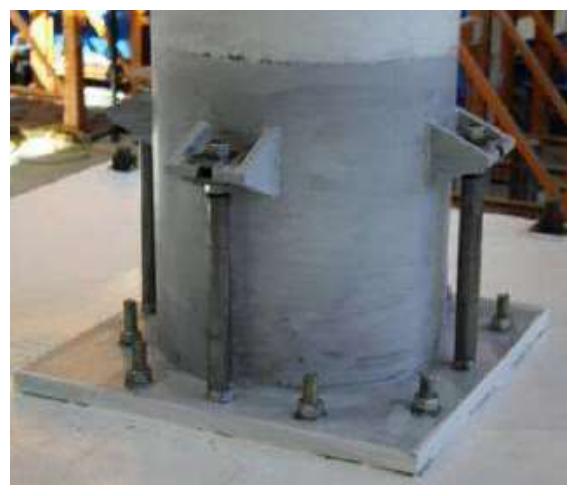

(a)

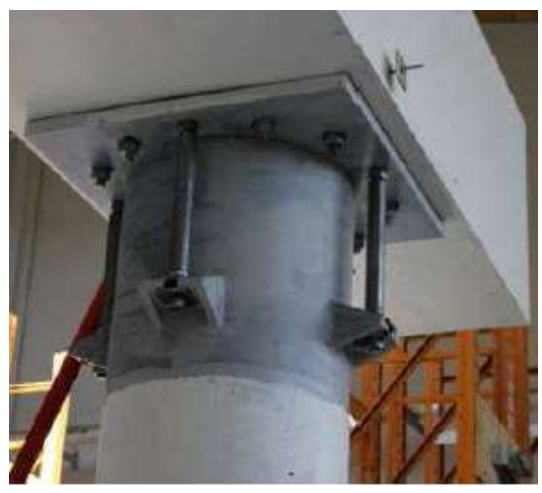

(b)

Figure 2.8: (a) Lower rocking interface, (b) Upper rocking face (Mashal, Palermo, \& Chegini, 2014)

Three quasi-static unidirectional tests were performed at three levels of post-tensioning. The protocol was repeated for the thee post-tensioning (PT) levels: $15 \%, 30 \%, 45 \%$ of yielding strength of Macalloy bars. As the PT force increase, less slipping at the rocking interface was observed. The authors also conclude that the capacity of the connection, size of gap opening, and re-centering ratio were directly related to the PT load. Each of the three tests were taken up to $2.2 \%$ drift and no damage or cracks in the columns were observed. For the lower PT levels, $15 \%$ and $30 \%$, slight sliding at the interfaces was observed.

Phase 1 of the ABC Low Damage system essentially tested a rocking system without supplemental damping. The system showed true re-centering with no damage to the columns, footings, and cap beams. The columns remained intact with not even hairline cracks visible. High re-centering ratios were observed, ranging from 1.2-1.5, and none of the tests presented residual displacement.

\subsection{Energy Dissipating Ductile Fuse Hold-downs}

In 1972, a novel approach was developed by Kelly et al. (1972) to increase the energy absorption capacity of structural connections using special devices as mechanisms of energy 
absorption. The special devices, called U-shaped Flexural Plates (UFPs), utilize the plastic deformation of mild steel to dissipate energy. Through testing, it was shown that the UFP's are an extremely efficient mechanism for the dissipation of energy (Kelly, Skinner, \& Heine, 1972).

Figure 2.9(a) is an illustration of a UFP dissipator located between flexibly based shear walls in a composite building. Figure 2.9(a) is just one of many possible scenarios where UFP's could be implemented to dissipate energy. This device can be implemented between any adjacent surfaces whose relative displacement is parallel. Recent research has shown successful implementation of UFP's for energy dissipating hold-downs in a rocking cross-laminated-timber shear wall (Smith, 2019). A view of the UFP's inside of the hold-down is illustrated in Figure 2.9(b). The outer angle of the hold-down is rigidly anchored to the foundation and connected to the wall through an alternating arrangement of UFP's. When the wall undergoes rocking, the adjacent surfaces of the UFPs are displaced in a parallel direction to one another, and energy is dissipated through plastic deformation.

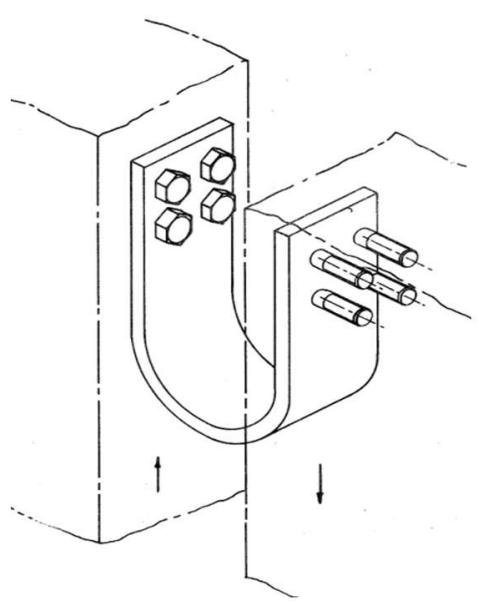

(a)
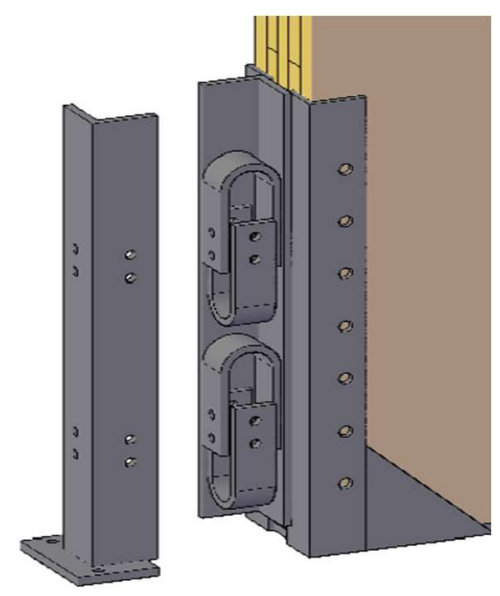

(b)

Figure 2.9: (a) UFP dissipator located between flexibly based shear walls in a composite building (Kelly, Skinner, \& Heine, 1972), (b) UFP's in an energy dissipating hold-down on a rocking CLT shear wall (Smith, 2019) 
Another compelling reason to utilize UFPs in energy dissipating hold-downs is that their strength is easily controllable. The maximum force they are able to resist is directly a function of their geometry and steel strength. Kelly et al. (1972) was the first to analytically derive the force provided by relating the plastic moment to the shear couple. The plastic moment occurs when the entire cross section has exceeded the yield strain and is given by equation (2.1). In this equation, the UFP width and thickness are $b_{u}$ and $t_{u}$ while $\sigma_{y}$ is the yield stress of the steel. Equation (2.2) relates the plastic moment to the shear couple to give the maximum force provided by the UFP where $\mathrm{D}_{\mathrm{u}}$ is the bend diameter of the UFP.

$$
\begin{gathered}
M_{p}=\sigma_{y} Z_{U F P}=\frac{\sigma_{y} b_{u} t_{u}{ }^{2}}{4} \\
F_{p}=\frac{2 M_{p}}{D_{u}}=\frac{\sigma_{y} b_{u} t_{u}{ }^{2}}{2 D_{u}}
\end{gathered}
$$

Figure 2.10(a) shows the geometry of a UFP with the controlling dimensions and Figure 2.10(b) shows a free body diagram of the forces and moments on the UFP.

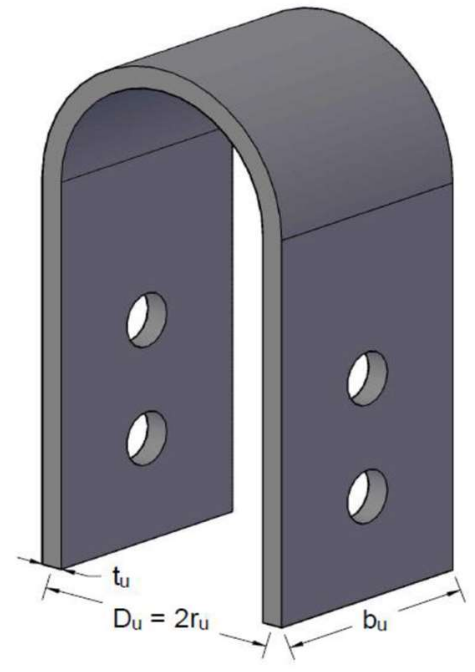

(a)

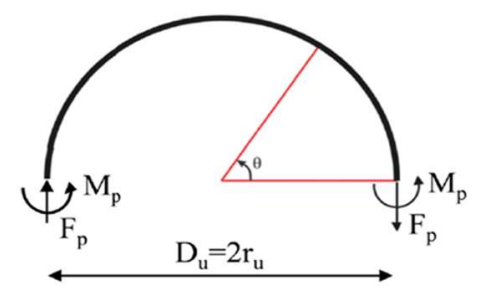

(b)

Figure 2.10: (a) UFP Geometry (Palnikov, 2017), (b) UFP shear couple (Baird, Smith, Palermo, \& Pampanin, 2014) 


\subsection{AS-BUILT COLUMN-TO-FOUNDATION TEST SPECIMEN AND RESULTS}

\subsection{Background}

The experimental validation of the proposed repair methodology will leverage test specimens from a companion ODOT project titled, "Seismic Performance Design Criteria for Bridge Bent Plastic Hinge Regions,” and hereby referred to as SPR \#802 (Murtuz, Dusicka, \& Schumacher, 2020). The project aims to experimentally evaluate the performance limit states of substandard ODOT bridges by constructing full scale test specimens and subjecting them to expected earthquake forces and displacements. Thus, providing columns that are representative of ODOT bridges built prior to 1990 that have already been constructed and damaged.

\subsection{Substandard ODOT Bridge Columns}

Reinforced concrete bridges columns built in Oregon before 1990 are generally considered to be seismically substandard. Reinforcement detailing does not meet modern code requirements leaving them vulnerable to seismic events. To define a typical substandard bridge, SPR \#802 investigated data from the National Bridge Inventory and ODOT. It was concluded that the most common type of concrete bridge in Oregon is the Concrete Continuous Stringer/Girder (CCSG) bridge. SPR \#208 reviewed drawings of 113 CCSG bridge substructures and established a typical detail for reinforced concrete bridge columns built in Oregon prior to 1990. The typical detail is illustrated in Figure 3.1 

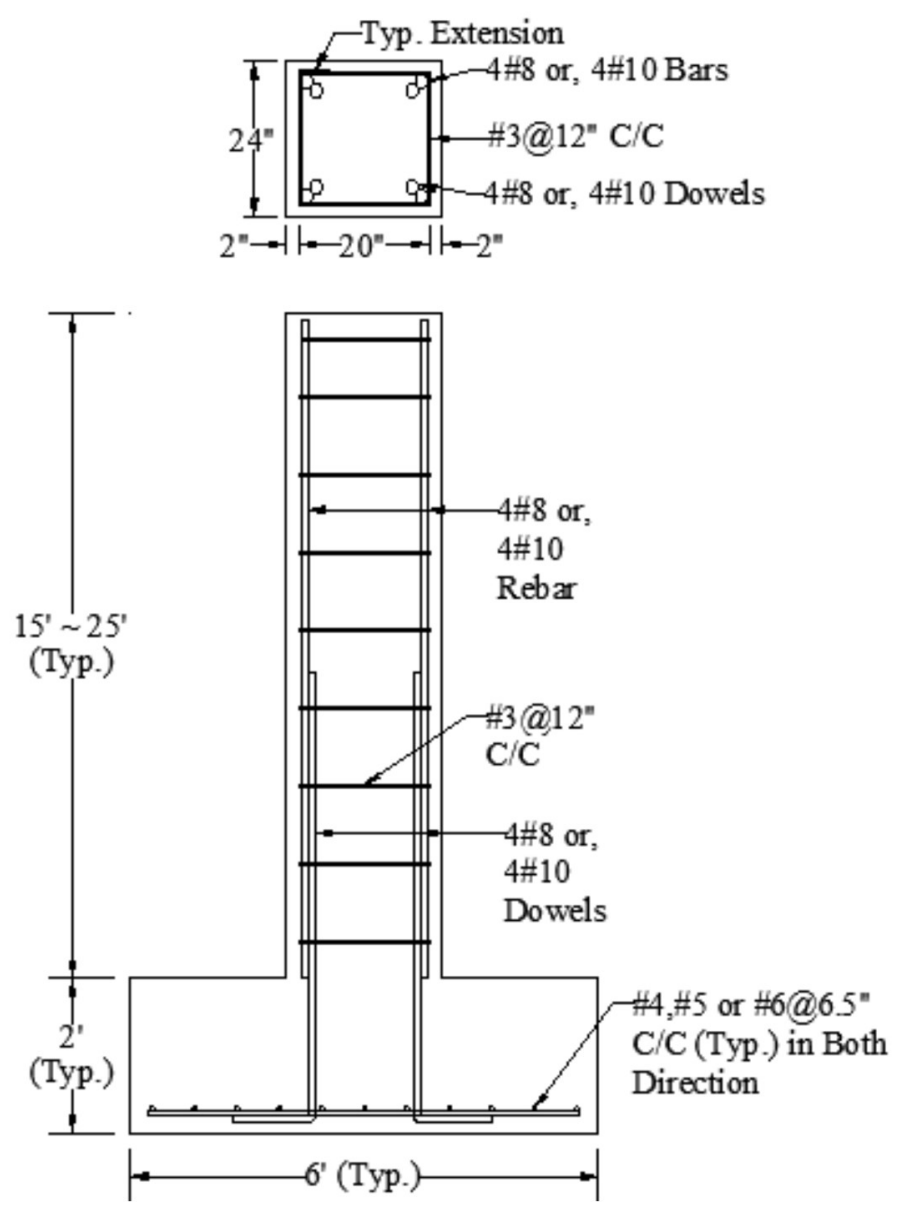

Figure 3.1: Typical substandard ODOT bridge column (Murtuz, Dusicka, \& Schumacher, 2020)

The typical column is part of a multi-column bent; in most cases a two-column bent. The typical column has a square cross section, $2 \mathrm{ft}$ by $2 \mathrm{ft}$, with a height between 15 and 25 feet. Longitudinal reinforcement is typically $4 \# 8$ bars or $4 \# 10$ bars placed at the column corners. Transverse reinforcement consisting of \#3 rebar is spaced at 12 inches - significantly further than modern code permits. The column is connected to the footing through dowels that have a moderate splice length (between excessively short and modern splice length). The typical footing reinforcement consists of a single layer mat at the bottom whereas modern detailing requirements usually include a cage with a second rebar mat at the top of the footing. 


\subsection{Test Specimens}

Two columns from SPR \#802 were utilized. The columns are designated as SVF\#8 and LVF\#8. This nomenclature is a combination of the lateral loading protocol, the axial loading protocol, the assembly type and the longitudinal reinforcement size. Column SVF\#8 was tested under a subduction zone lateral loading protocol with variable axial loading, it was a column-tofooting assembly, and the longitudinal reinforcement consisted of \#8 rebar. Column LVF\#8 was tested under a conventional laboratory lateral loading protocol (ACI Committee 374, 2013) with variable axial loading, it was a column-to-footing assembly, and the longitudinal reinforcement consisted of \#8 rebar. The variation in axial load is intended to simulate the rocking frame action that would be present in a multicolumn bent during an earthquake and is further discussed in section 3.4 along with the lateral loading protocol. The specimen designations are tabulated in Table 3.1.

Table 3.1: As-built test specimen details (Murtuz, Dusicka, \& Schumacher, 2020)

\begin{tabular}{cccccccc}
\hline Test & $\begin{array}{c}\text { Specimen } \\
\text { Designation }\end{array}$ & $\begin{array}{c}\text { Lateral } \\
\text { Load } \\
\text { History }\end{array}$ & $\begin{array}{c}\text { Axial } \\
\text { Load } \\
\text { History }\end{array}$ & $\begin{array}{c}\text { Aspect } \\
\text { Ratio } \\
(\mathrm{L} / \mathrm{D})\end{array}$ & $\begin{array}{c}\text { Steel } \\
\text { Content } \\
\left(\rho_{\mathrm{l}}\right)\end{array}$ & $\begin{array}{c}{ }^{*} \text { Transverse } \\
\text { Steel Details } \\
\left(\rho_{\mathrm{s}}\right)\end{array}$ & ${ }^{* *} \mathrm{P} /\left(\mathrm{fc}^{\prime} \mathrm{A}_{\mathrm{g}}\right)$ \\
\hline 1 & \multirow{2}{*}{ SVF\#8 } & $\begin{array}{c}\text { Subduction } \\
\text { Variable }\end{array}$ & 3.75 & $0.62 \%$ & $\begin{array}{c}\# 3 \text { at } 12 " \\
(0.17 \%)\end{array}$ & $\begin{array}{c}\text { Min-6\% } \\
\text { Max-9\% }\end{array}$ \\
& LVF\#8 & $\begin{array}{c}\text { Standard } \\
\text { Laboratory }\end{array}$ & Variable & 3.75 & $0.62 \%$ & $\begin{array}{c}\# 3 \text { at } 12 " \\
(0.17 \%)\end{array}$ & $\begin{array}{c}\text { Min-6\% } \\
\text { Max-9\% }\end{array}$ \\
\hline
\end{tabular}

*The volumetric ratio of the transverse reinforcement for a square column section was calculated as $\rho_{\mathrm{s}}=4 * \mathrm{~A}_{\mathrm{v}} /\left(\mathrm{h}_{\mathrm{c}}{ }^{*} \mathrm{~S}\right) ; \mathrm{A}_{\mathrm{v}}=$ Area of transverse reinforcement, $\mathrm{h}_{\mathrm{c}}=$ Depth of core column concrete and $\mathrm{S}=$ Spacing of the transverse reinforcement.

**The axial load ratio was calculated considering the 28 -day strength (4.74 ksi) of the column concrete.

Both specimens were designed as full-scale models of a typical substandard ODOT bridge column-to-footing assembly as defined in section 3.2. The specimens were built to half of the 
typical height with a hinged connection at the top to allow free rotation during loading. Assuming a half-height point of inflection during lateral displacements, these half-height columns model full scale behavior of a column-to-footing assembly. The specimen details are illustrated in Figure 3.2. The spacing of transverse reinforcement at the top of the column is decreased to strengthen the load application connection.

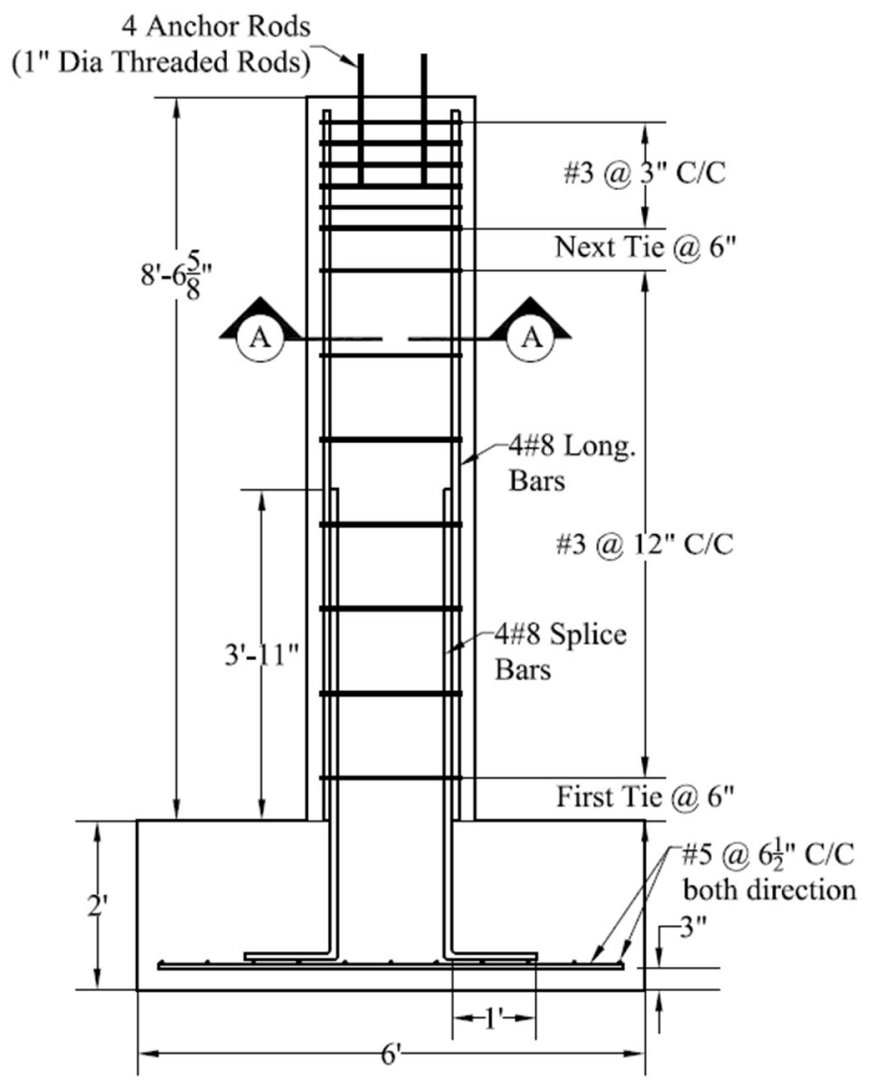

(a)

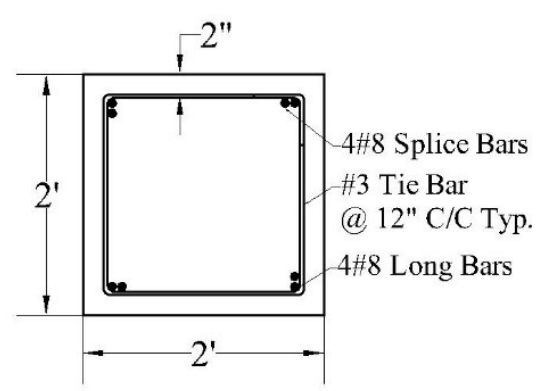

Section A-A

(b)

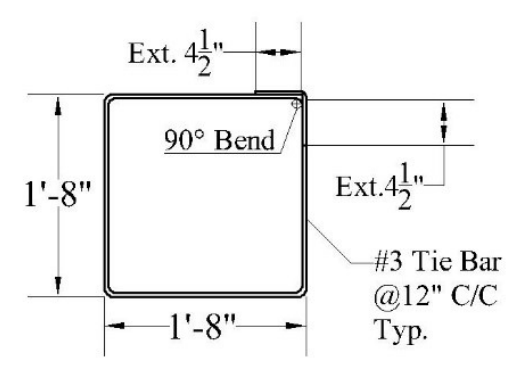

(c) 


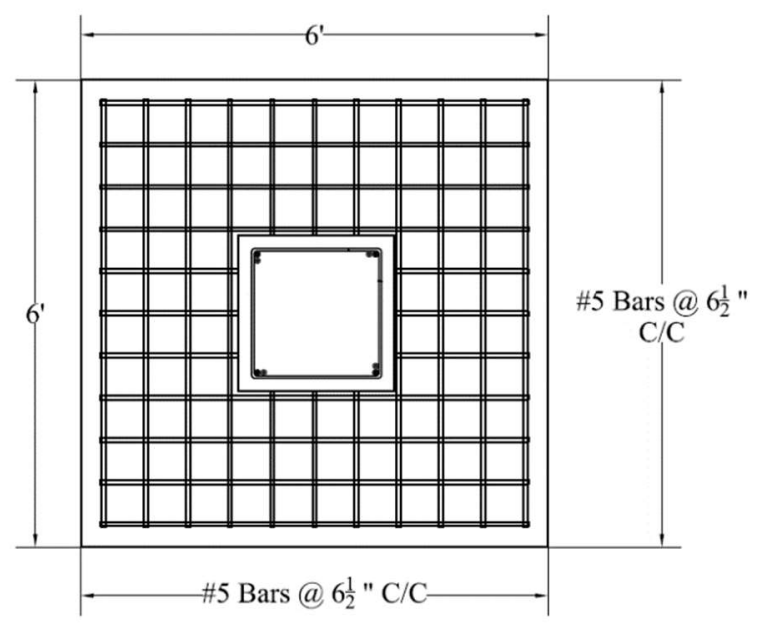

(d)

Figure 3.2: (a) Column cross sectional details (Section A-A), (b) Tie bar details, (c) ColumnFoundation longitudinal section details (d) Foundation cross section details (Murtuz, Dusicka, $\&$ Schumacher, 2020)

\subsection{Loading Protocol}

A loading protocol was developed to represent the forces and displacements of a two-column bent under earthquake excitation. The loading protocol includes quasi-static cyclic lateral loading acting in unison with a varying axial load. Two different lateral loading protocols were tested and are further discussed in section 3.4.1. The details of the variable axial loading is discussed in section 3.4.2.

\subsubsection{Lateral Loading Protocol}

Subduction zone earthquakes typically produce shaking that is significantly longer in duration than that of a crustal earthquake. Records from the 2011 Tohoku earthquake (Mw9.0) show that the attenuation and spectral characteristics were similar to those of smaller magnitude earthquakes, however the duration was much longer (Midorikawa, Miura, \& Si, 2012). With 
Oregon's close proximity to the CSZ, it is likely that the substandard bridges in Oregon will see long duration ground motions, similar to the 2011 Tohoku earthquake.

To adequately represent the inelastic demands from a subduction mega earthquake, test specimen SVF\#8 was tested under an extended lateral loading protocol with a larger number of cyclic deformations (Bazaez \& Dusicka, 2014). Test specimen LVF\#8 was tested under a conventional laboratory lateral loading protocol, suggested by the American Concrete Institute, which is more representative of a crustal earthquake (ACI Committee 374, 2013). Figure 3.3 shows a comparison of the subduction zone protocol, the conventional ACI protocol, and an intermediate protocol known as the modified New Zealand protocol (Priestley, Seible, \& Hines, 2002). The figure shows that the subduction zone protocol has more cycles than a conventional cyclic loading protocol and includes a greater number of cycles at lower ductility levels and fewer cycles at high ductility levels.

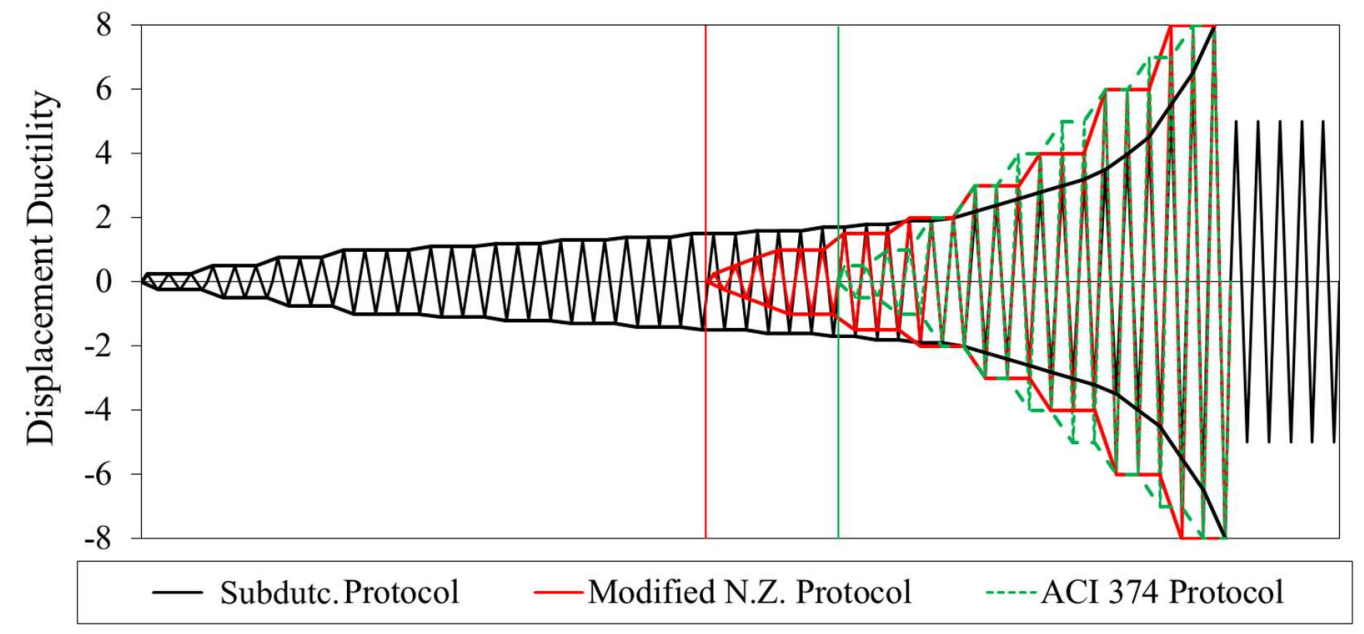

Figure 3.3: Comparison of subduction zone and conventional loading protocols (Bazaez \& Dusicka, 2016) 


\subsubsection{Axial Loading Protocol}

An axial load of 200 kips was selected to represent the dead weight of the structure above. An axial load variation of up to \pm 40 kips was introduced to simulate the effect of the frame action of a two-column bent during an earthquake. Therefore, on forward cycles the axial load will increase to $240 \mathrm{kips}$, and on reverse cycles the axial load will decrease to $160 \mathrm{kips}$. The protocol is shown in Figure 3.4 .

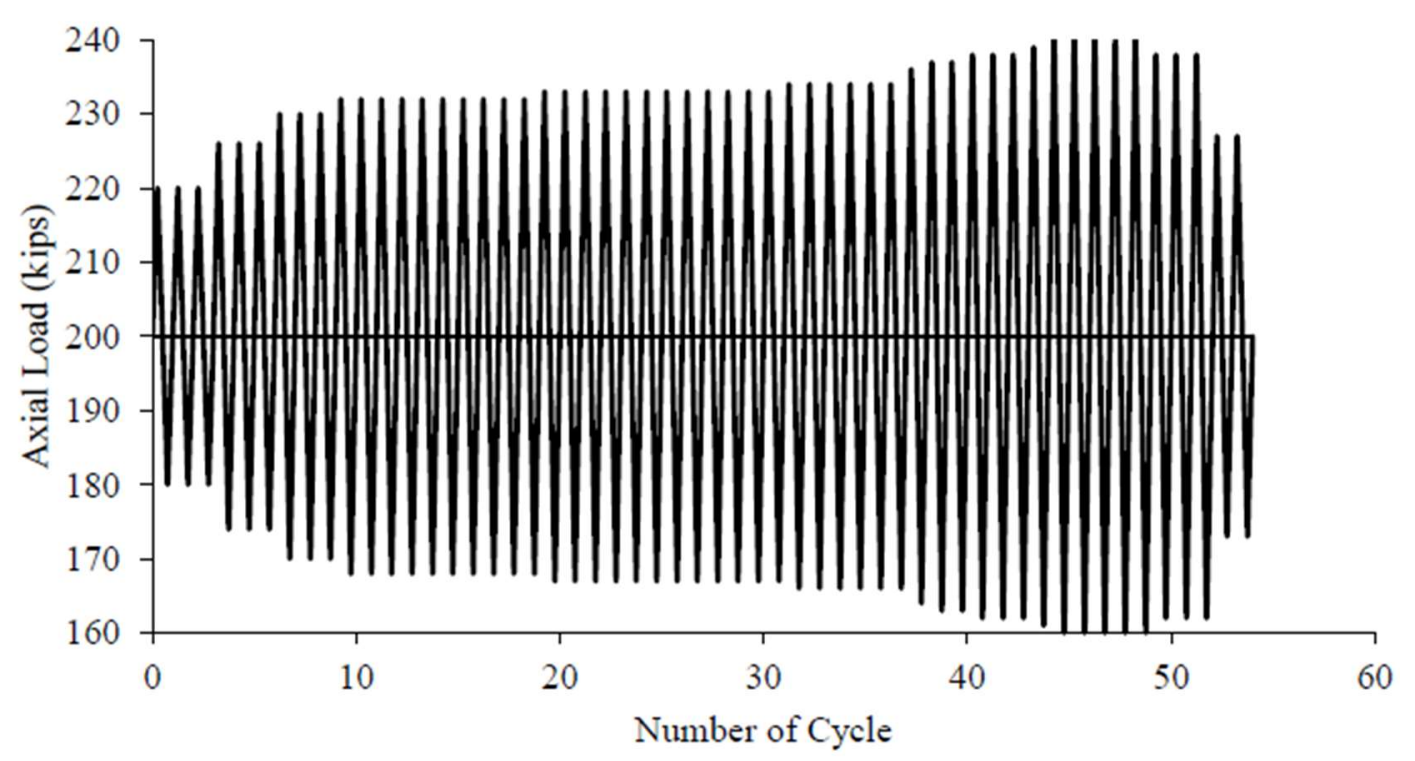

Figure 3.4: Axial Loading Protocol (Murtuz, Dusicka, \& Schumacher, 2020)

\subsection{As-built Performance}

The column-to-footing specimens were tested with the previously described loading protocols. For both tests, the column response was flexural dominated, and the resulting plastic hinge damage was typical for a sub-standard concrete column under earthquake loading. The first sign of damage was flexural cracking followed by yielding of the longitudinal rebar and is pictured in Figure 3.5 (a). The next stage of damage was spalling of the concrete cover, which was observed at the base of the column near the foundation and is pictured in Figure 3.5 (b). Ultimately, buckling 
of the longitudinal rebar occurred at the base of the column after a 12-inch section of cover spalled from the corner. The final damage state is pictured in Figure 3.5 (c).

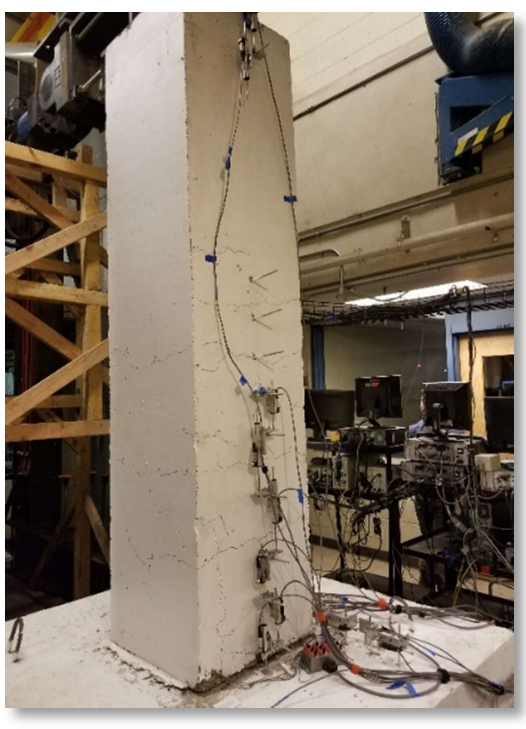

(a)

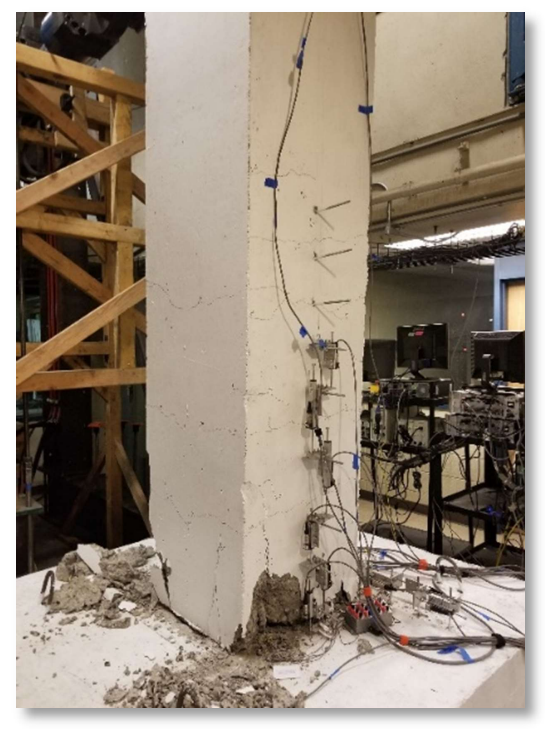

(b)

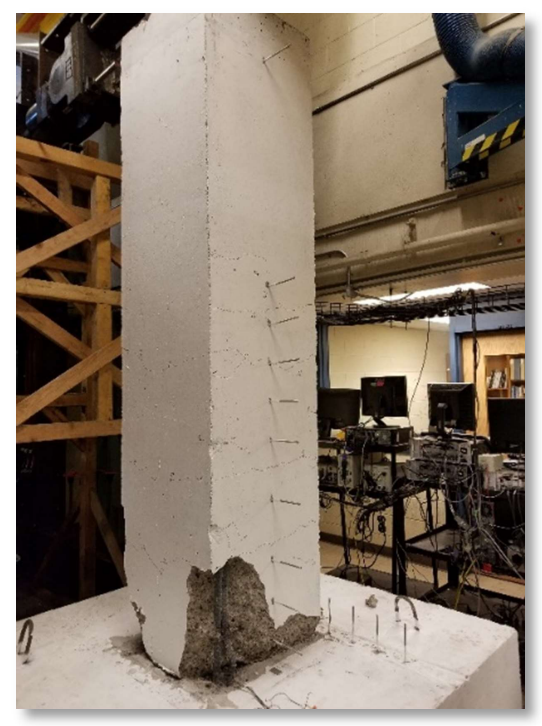

(c)

Figure 3.5: As-build damage progression (specimen SVF\#8)

The cyclic hysteresis of specimen SVF\#8 and LVF\#8 are shown in Figure 3.6 (a) and (b), respectively. The peak lateral loads were 44.9 kips and 40.3 kips. The difference in peak load between positive and negative displacements can be attributed to the variation in axial load. Both specimens demonstrated strength degradation of more than $15 \%$ at large drift angles. 


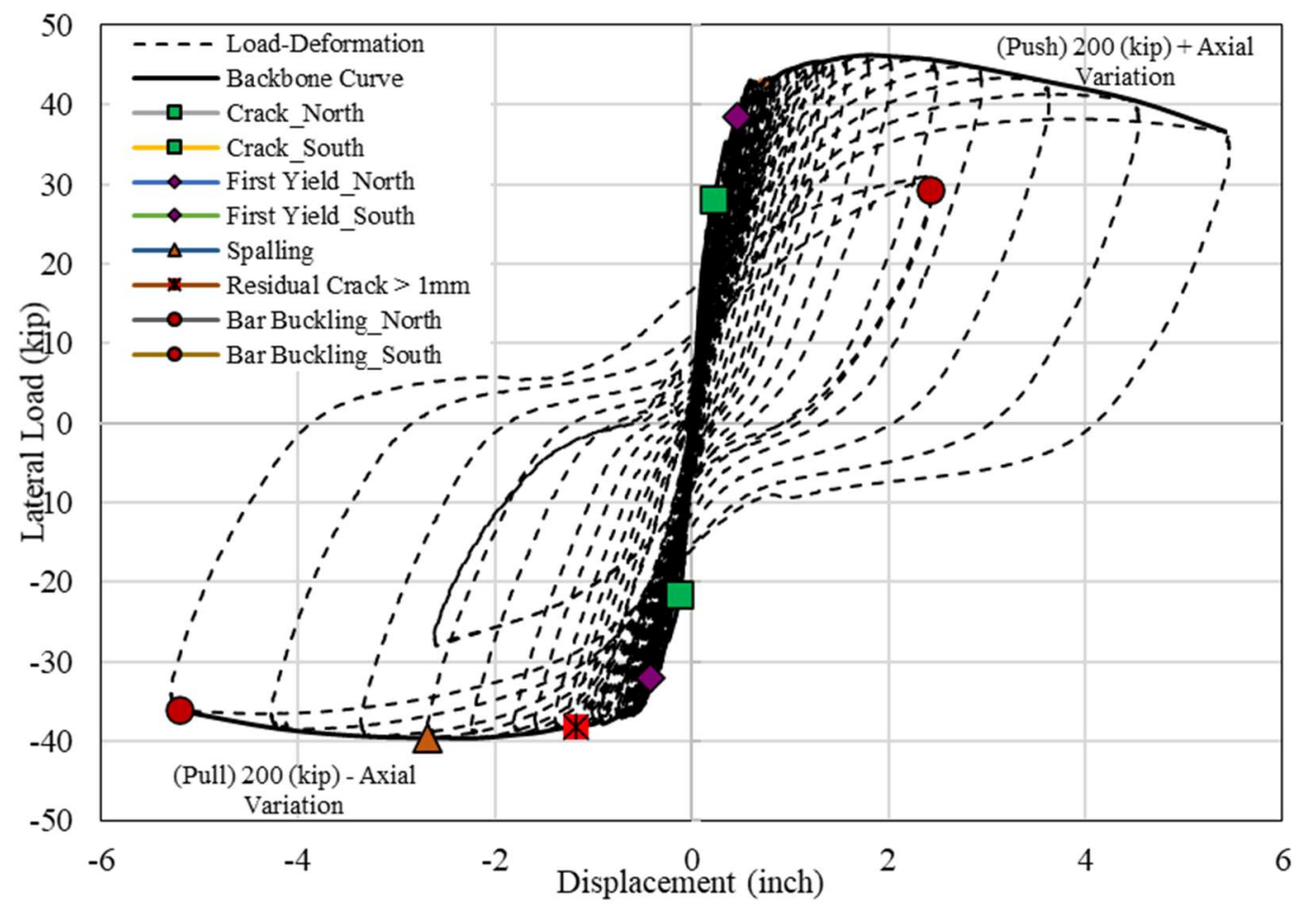

(a)

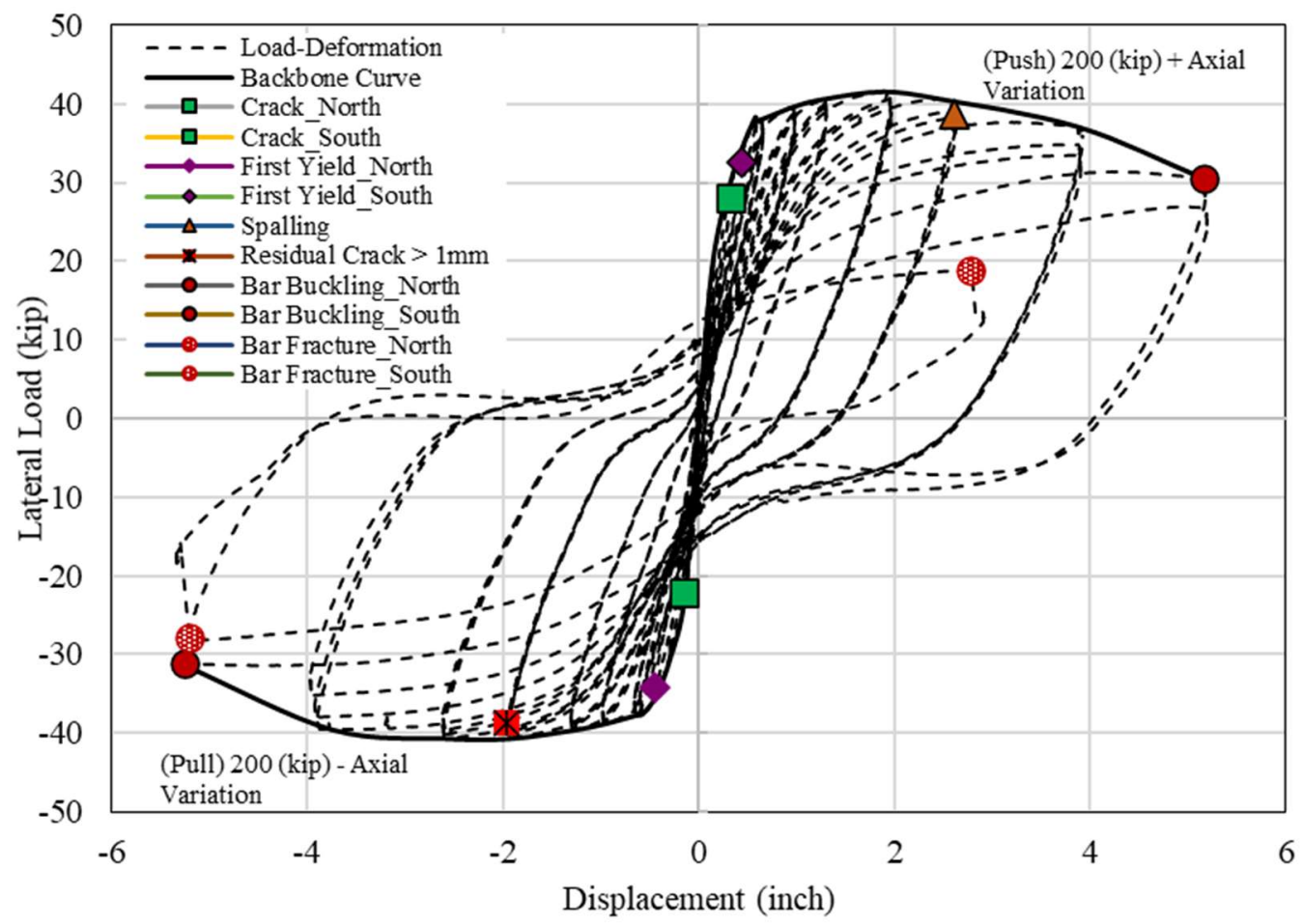

(b)

Figure 3.6: As-built performance of substandard column (a) specimen SVF\#8, (b) specimen LVF\#8 (Murtuz, Dusicka, \& Schumacher, 2020) 


\subsection{PROPOSED REPAIR METHODOLOGY}

\subsection{Repair Objectives}

The primary objective of this research is to develop a post-earthquake repair methodology that not only restores a damaged column to its original strength, but also results in a low-damage structure that is resilient to aftershocks and future earthquakes. It is also necessary that the methodology can be rapidly implemented for post-earthquake repair and is economically competitive to conventional repair methodologies. The following is a list of the primary objectives that were considered in the design of the proposed repair methodology:

1. Primary structure remains elastic without bar yielding

2. Eliminate or limit damage in bridge columns

3. Accessible and replaceable external energy dissipaters

4. Ability to sustain aftershocks and future seismic events

5. Rapid repair approach

6. Economically competitive to conventional repair methods

\subsection{Proposed Repair Concept}

The adopted repair concept is to utilize a short external steel collar that is used to encase the damaged parts of the column. The collar utilizes externally attached ductile fuses to bypass the damaged zone and connect to the rest of the bridge to restore the lateral capacity. The advantage of this approach is bypassing the internal rebar continuity within the damaged zone, which can significantly simplify the repair, and also provides control over the strength of the hinging by selecting appropriately sized ductile fuses. The number of fuses and their individual capacity then controls the behavior, leaving the rest of the repair to be relatively generic. Figure 4.1 is an 
illustration of the proposed repair methodology. In this illustration, one of the hold-downs is pulled away from the jacket, exposing the arrangement of ductile fuses.

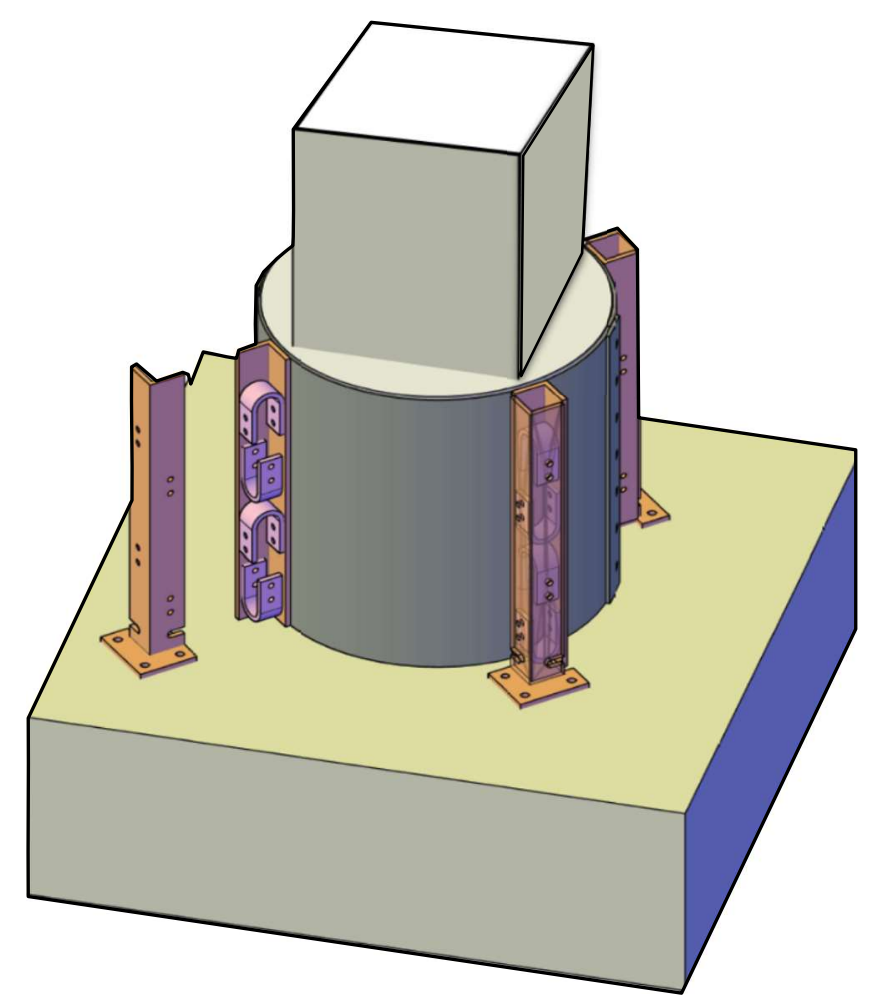

Figure 4.1: Proposed Repair Methodology

The steel jacketing method has been used for both repair and retrofit of reinforced concrete bridge columns. The Seismic Retrofitting Manual for Highway Structures, published by the Federal Highway Administration (Buckle, et al., 2006), provides design guidelines for the steel jacketing method. It states that the steel jacketing method is the preferred method by the California Department of Transportation. This manual was used in the design of the proposed repair methodology. The following subsections will address individual considerations in the design of the proposed methodology. 


\subsubsection{Cross-Sectional Shape}

The adopted repair concept utilizes a jacket with a circular cross section. A rectangular jacket was considered in the design, but the circular jacket was selected for two reasons: (1) superior strength, and (2) easier to construct and assemble. The manual (Buckle, et al., 2006) suggests the use of circular jackets rather than rectangular jackets, even if the column is rectangular. The manual states that attempts to retrofit rectangular columns with rectangular jackets have been less successful.

\subsubsection{Jacket Height}

It is necessary for the steel jacket to entomb areas with extensive damage. Previous research has been conducted regarding the flexural behavior of reinforced concrete columns. It has been found that extensive damage such as cover concrete spalling and rebar buckling will occur with the plastic hinge zone (Zhao, Wu, Leung, \& Lam, 2011). The length of the plastic hinge can be estimated using equation (4.1) which was developed by (Priestley \& Park, 1987). In this equation,

the distance from the critical section to the point of contraflexure is $z$, and the diameter of longitudinal bar is $d_{b}$. For the specimens in this study, $z=102.675$ inches and $d_{b}=1.00$ inches. The resulting plastic hinge length, $\mathrm{L}_{\mathrm{p}}$, is estimated to be 14.2 inches.

$$
L_{p}=0.08 z+6 d_{b}
$$

For the proposed repair methodology, a jacket height of 36 inches was selected. This was a conservative decision to ensure that all serious damage would be entombed within the steel jacket. 


\subsubsection{Jacket Diameter}

The Seismic Retrofitting Manual for Highway Structures (Buckle, et al., 2006) suggests that the steel jacket be comprised of two steel plate half-shells that are rolled to a diameter large enough to leave 1 inch of clearance at the corner of the column. Figure 4.2 illustrates the clearance space required at the column corners. The purpose of this clearance space is to allow the flow of grout around the corner of the column. However, the manual also suggests for grout to be poured from all four openings as to not rely on the flow of grout around the corners. For repair of the 24-inch square test specimen, a shell diameter of 36 inches was selected, leaving a clearance space of approximately 1 inch at each corner.

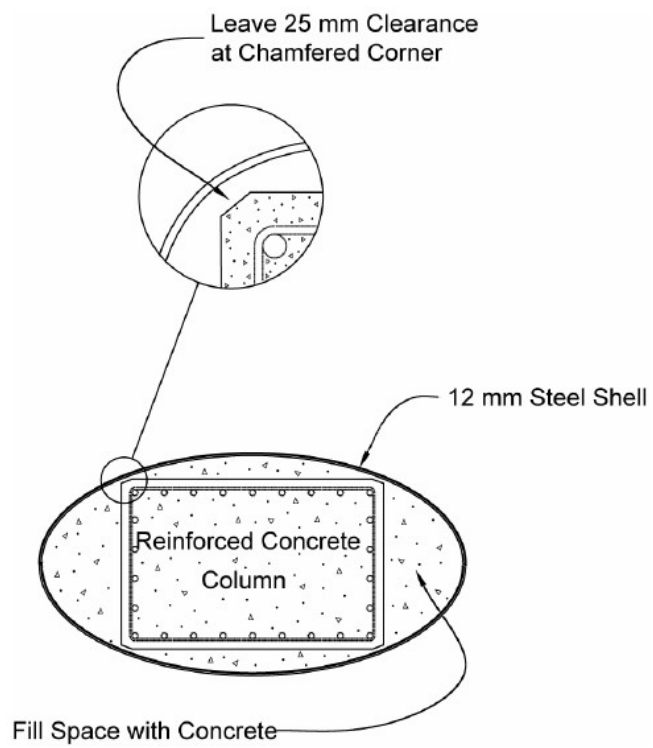

Figure 4.2: FHWA steel shell recommendations (Buckle, et al., 2006)

\subsubsection{Jacket Thickness}

A jacket thickness of 0.375 in was selected for the proposed repair methodology. The Seismic Retrofitting Manual for Highway Structures (Buckle, et al., 2006) suggests a minimum 
jacket thickness of 0.375 inch. This limitation is based on handling the required strength from flexural forces in the column. The manual also places a limit on the maximum thickness of the plate due to restrictions on the construction and fabrication procedures typically used for bending thick plates. The maximum plate thickness is suggested to be $1 \mathrm{inch}$.

\subsubsection{Axial Load Path}

The axial load is designed to be transferred to the footing through the as-built column, meaning the attached steel collar and ductile fuses are not intended to transfer axial load. The Seismic Retrofitting Manual for Highway Structures (Buckle, et al., 2006) suggests a vertical space of 2 inches be provided between the jacket and the footing. This space is necessary to allow the column to rotate at its base without bearing on the steel collar at large drift angles. Even at large angles, the jacket will not contact the footing, and axial load will be transferred through the concrete of the as-built column and not through the jacket.

\subsubsection{Hold-down Orientation}

Figure 4.3 illustrates two possible orientations of the hold-downs around the column. In Figure 4.3 (a), the hold-downs are oriented at the column corners and will be referred to as corner orientation, while Figure 4.3 (b) has the hold-downs oriented at the column faces and will be referred to as face orientation. Hold-down orientation has performance implications because it alters the lever arm distance for each hold-down. Both corner and face orientation were tested as part of this study and the performance implications were explored. 


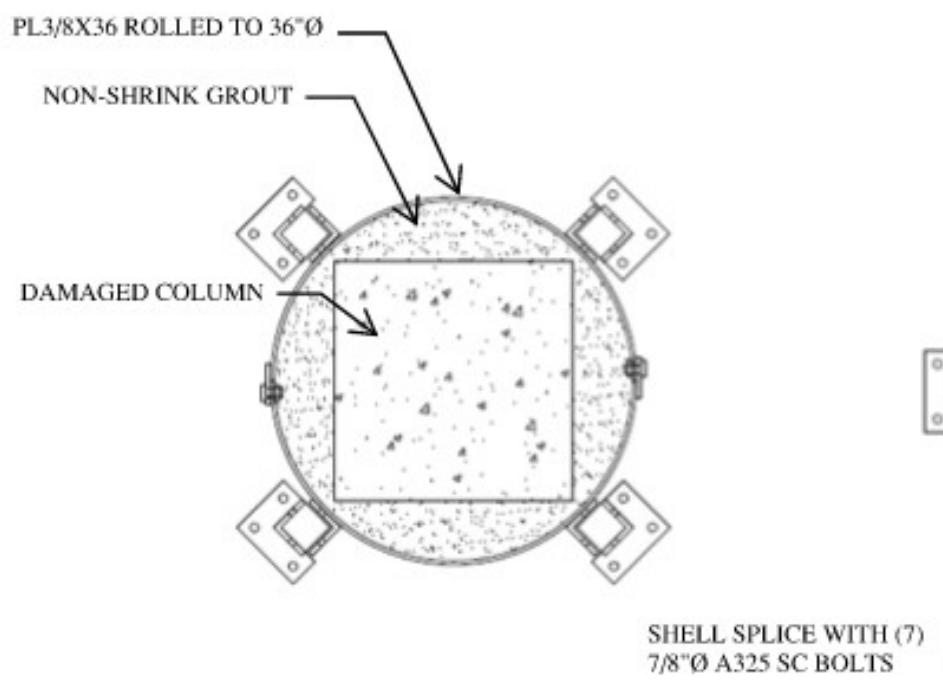

(a)

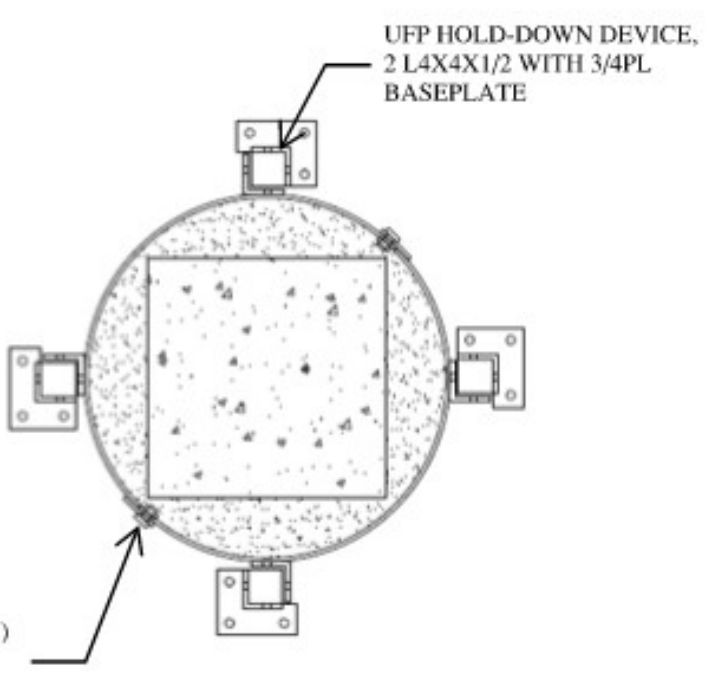

(b)

Figure 4.3: Hold-down orientations (a) corner orientation (b) face orientation

\subsection{Analytical Predictions and Initial Design Philosophy}

This section provides an analytical approach to estimate the strength and behavior of the proposed repair methodology. The analytical approach outlined in section 4.3.1 was used to select the appropriate UFP geometry for the initial test. Analytical predictions are also necessary prior to testing to determine the force and displacement capabilities of the instrumentation and equipment (ACI Committee 374, 2013).

The following analytical procedures are expected to overestimate the strength of the repair for two reasons. First, the following procedures are based on rigid body deformation of the column where the horizontal displacement of the column is due to the rotation between the repaired column and its footing and the curvature of the column is assumed to be negligible. Second, the following procedures assume that the rocking point, or neutral axis, will be on the outer edge of the column. The actual rocking point will not be directly at the edge of the column, it will be at an unknown 
distance inside of the column. Through testing, the actual rocking point of the column will be found and used to refine the analytical predictions.

\subsubsection{Static Analysis}

For initial design considerations and selection of the UFP's, the static analysis was developed. This simple analysis characterizes the horizontal force on the column as a function of the hold-down force and the axial load by equating the moments acting about the rocking point. For this analysis, the following assumptions are made:

1) The rocking point is at the edge of the column

2) Column curvature is negligible

3) Maximum expected hold-down forces are acting about the column in its undeformed state

The forces acting around the assumed rocking point are illustrated in Figure 4.4 (a) for corner hold-down orientation and Figure 4.4 (b) for face hold-down orientation. It is important to note that the hold-down orientation affects the distance from each hold-down to the assumed rocking point and will thus affect the overall performance of the repair. 


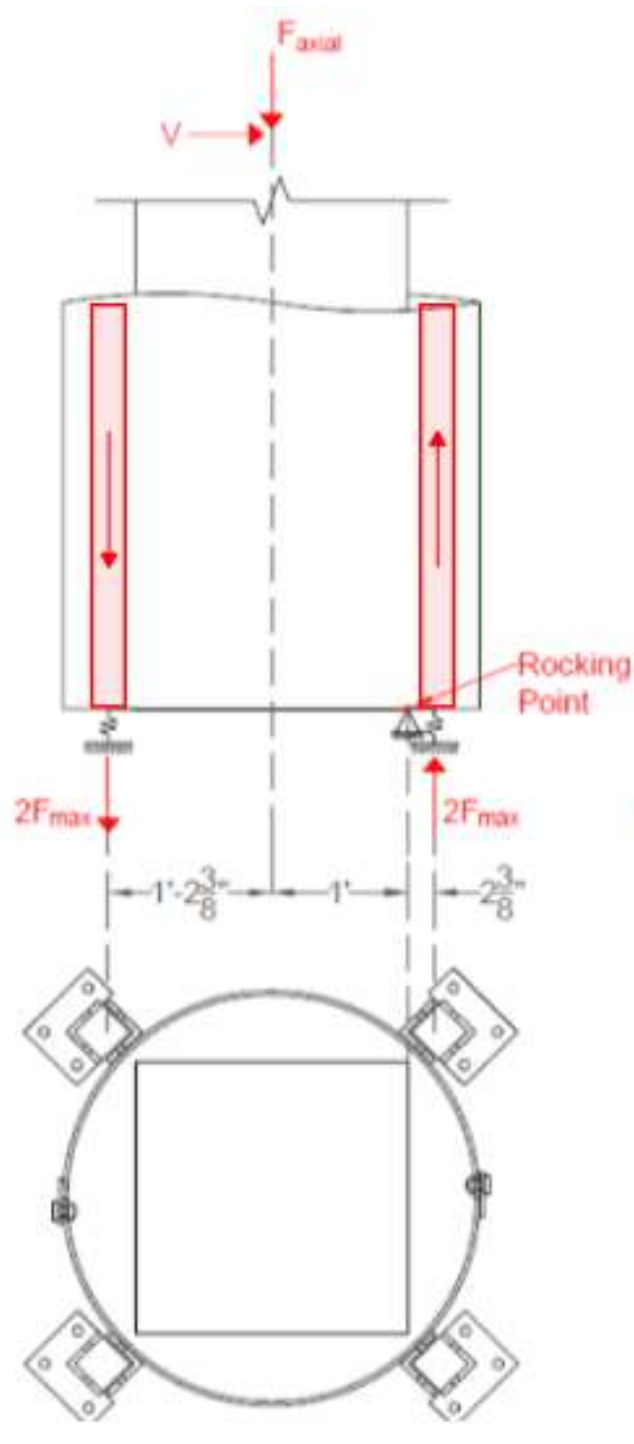

(a)

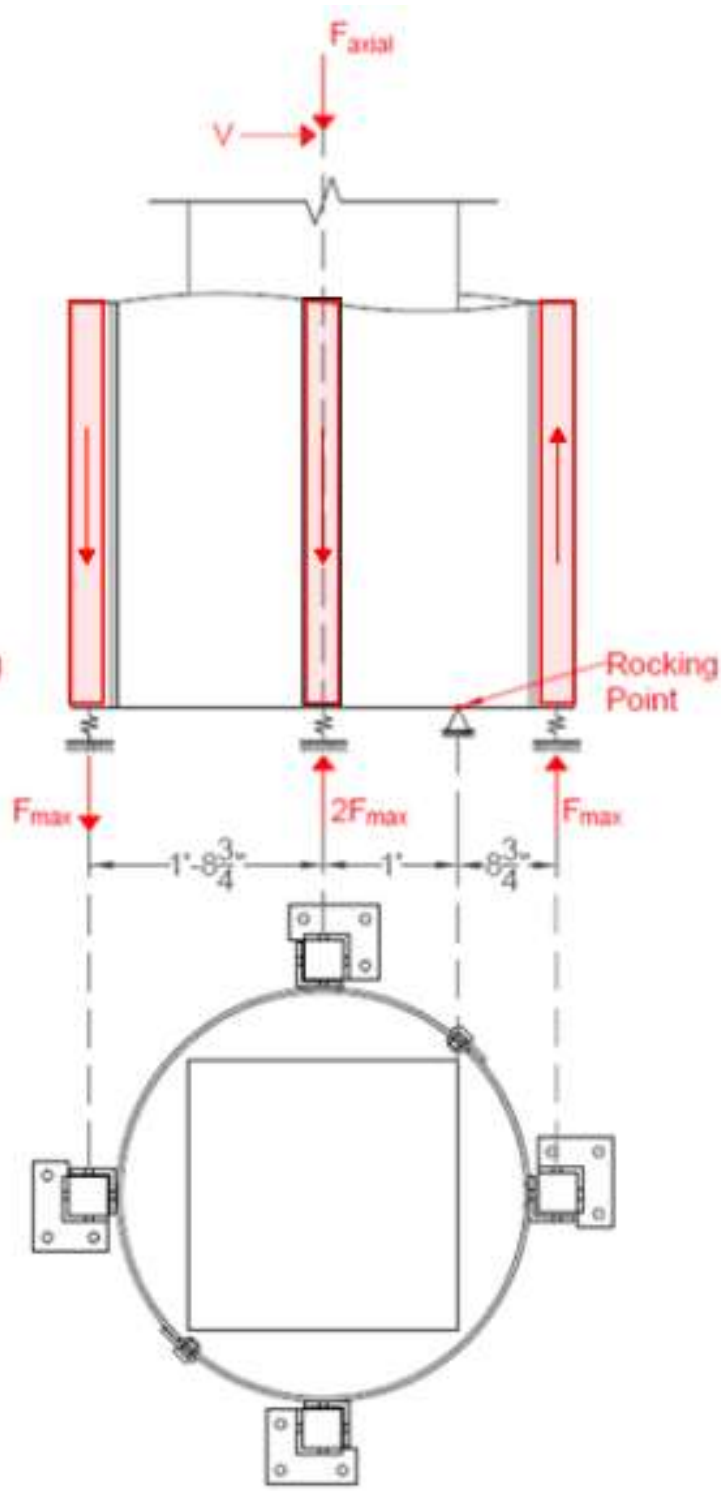

(b)

Figure 4.4: Forces about the rocking edge (a) corner orientation (b) face orientation

By taking the sum of the moments around the rocking point, equations (4.2) and (4.3) can be derived. Equation (4.2) gives the maximum horizontal force expected for the corner hold-down orientation and equation (4.3) gives the maximum horizontal force expected for the face holddown orientation. 


$$
\begin{aligned}
& V_{\text {max }}=\frac{12 F_{\text {axial }}+57.5 F_{H D}}{h_{c}} \\
& V_{\text {max }}=\frac{12 F_{\text {axial }}+65.5 F_{H D}}{h_{c}}
\end{aligned}
$$

This analysis does not address the force-displacement relationship of the hold-downs. In the undeformed state the hold-down force will be zero. The following section provides a more indepth analysis that accounts for the force-displacement relationship of the hold-downs.

\subsubsection{Pushover Analysis}

This analysis method was developed to refine the static analysis method by addressing the assumption that the hold-down force is equal to its theoretical maximum. However, the first two assumptions from the static analysis are still applied to the pushover analysis. The assumptions are:

1) The rocking point is at the edge of the column

2) Column curvature is negligible

In this analysis, the hold-down force is no longer assumed to be its theoretical maximum. The hold-down force is now considered to be a function of total horizontal displacement. When the column is undeformed, the hold-downs are at rest and the force is zero. As the column is displaced horizontally, the hold-downs engage and build load. The relationship between holddown deformation and horizontal column displacement is based on ridged body deformation and is given by equation (4.4) where $\Delta_{\mathrm{HD}}$ is the hold-down deformation, $\Delta_{\text {column }}$ is the horizontal 
deformation at the top of the column, $\mathrm{d}_{\mathrm{HD}}$ is the horizontal distance between the hold-down and the assumed rocking point and $\mathrm{h}_{\text {column }}$ is the height of the column.

$$
\Delta_{H D}=\Delta_{\text {Column }}\left(\frac{d_{H D}}{h_{\text {column }}}\right)
$$

The force in each hold down is given by equation (4.5) where $\mathrm{F}_{\mathrm{HD}}$ is the force provided by the hold-down, $\mathrm{K}_{\mathrm{HD}}$ is the initial stiffness of the hold down and $\mathrm{F}_{\mathrm{p}}$ is the plastic moment force of the hold-down. $\mathrm{K}_{\mathrm{HD}}$ and $\mathrm{F}_{\mathrm{p}}$ are described in more detail in section 2.4. Based on previous studies, the maximum force in each hold-down is limited to $1.5 \mathrm{~F}_{\mathrm{p}}$.

$$
F_{H D}=\Delta_{H D} K_{H D} \leq 1.5 F_{p}
$$

This analysis also accounts for the varying position of the axial load. In the static analysis, the moment arm for the axial load was taken to be half of the column width. In the pushover analysis, the moment arm of the axial load is reduced by the horizontal displacement at the top of the column and is given by equation (4.6) where $d_{\text {axial }}$ is the length of the moment arm of the axial load about the assumed rocking point.

$$
d_{\text {axial }}=12^{\prime \prime}-\Delta_{\text {column }}
$$

Figure 4.5 show a comparison of the static analysis and the pushover analysis. This figure is for a column that was repaired with hold-downs in the face orientation and with UFP's that have a plastic force of 5.4 kips. 


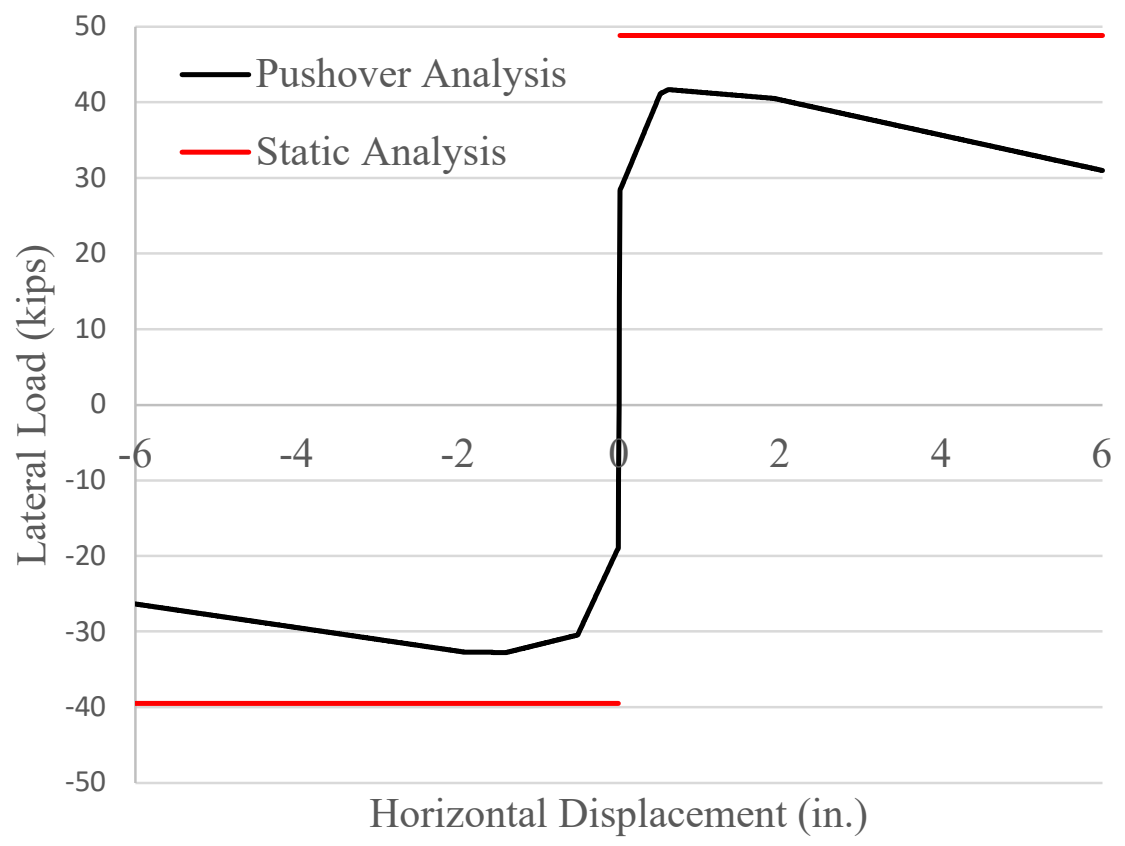

Figure 4.5: Pushover analysis vs. static analysis 


\subsection{EXPERIMENTAL VALIDATION}

\subsection{Test Setup}

To validate the repair methodology, an experimental test setup was constructed in Portland State University's infraStructure Testing and Applied Research (iSTAR) Laboratory. A layout of the test setup is illustrated in Figure 5.1. The test setup was designed to subject a full-scale columnto-foundation assembly to the forces and deformations expected in an earthquake. In order to impose the expected forces and deformations, it was necessary for the test setup to be designed with three considerations. First, the test setup must be capable of imposing cyclic lateral deformations. Second, the test setup must be capable of imposing a variable axial load. And third, the variation in axial load must be synchronized with the lateral deformations to simulate the frame action of a multi-column bridge bent.

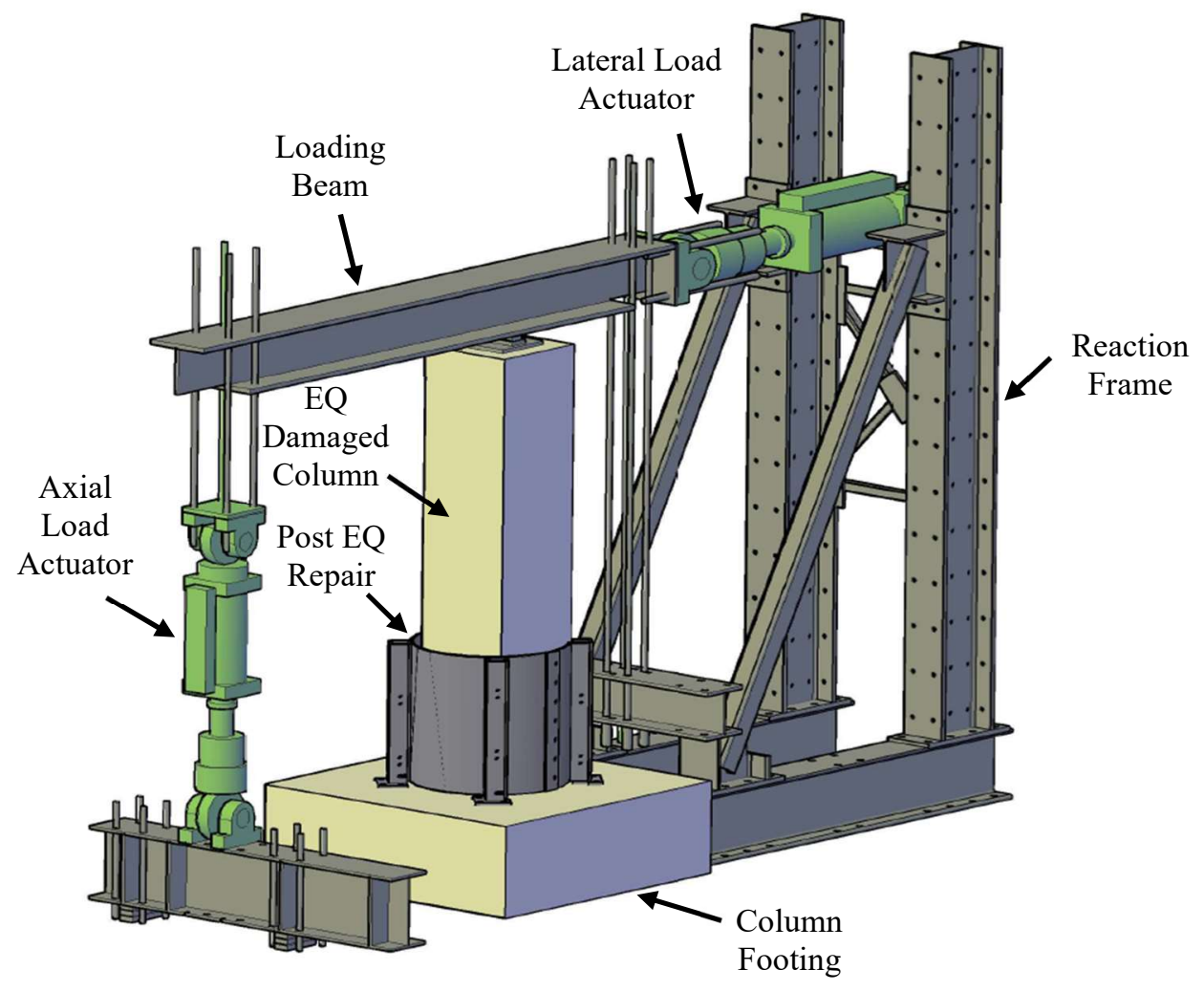

Figure 5.1: Experimental Test Setup Layout 
To impose both lateral deformation as well as axial load, the test setup includes two hydraulic actuators. The lateral load actuator is a Shore Western 92 Series Actuator with a stroke of \pm 10 inches. This actuator can produce 220 kips in tension and 335 kips in compression which greatly exceeds the expected maximum lateral load. The axial load is applied by a \pm 100 kip MTS actuator with a stroke of \pm 6 inches. The loading beam is proportioned such that the column axial load is applied at one third of its overall length, creating a lever capable of imposing an axial load of up to 300 kips.

\subsection{Test Matrix}

Two columns from ODOT SPR\#802 were repaired and four experimental tests were conducted. The first specimen, column SVF\#8, was repaired with the hold-downs oriented at column corners and tested once. The second specimen, column LVF\#8, was repaired with holddowns oriented at column corners. This repair was tested three times by re-implementing the same repair but with new ductile fuse UFPs. Table 5.1 summarizes the experimental program. The column designation is adopted from ODOT SPR\#802 and is explained in section 3.3. Table 5.2 shows the ductile fuse UFP properties for each of the four tests.

Table 5.1: Experimental test matrix

\begin{tabular}{lcccccc}
\hline Test & $\begin{array}{c}\text { SPR\#802 } \\
\text { Column } \\
\text { Designation }\end{array}$ & $\begin{array}{c}\text { Hold-down } \\
\text { Orientation }\end{array}$ & $\begin{array}{c}\text { Lateral } \\
\text { Loading } \\
\text { Protocol }\end{array}$ & $\begin{array}{c}\text { UFP } \\
\mathrm{F}_{\mathrm{p}} \\
\text { (kips) }\end{array}$ & $\begin{array}{c}\text { Expected } \\
\text { Hold-down } \\
\text { Force, } \mathrm{F}_{\max } \\
\text { (kips)* }\end{array}$ & $\begin{array}{c}\text { Expected Lateral } \\
\text { Load } \mathrm{V}_{\max }(\mathrm{kips})^{* *}\end{array}$ \\
\hline 1 & SVF\#8 & Corner & Subduction & 5.45 & 32.73 & 46.4 \\
2 & LVF\#8 & Face & Conventional & 5.43 & 32.60 & 48.9 \\
3 & LVF\#8 & Face & Subduction & 5.43 & 32.60 & 48.9 \\
4 & LVF\#8 & Face & Subduction & 8.83 & 52.97 & 61.9 \\
\hline *The maximum expected hold-down force was calculated as $\mathrm{F}_{\max }=\left(1.5 \mathrm{~F}_{\mathrm{p}}\right) *(4$ UFP's per \\
hold-down) \\
**Expected lateral load as calculated in section 4.3
\end{tabular}


Table 5.2: Hold-down properties by test

\begin{tabular}{cccccccc}
\hline Test & $\begin{array}{c}\text { Width, } \\
\mathrm{b}(\mathrm{in})\end{array}$ & $\begin{array}{c}\text { Bend } \\
\text { diameter, } \\
\mathrm{d} \text { (in) }\end{array}$ & $\begin{array}{c}\text { Thickness, } \\
\mathrm{t}(\mathrm{in})\end{array}$ & $\begin{array}{c}\text { Steel yield } \\
\text { stress, } \sigma_{\mathrm{y}} \\
\text { (ksi) }\end{array}$ & $\begin{array}{c}\text { UFP yield } \\
\text { force, } \mathrm{F}_{\mathrm{y}} \\
\text { (kips) }\end{array}$ & $\begin{array}{c}\text { UFP plastic } \\
\text { force, } \mathrm{F}_{\mathrm{p}} \\
\text { (kips) }\end{array}$ & $\begin{array}{c}\text { Expected } \\
\text { Lateral Load } \\
\mathrm{V}_{\max }(\mathrm{kips})^{*}\end{array}$ \\
\hline 1 & 2.5 & 3.25 & 0.50 & 56.7 & 3.64 & 5.46 & 46.4 \\
2 & 2.5 & 3.25 & 0.50 & 56.5 & 3.62 & 5.43 & 48.9 \\
3 & 2.5 & 3.25 & 0.50 & 56.5 & 3.62 & 5.43 & 48.9 \\
4 & 2.5 & 3.125 & 0.625 & 56.5 & 5.89 & 8.83 & 61.9 \\
\hline
\end{tabular}

*Expected lateral load as calculated in section 4.3

\subsection{Repair Implementation Process}

To apply the proposed repair concept, the existing longitudinal rebar between the column and the foundation needs to be disconnected so as not to participate in the load path. The disconnected rebar can be seen in Figure 5.2(a). In this study, the damaged columns had four \#8 rebar dowels, one at each corner of the column. At the time of the repair, these rebars were mostly exposed due to spalling in the damaged zone of the column. The remaining concrete around the rebar was removed and the rebar was cut with an oxy-acetylene torch. Figure 5.3(a) is a picture of the column after the longitudinal rebar was exposed and cut. If this repair methodology were to be applied to a column with less damage (i.e. no spalling), the longitudinal rebar does not necessarily need to be exposed. The rebar could be disconnected by plunge cutting with a circular saw blade. 


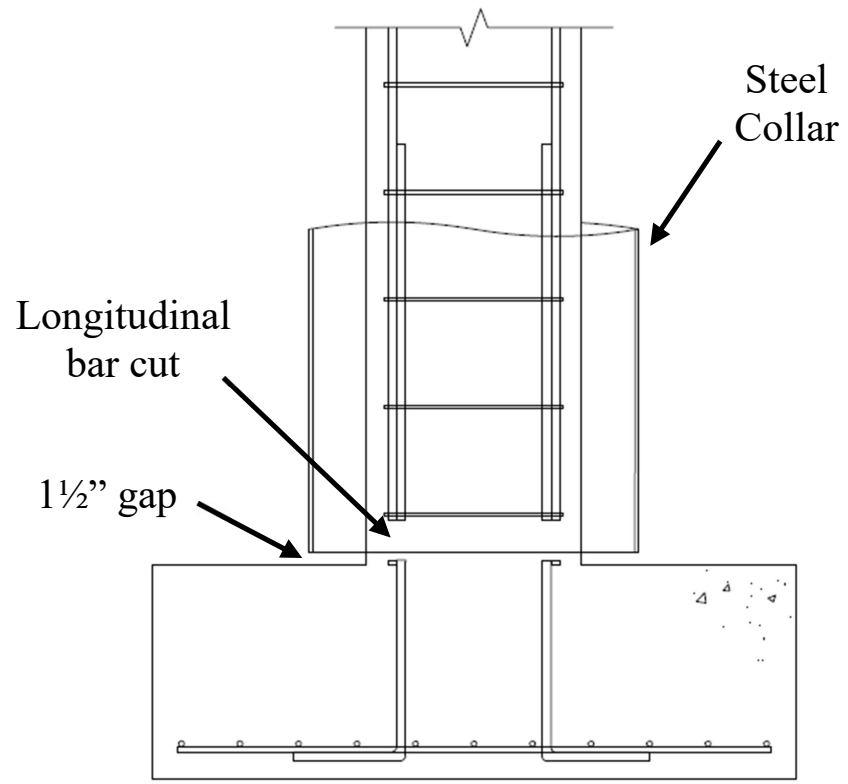

(a)

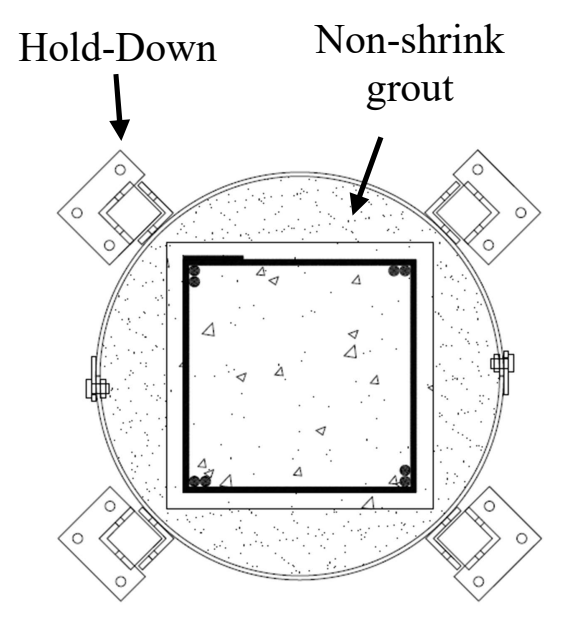

(b)

Figure 5.2: Repair Methodology (a) elevation view (b) section view

The next step of the repair process is to place the prefabricated steel collar around the column with the necessary 1.5 -inch space above the foundation. In order to place the jacket for attachment, the jacket was set on top of two layers of $3 / 4$ " plywood which act as temporary spacers to create the necessary gap. Figure 5.3(b) is a picture of the steel jacket sitting on top of the temporary spacers. The collar is then filled with non-shrink grout to secure it to the column. The placement of the steel collar around the column can be seen in Figure 5.2(b) in a top section view. After the grout has cured, the temporary spacers can be removed.

The final step of the repair is to attach the ductile fuse hold-downs. Inside of the hold-down, there are four UFP's which act as ductile fuses. One side of the hold down is welded to the steel jacket while the other side is anchored to the foundation via conventional threaded rods with Hilti epoxy. Figure 5.4 shows the ductile fuse hold-down before the outer leg is installed. The UFP's are bolted with two 5/8-inch diameter slip-critical A325 bolts on each leg. Nuts are welded to the 
inside of the UFP such that the bolts can be secured without access to the inside of the UFP. Upon installation of the hold-downs, there is a gap between the hold-down base plate and the foundation. This gap is to be filled with self-leveling grout before the anchor rod nuts are tightened. Figure 5.3(c) shows a picture of temporary forms that were installed for the base plate grout. Figure 5.5 shows the base plate with anchor rods after the forms have been removed.

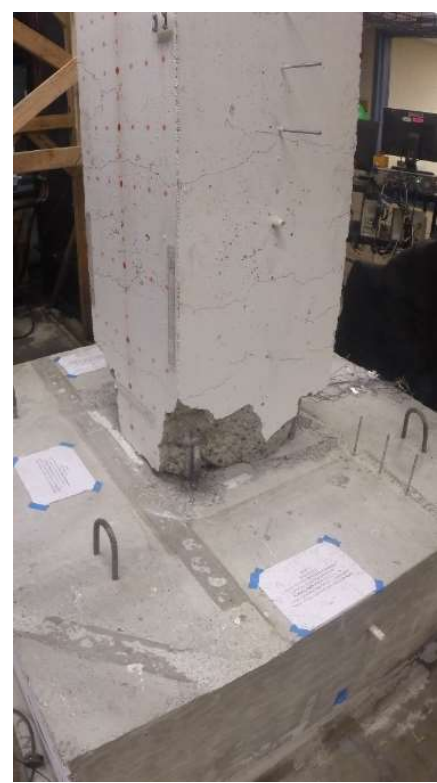

(a)

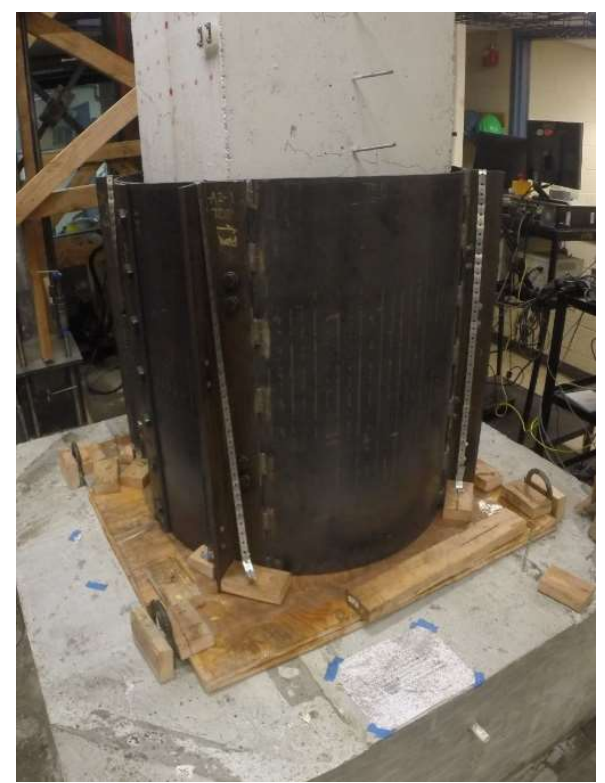

(b)

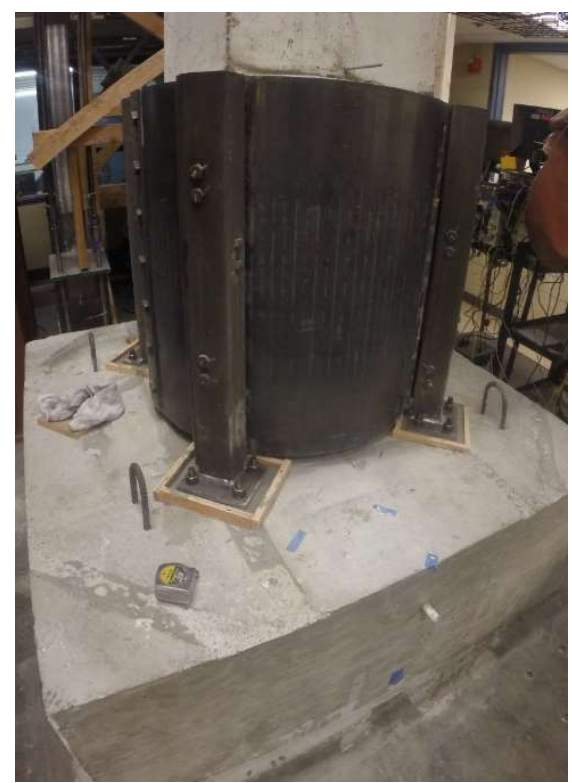

(c)

Figure 5.3: Prototype Repair Sequence 


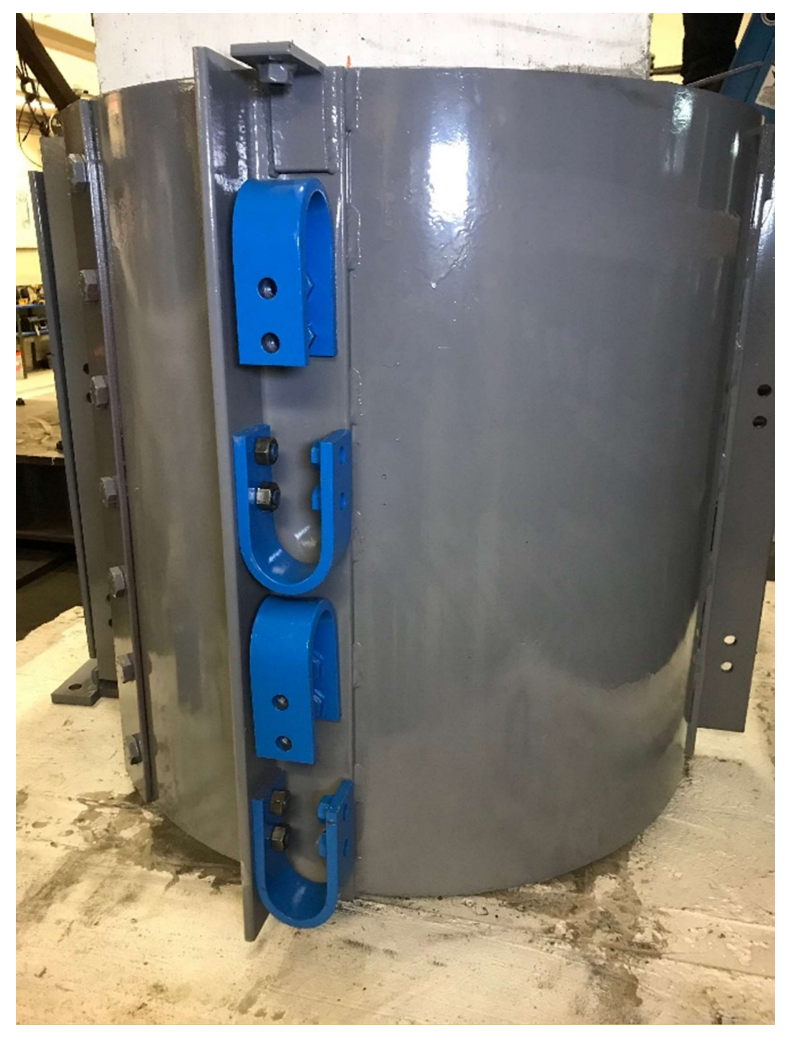

Figure 5.4: UFP's inside hold-down

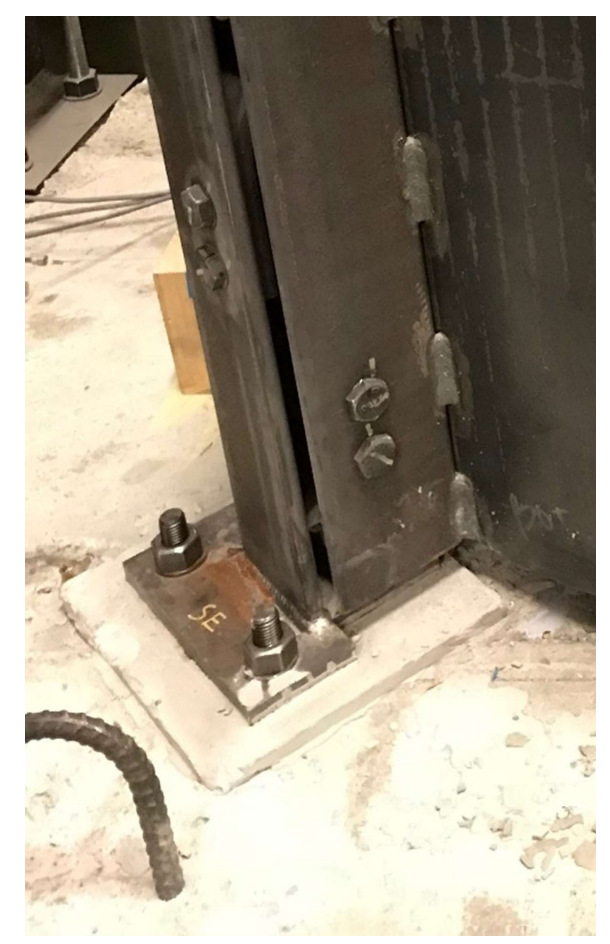

Figure 5.5: Hold-down base plate 


\subsection{Instrumentation}

The actuators in the test setup are equipped with load cells which were used to measure the horizontal and axial load that were applied to the column. The global displacement at the top of the column was instrumented with a string potentiometer and is labeled in Figure 5.6. The repaired column was instrumented with linear variable displacement transducers (LVDT) to measure local deformations and global displacements. Figure 5.6 illustrates the layout of LVDT's on a repaired column.

Each hold-down was equipped with one vertical LVDT to measure local displacement of the hold-down. These LVDT's are labeled on plan in Figure 5.6 and an example of how it was installed is pictured in Figure 5.7. Five LVDT's on each side of the column were used to measure the curvature of the column above the repaired zone. One LVDT on each side was used to measure vertical slippage between the steel collar and the grout. Three LVDT's were equipped at each shell splice to monitor slip at the bolted connection of the steel collar. Two LVDT's were attached via a string tangent to the circumference of the shell to monitor rotation that could result from undesired non-symmetric behavior. The foundation was equipped with two vertical LVDT's to monitor uplift/rocking and two horizontal LVDT's to measure sliding. 

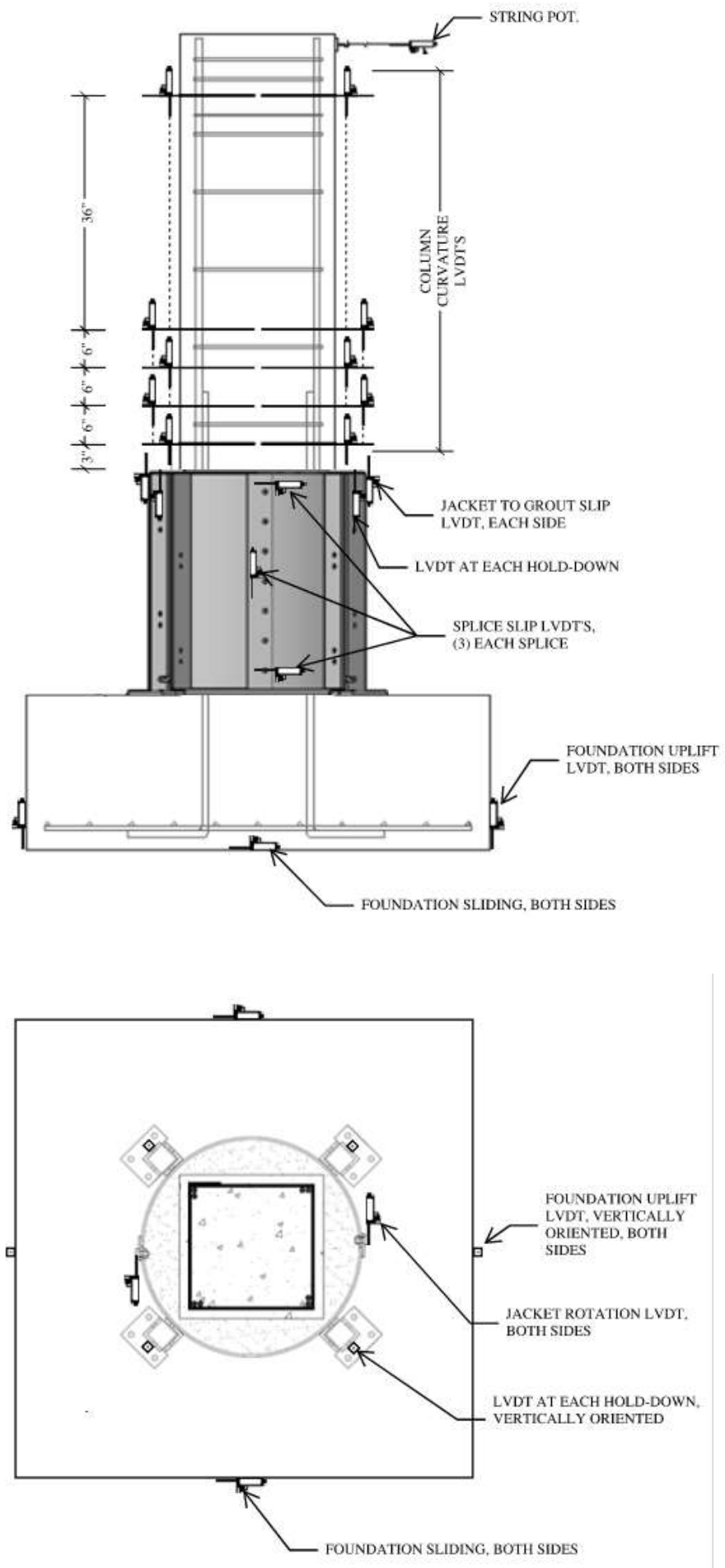

Figure 5.6: Instrumentation Plan 


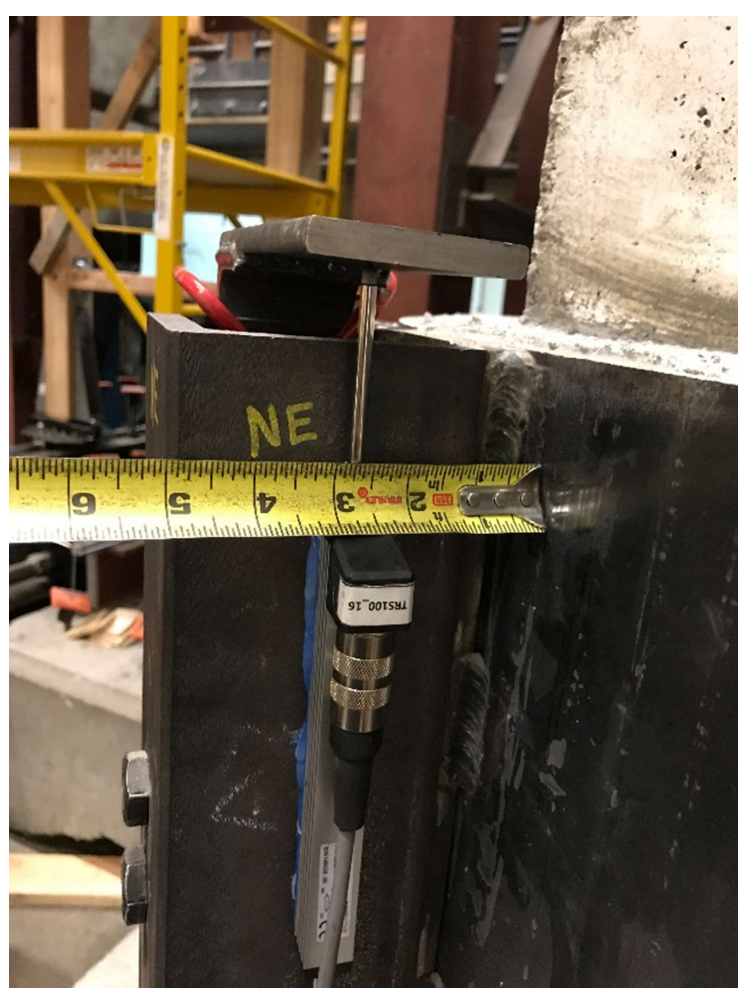

Figure 5.7: Hold-down instrumentation

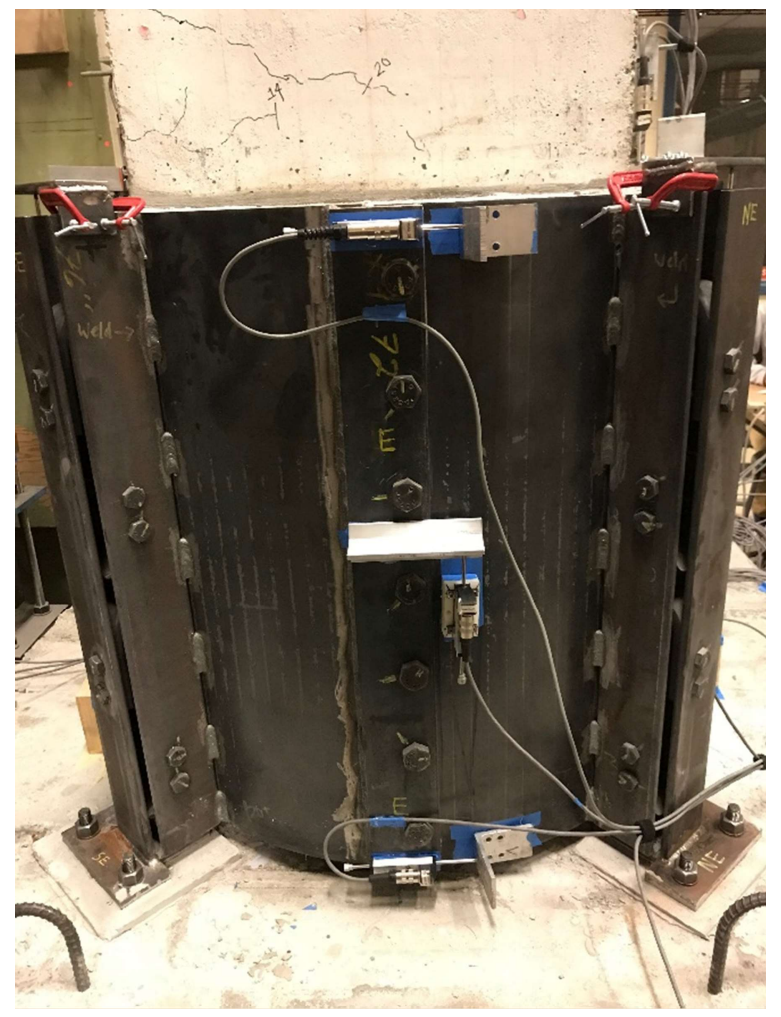

Figure 5.8: Shell splice instrumentation 


\subsection{Results}

This section presents the observations and data from each of the four tests. Qualitative observations and inter-test design modifications are presented in section 5.5.1. Quantitative data from instrumentation is presented in section 5.5.2. The observations and data from all four tests are then discussed in section 5.5.3 in an effort to evaluate the success of the design objectives.

\subsubsection{Observations}

\subsubsection{Test 1}

The first test was conducted on specimen SVF\#8. The subduction zone lateral loading protocol was used for both the as-built test, and the repaired test. The maximum lateral load from the as-built column was 45 kips. The repair was implemented using the corner orientation. The repair was designed with the intention of matching the as-built behavior by selecting UFP's to yield a similar expected lateral load based on the procedure outlined in section 4.3. The chosen UFP's were PL1/2X2-1/2 grade A36 steel with a bend diameter of 3.25 inches. With four UFP's per hold-down, the expected maximum holddown force was 32.7 kips and the expected maximum lateral load was 46.4 kips. The repaired column can be seen with the test set-up in Figure 5.9.

The repair implementation functioned as expected. The column was rocking along the compression edge and the hold-downs were engaging to resist overturning forces. Figure 5.10 shows the column at a displacement of 2.5 inches. Vertical displacement can be seen at each hold-down along with rotation of the individual hold-down legs. In this picture, there is visible separation between the legs of the tension hold-down. The outer hold-down legs appeared to undergo plastic rotation causing residual deformation during 
compression cycles, which was not restored upon the opposite tension cycle. The residual deformation is pictured in Figure 5.11.

At the final target displacement of 5.4 inches, the axial load actuator stroked out and axial load on the column was lost. The column was returned to its unloaded state while the test set-up was adjusted. The test was resumed, but after three more cycles at the same target displacement of 5.4 inches, the test was terminated when the south east hold-down failed while in tension. The weld between the L4X4X1/2 and the base plate ruptured. The ruptured weld is pictured in Figure 5.12. The weld was a 5/16-inch fillet weld around the perimeter of the angle. While the weld was sufficient to resist the axial capacity of the hold down, it was not designed for combination axial plus flexural forces. 


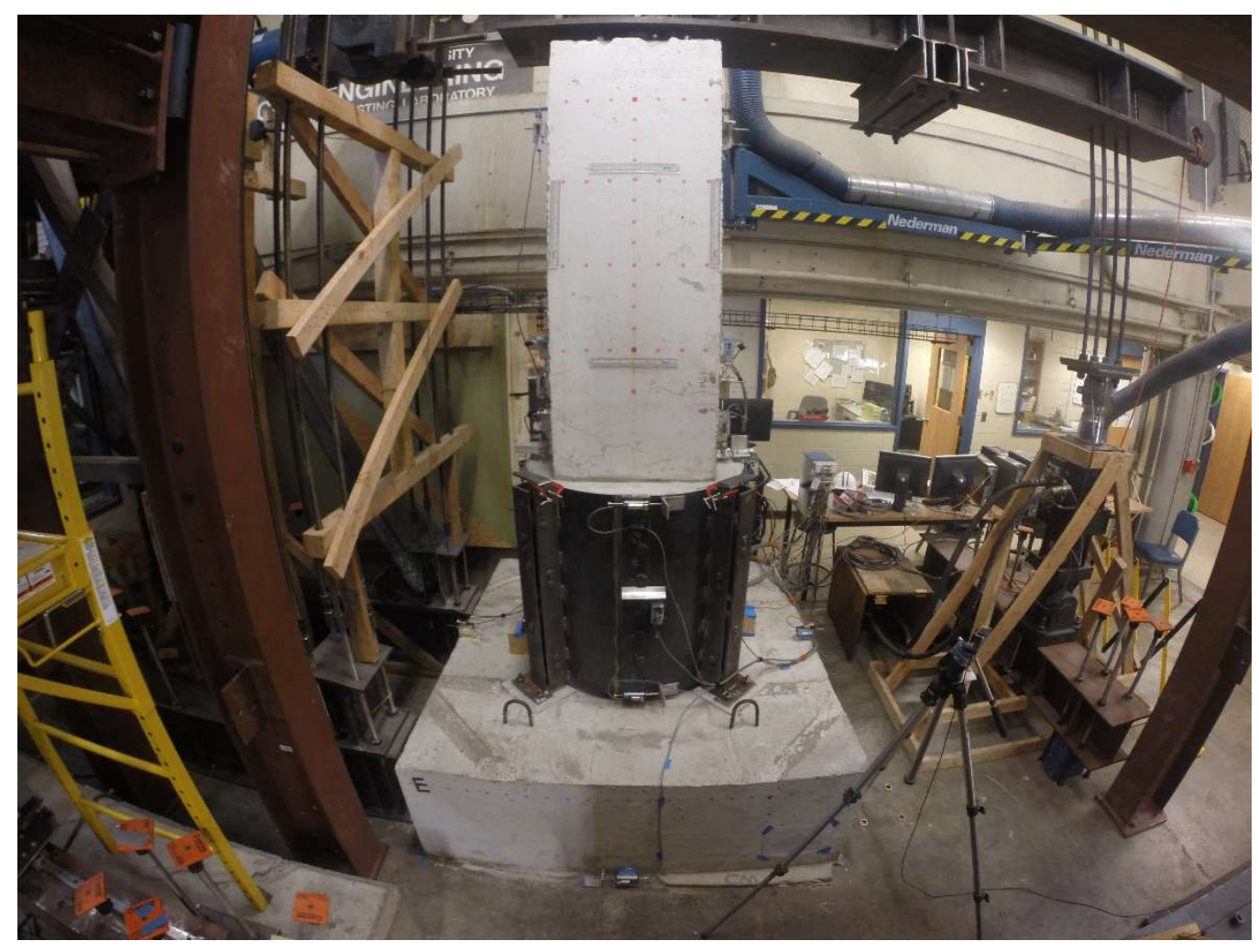

Figure 5.9: Test 1 initial state

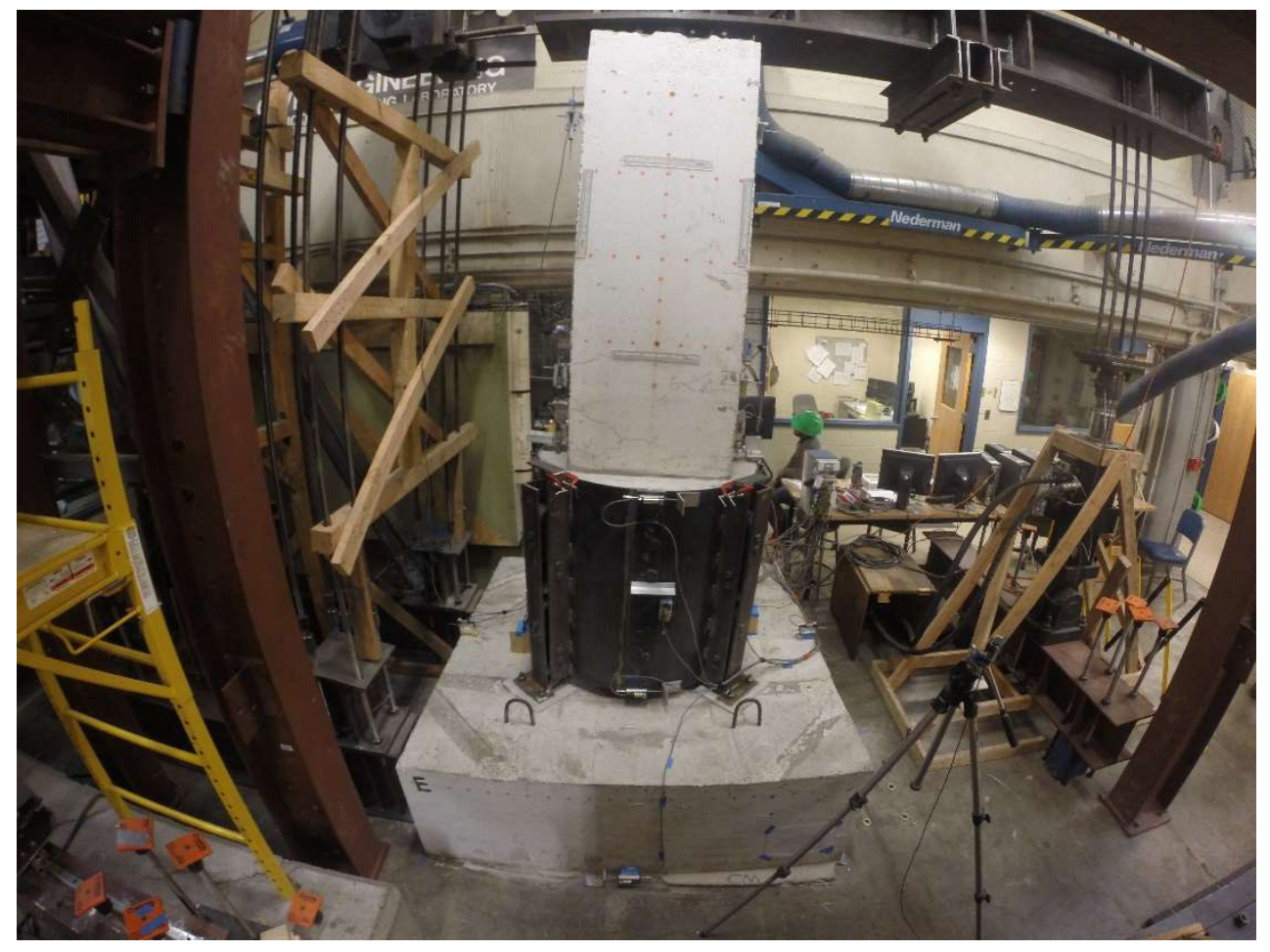

Figure 5.10: Test 1 displacement $=2.5$ inches 


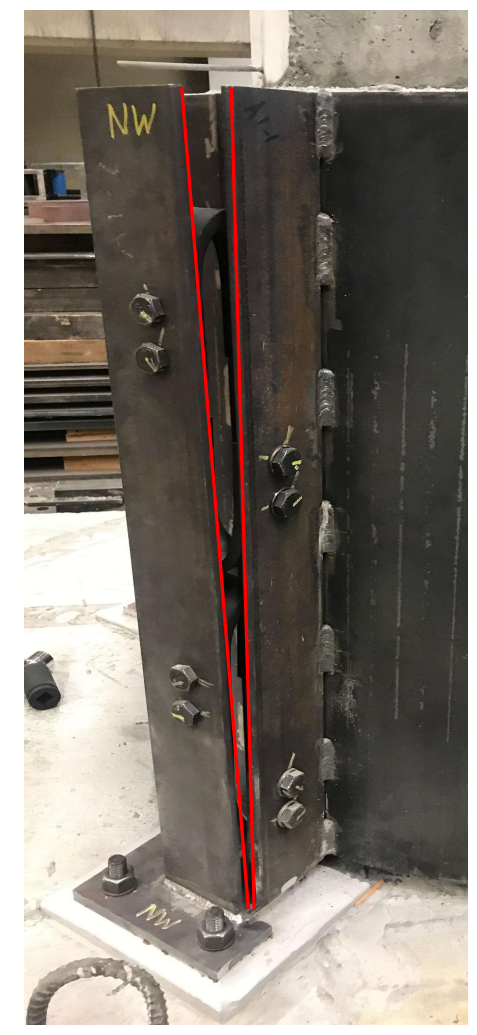

Figure 5.11: Residual hold-down deformation

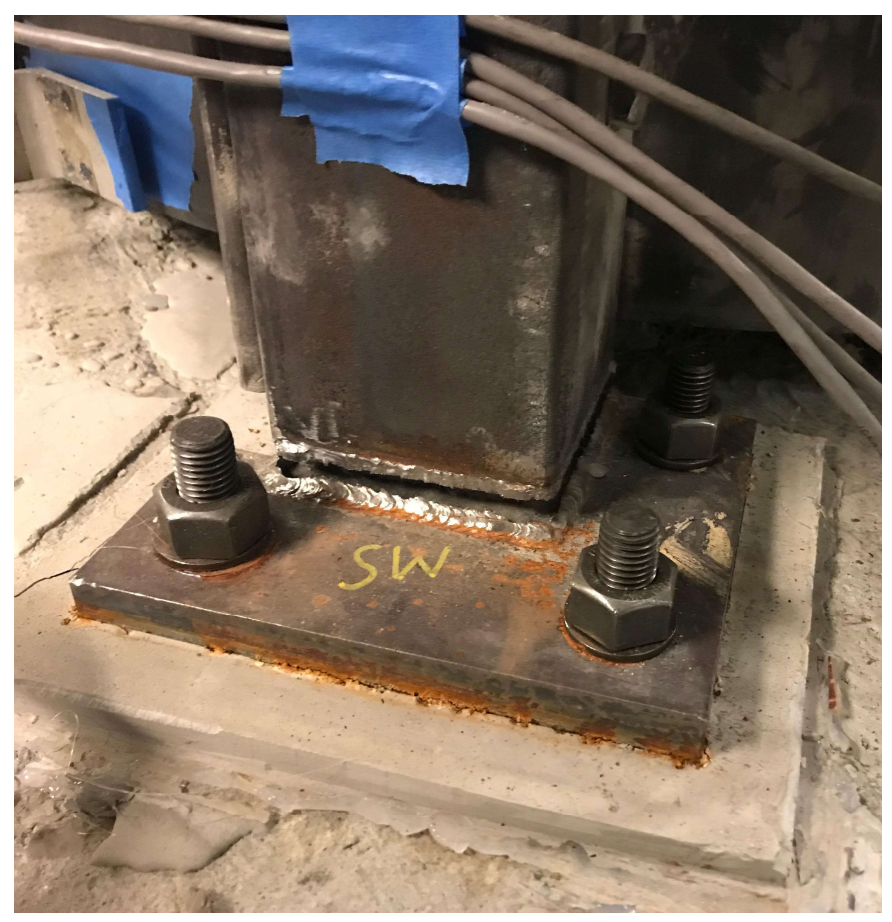

Figure 5.12: Hold-down weld failure 


\subsubsection{Test 2}

Lessons of the previous test provoked three design modifications which are shown in Figure 5.13 and are also visible in Figure 5.14. The three design modifications are:

(1) Oversized holes and plate washers - the first repair revealed constructability issues due to bolt hole alignment tolerances. It was found that imperfections in UFP bend geometry and zero tolerance from welded nuts created misalignments between bolt holes. Installation was difficult and time consuming. To improve constructability and reduce assembly time, oversized holes and plate washers were added to the exterior leg of the hold-down. This resulted in a much easier and faster installation.

(2) Reduced section plastic hinge - A reduced section was introduced at the base of the exterior hold-down legs. $1 \frac{1}{2}$ inch slots with a $1 / 2$ inch radius were cut into the legs of the $\mathrm{L} 4 \mathrm{X} 4 \mathrm{X} 1 / 2$, reducing its cross-sectional properties to that of a L2$1 / 2 \mathrm{X} 2-1 / 2 \mathrm{X} 1 / 2$. This hinge allows the hold-down to rotate with the column and shell, while limiting flexural forces to the previously failed weld.

(3) Hold-down caps - Each hold-down was equipped with a cap. The cap was attached via an angle bracket that was welded to the interior hold-down on the inside of the hold-down. This cap serves two purposes. First, it prevents separation of the exterior leg while allowing the leg to slide within, displacing vertically. Secondly, the cap serves as an encapsulation for subgrade applications. 

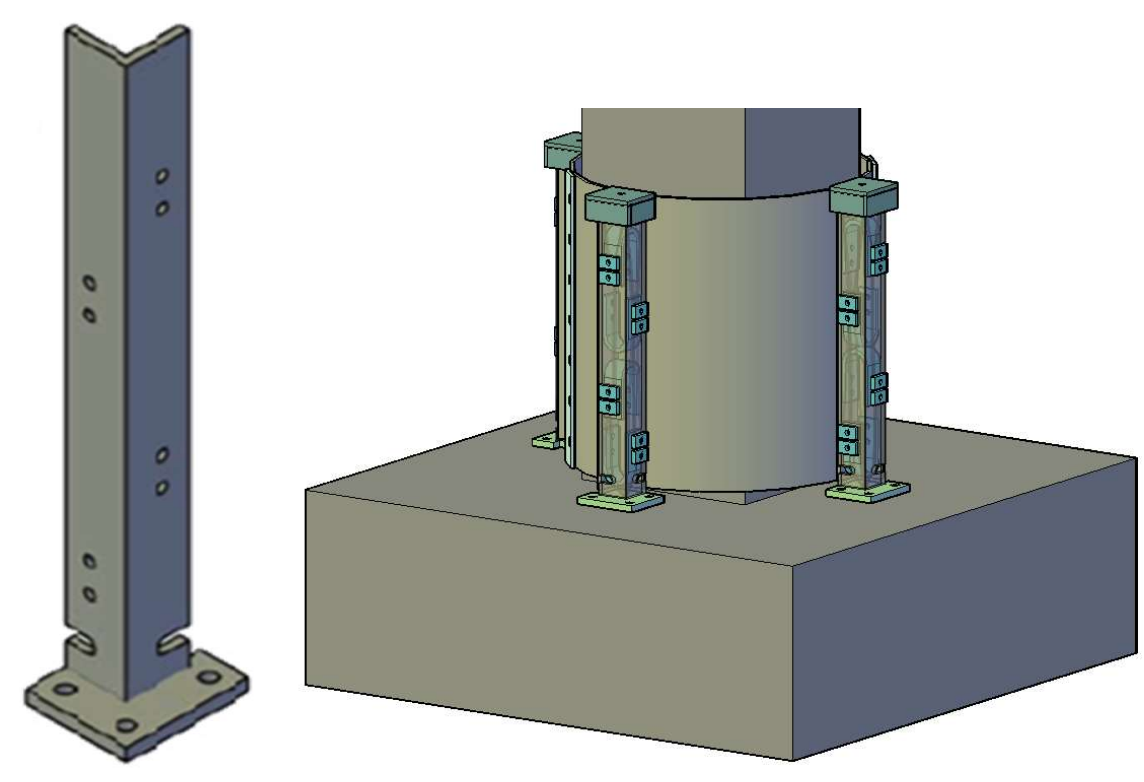

Figure 5.13: Test 2 design modifications

For the second test, specimen LVF\#8 was repaired using the face orientation and the three design modifications were implemented. The standard laboratory lateral loading protocol was used for both the as-built test, and the repaired test. The hold-down UFP's were the same as test 1, PL1/2X2-1/2 grade A36 steel with a bend diameter of 3.25 inches. The expected maximum hold-down force was also the same as test 1, 32.7 kips. However, the expected maximum lateral load was 48.9 kips which is an increase due to the holddown orientation. The repaired specimen and test setup are pictured in Figure 5.14 in its initial state before testing.

The hold-down caps did not function as intended. With each cycle, the cap was slowly pushed up as the angle bracket yielded. Figure 5.15 show the final state of the test specimen. The cap bracket has yielded and no longer engages the exterior leg of the holddown. Following this test, the hold-down cap was abandoned and replaced by hold-down rollers which are discussed in the following section. 


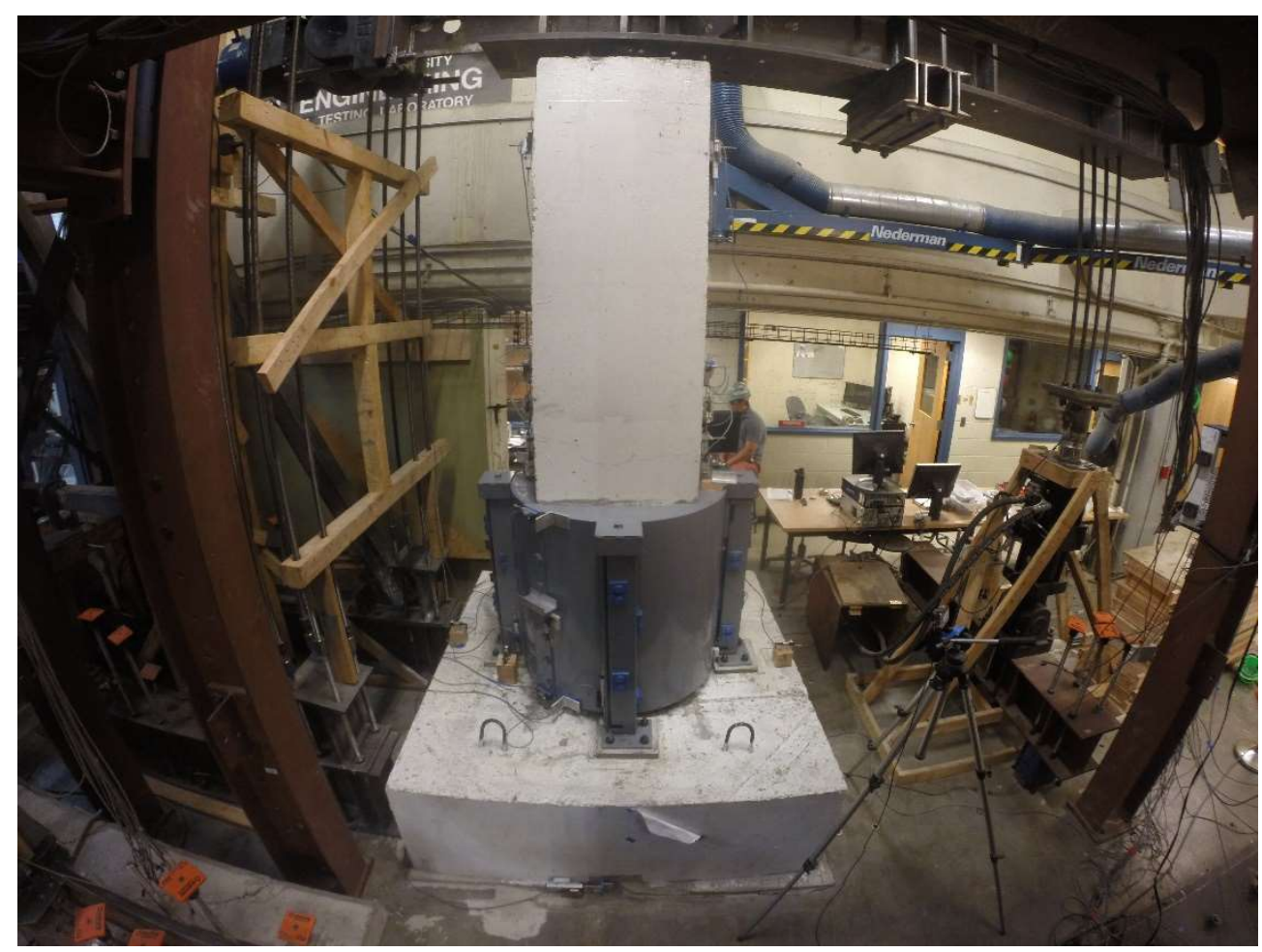

Figure 5.14: Test 2 initial state

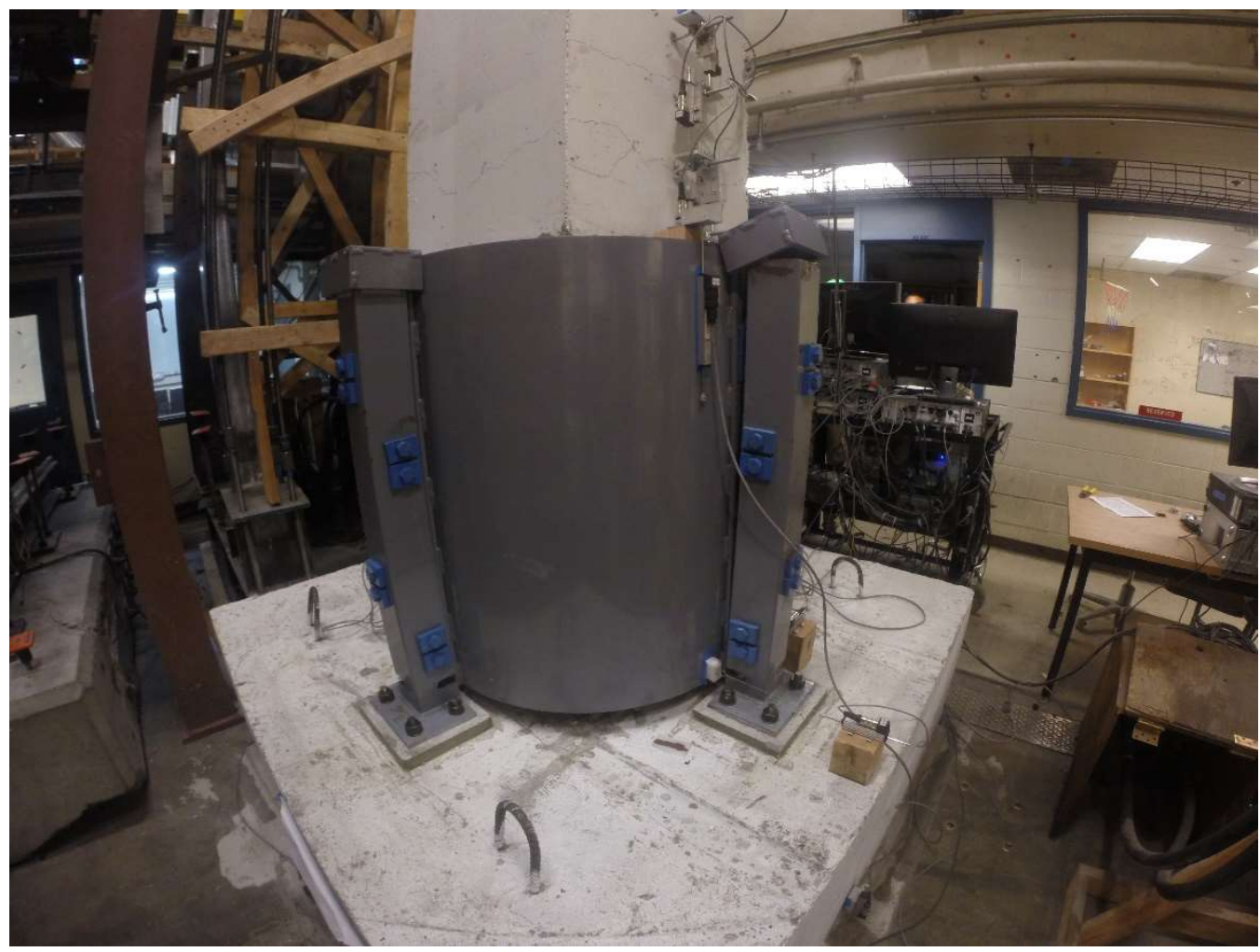

Figure 5.15: Test 2 final state 


\subsubsection{Test 3}

For the third test, the hold-down caps were removed, and new hold-down rollers were installed. The hold down roller is shown in Figure 5.16. The roller was made from a $1 / 2$ inch threaded rod and a hollow pipe which were mounted using $1 / 4$ inch plate welded to the shell. The rollers prevent hold-down separation while allowing vertical displacement.
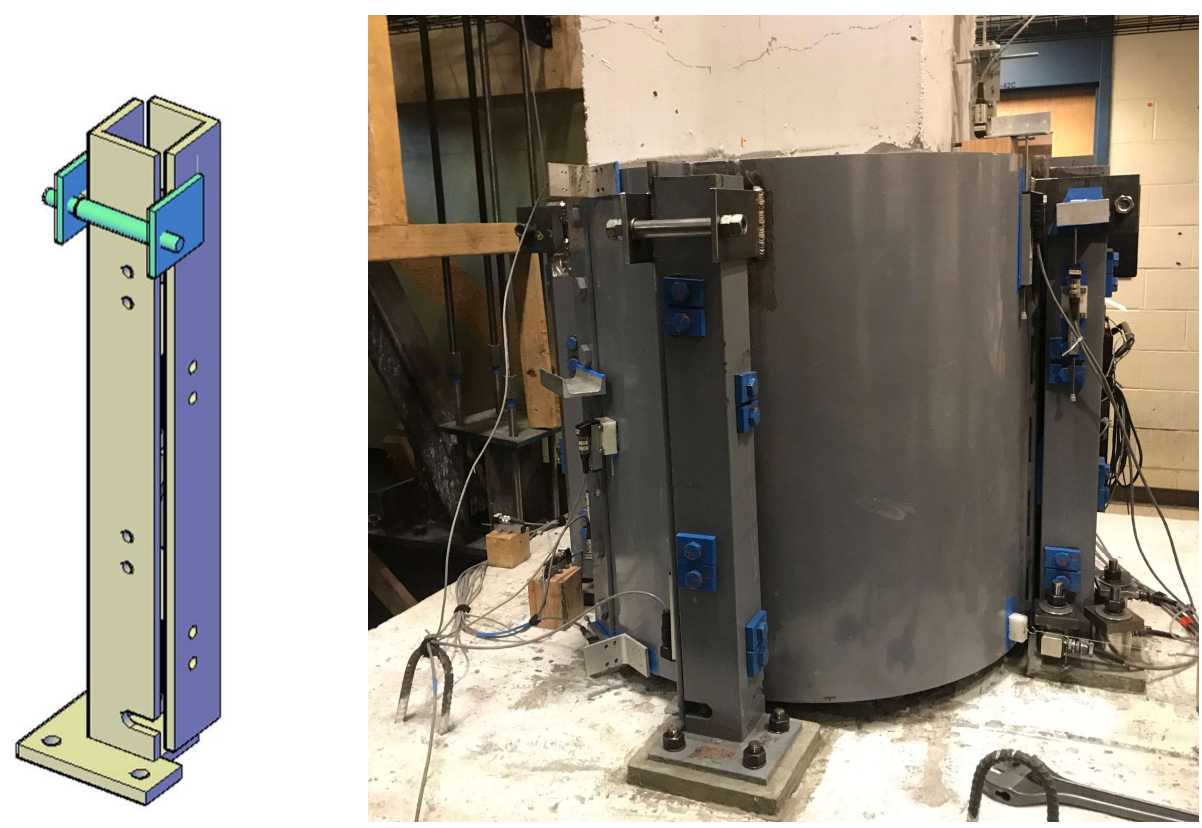

Figure 5.16: Test 3 modification - hold-down roller

(a) The third test was a repeated repair on specimen LVF\#8. The shell remained attached to the column in face orientation. Only the hold downs were replaced. The hold-down UFP's were the same as test geometry as test 1 and 2, PL1/2X2-1/2 grade A36 steel with a bend diameter of 3.25 inches. The subduction zone loading protocol was used. The repaired specimen and test setup are pictured in Figure 5.17 in its initial state before testing. The hold-down rollers functioned as intended, preventing separation of the hold-down legs.

(b)

Figure 5.18 shows the hold down rollers before and after the test. They were designed and installed with a $1 / 4$ " gap between the roller and the hold-down leg. During the test, the gap opened and closed on push and pull cycles. 


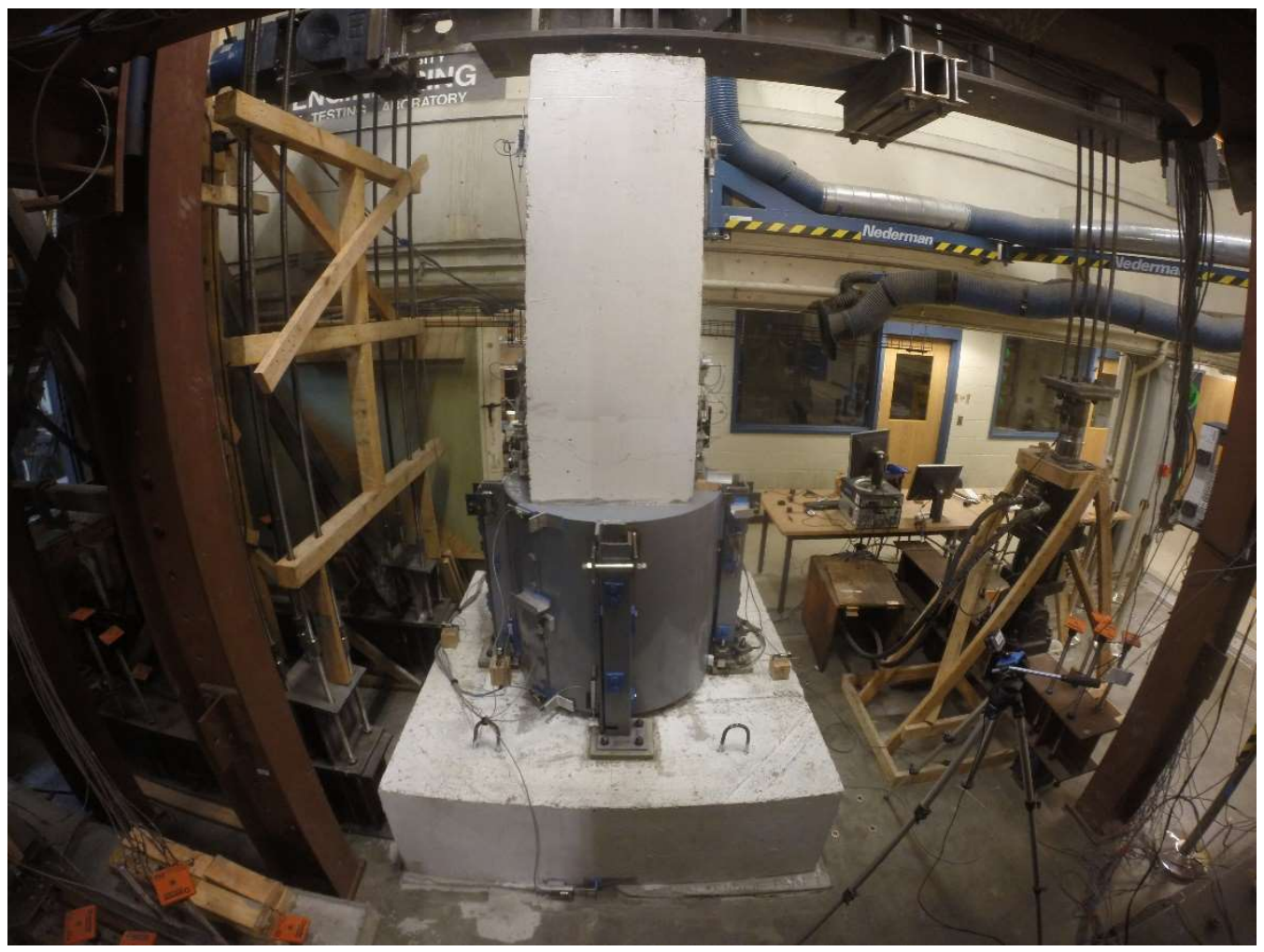

Figure 5.17: Test 3 initial state

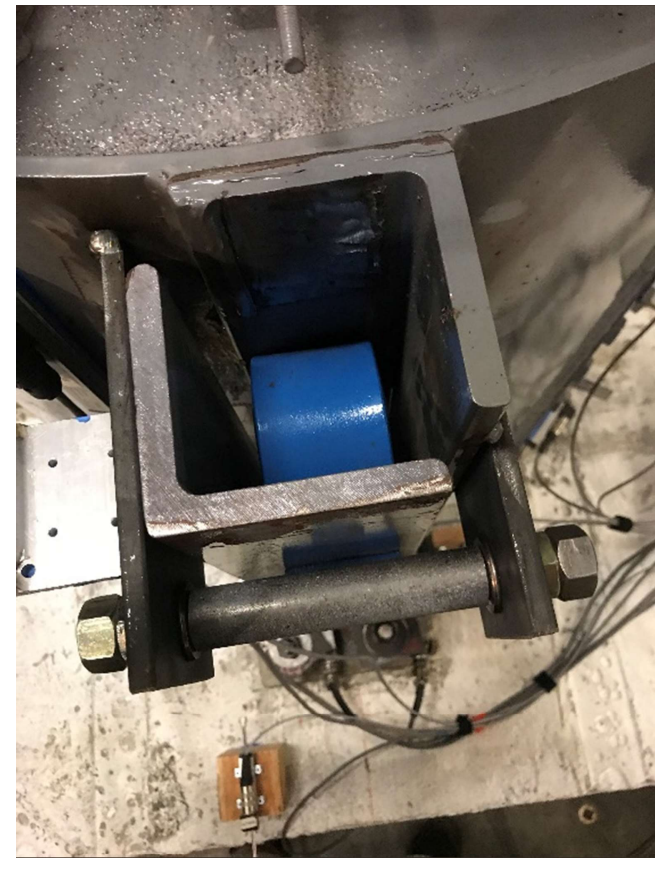

(b)

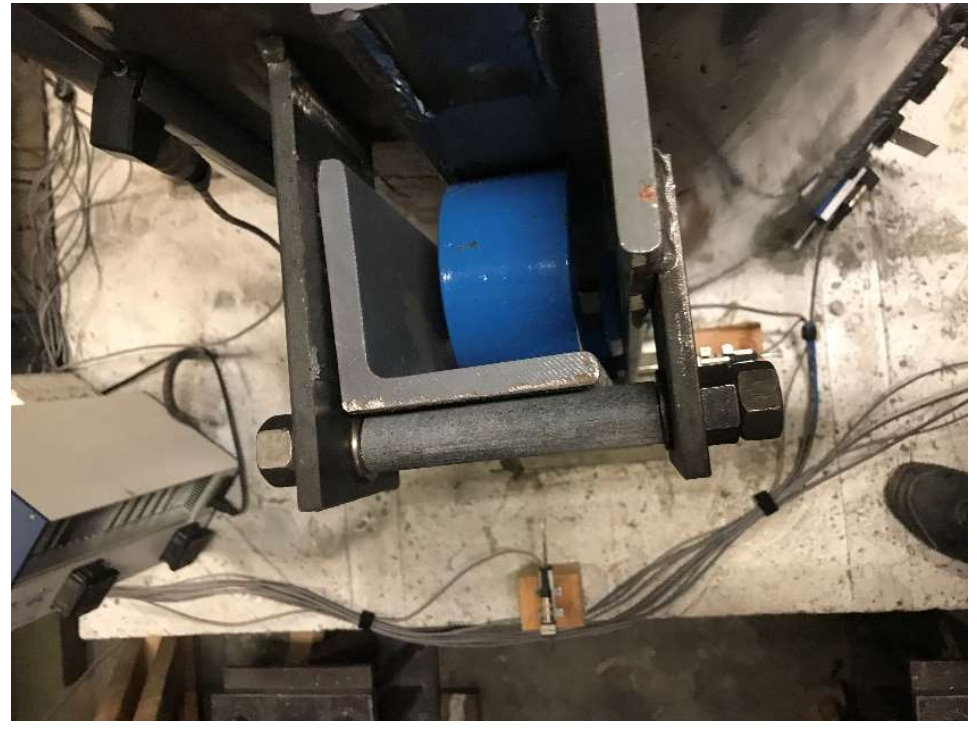

(b)

Figure 5.18: Hold-down rollers (a) before and (b) after test 


\subsubsection{Test 4}

The fourth test was also a repeated repair on specimen LVF\#8. New exterior legs were installed. The previous legs were permanently distorted and fatigued from cyclic loading over the first three tests. For this test, the objective was to design the hold-downs such that the lateral capacity of the repaired column would be greater than the as-built column. To increase capacity, the UFP thickness was increased by $1 / 8$ inch and the bend diameter was decreased such that the outside diameter remained constant. This results in a $63 \%$ increase in maximum hold-down force and a $27 \%$ increase in expected lateral load. The fourth test is shown in its initial state in Figure 5.19.

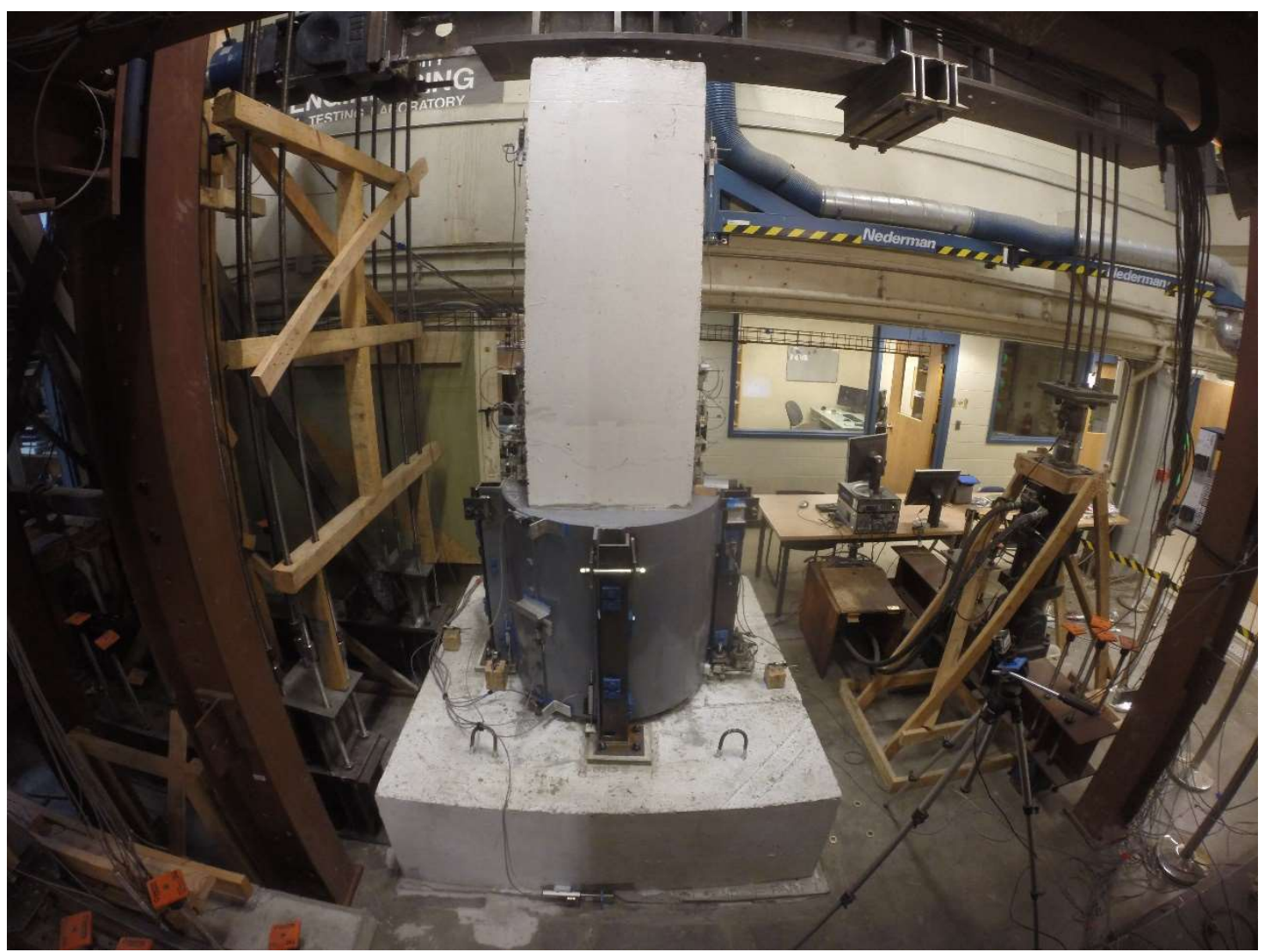

Figure 5.19: Test 4 initial state 


\subsubsection{Measured Data}

The following subsections include load-displacement responses for all four tests. The loaddisplacement response for the repaired column is plotted in black and the as-built loaddisplacement response is plotted in blue. Under positive displacements (push cycles), the axial load increased to a maximum of +240 kips. Under negative displacements or pull cycles, the axial load decreased to a minimum of +160 kips.

\subsubsection{Test 1}

The lateral load-displacement response for test 1 is shown in Figure 5.20. The peak lateral load from the as-built column was 44.9 kips and the target peak lateral load was 46.4 kips. The peak lateral load measured from the repaired test was $40.2 \mathrm{kips}, 13.3 \%$ less than target. The hysteresis shows self-centering behavior. On the return cycles, as the lateral displacement is returned to zero, the lateral load approaches zero. This behavior is a result of the location and magnitude of the axial force, working to restore the column to its original position.

There are two negative displacement cycles on the repaired column test which are different than the rest. These cycles occurred when the axial load actuator stroked out and axial load was lost. Following these two cycles, the test-setup was adjusted, and the test continued. These cycles can be observed in the hysteresis on Figure 5.20 where the load decreases to 0 at a displacement of approximately -2.75 inches and does not follow the typical self-centering behavior of the hysteresis.

The repaired column shows less strength degradation than the as-built column. At the maximum displacement of 5.4 inches, the as-built column lateral load has degraded to 
approximately $77 \%$ of its peak while the repaired column maintains approximately $85 \%$ of its peak lateral load.

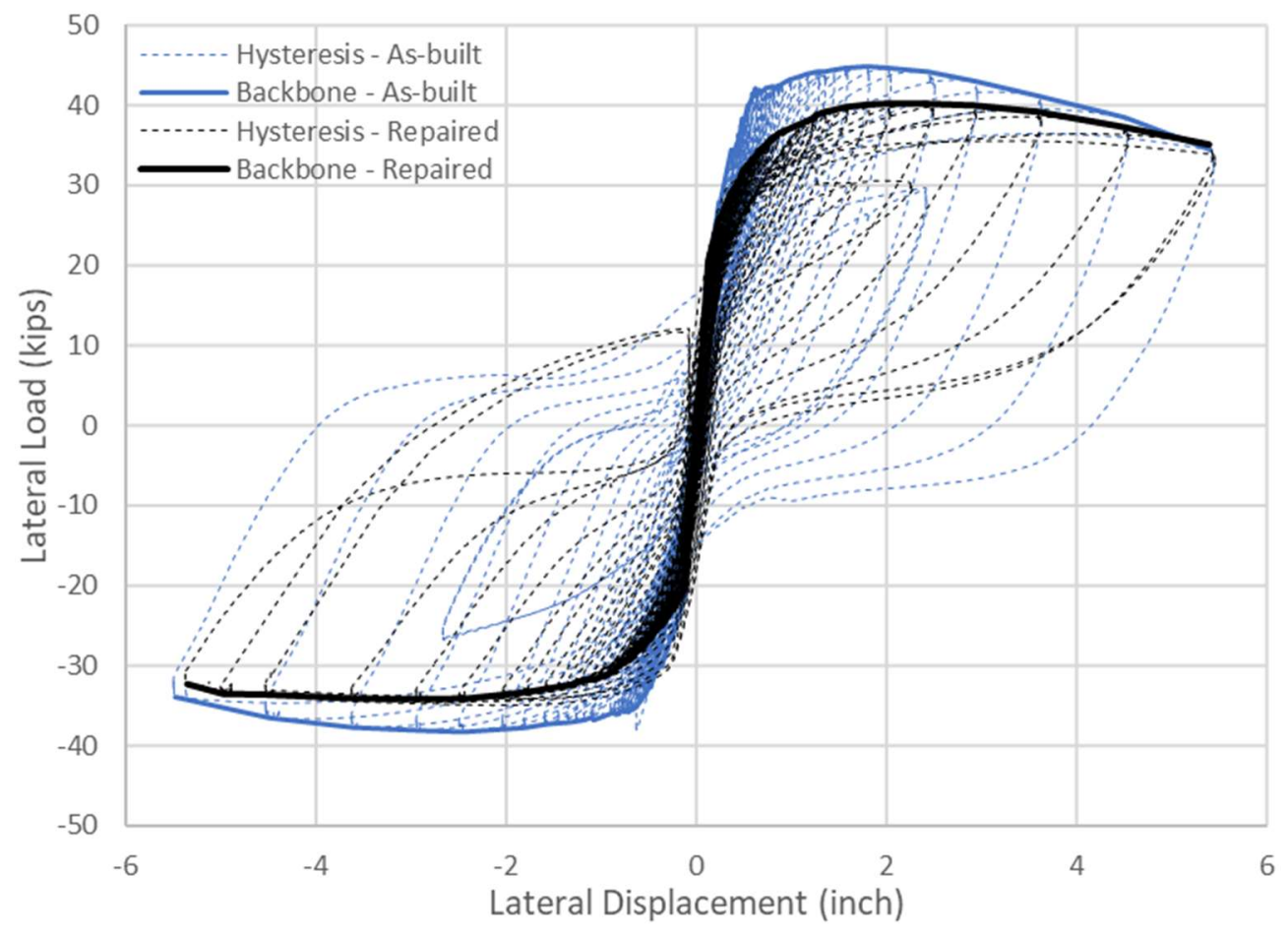

Figure 5.20: Test 1 Hysteresis

\subsubsection{Test 2}

The second specimen was repaired for Test 2 and the conventional ACI lateral loading protocol was used for the as-built column test and the repaired column test. The repair was oriented with the hold-downs at each face of the column and the hold-down caps were installed. The lateral load-displacement response for Test 2 is shown in Figure 5.21. The as-built column had a peak horizontal load of $40.3 \mathrm{kips}$, and the expected lateral load based on the static analysis is 48.9 kips. The measured peak lateral load for the repaired column was 31.6 kips, $35 \%$ less than expected and $21 \%$ less than as-built. Test 2 showed 
greater strength degradation than Test 1. At the final cycle displacement of 5.4 inches, the strength degradation was $25 \%$ compared to $15 \%$ in Test 1 .

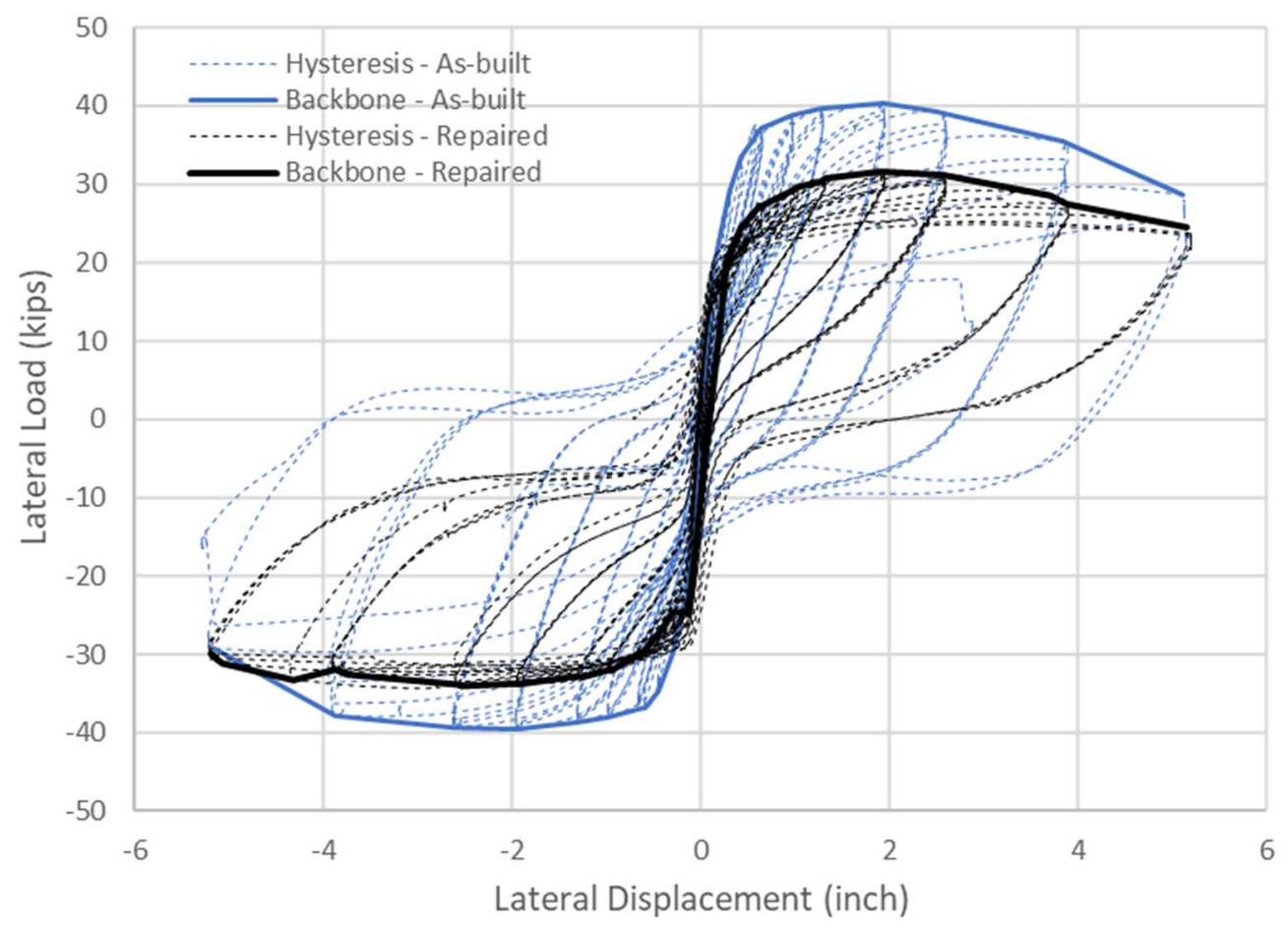

Figure 5.21: Test 2 Hysteresis

\subsubsection{Test 3}

After Test 2, new UFPs were installed and the specimen was used again for Test 3. The UFP's matched the geometry of those in Test 2 . Therefore, the as-built peak horizontal load and expected repaired peak horizontal load are the same as Test 2, 40.3 kips and 48.9 kips respectively. The differences between Test 2 and Test 3 are the addition of the holddown rollers and the cyclic history of the specimen. The lateral load-displacement response for Test 3 is shown in Figure 5.22. The measured peak lateral load for the repaired column was 30.5 kips, $37 \%$ less than expected based on the static approach and $24 \%$ less than asbuilt. 


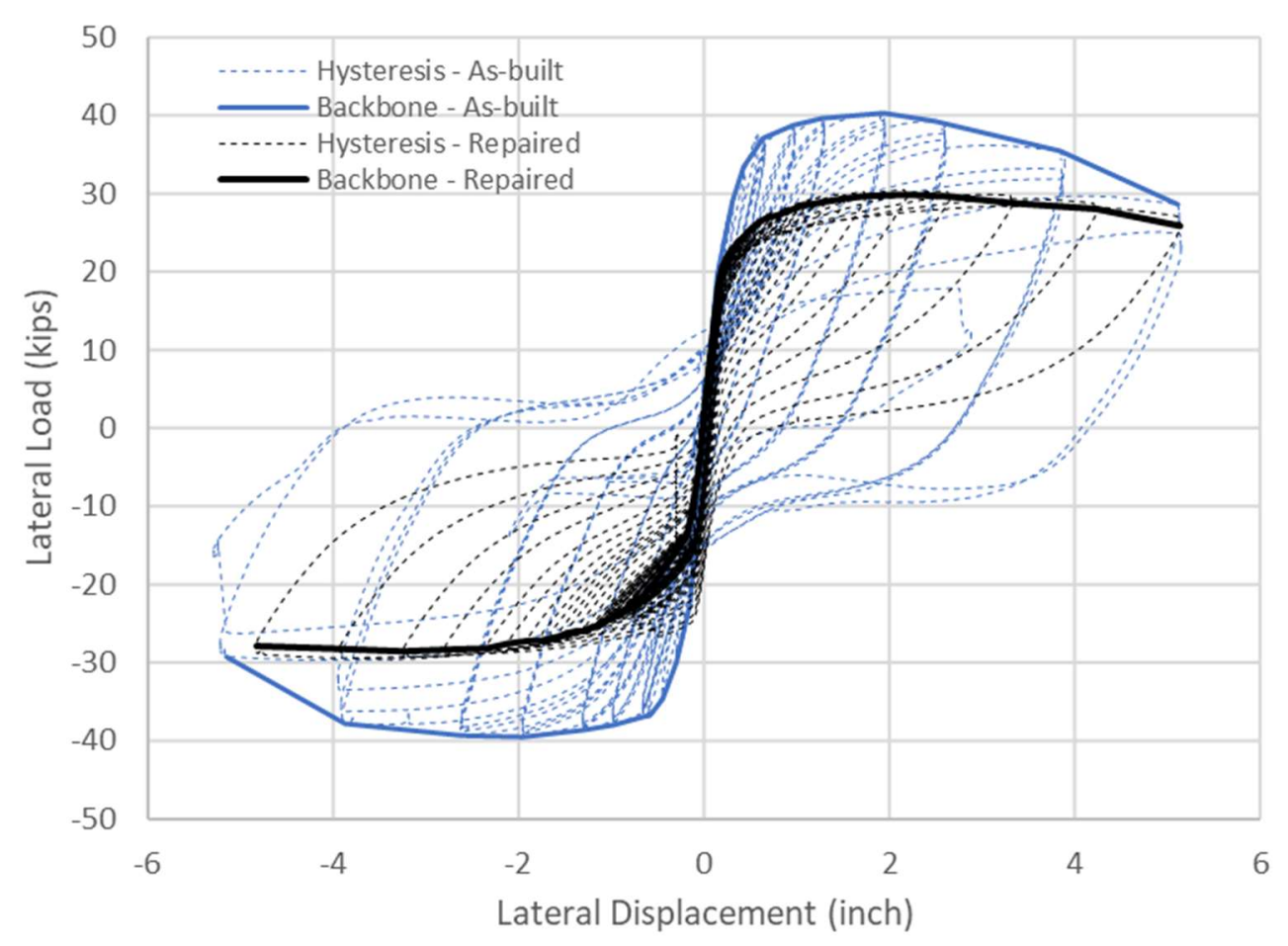

Figure 5.22: Test 3 Hysteresis

\subsubsection{Test 4}

The repair for Test 4 utilized the same specimen from Test 2 and Test 3; however, Test 4 was designed to increased lateral capacity. The UFP thickness was increased by $1 / 8^{\text {th }}$ inch which results in an expected hold-down force of $53 \mathrm{kips}, 62 \%$ greater than the previous three tests. The lateral load-displacement response for test 4 is shown in Figure 5.23. The peak lateral load measured from the repaired test was 38.6 kips, up from 30.5 kips in the previous test.

The increase in hold-down strength reduced the self-centering behavior which was observed in the previous tests. The hysteresis shows that on the return cycles, as the lateral displacement is returned to zero, the lateral load does not return to zero. This behavior is a result of increased hold-down strength and the plastic deformation. The axial force is not enough to restore the hold-downs to their original position. 


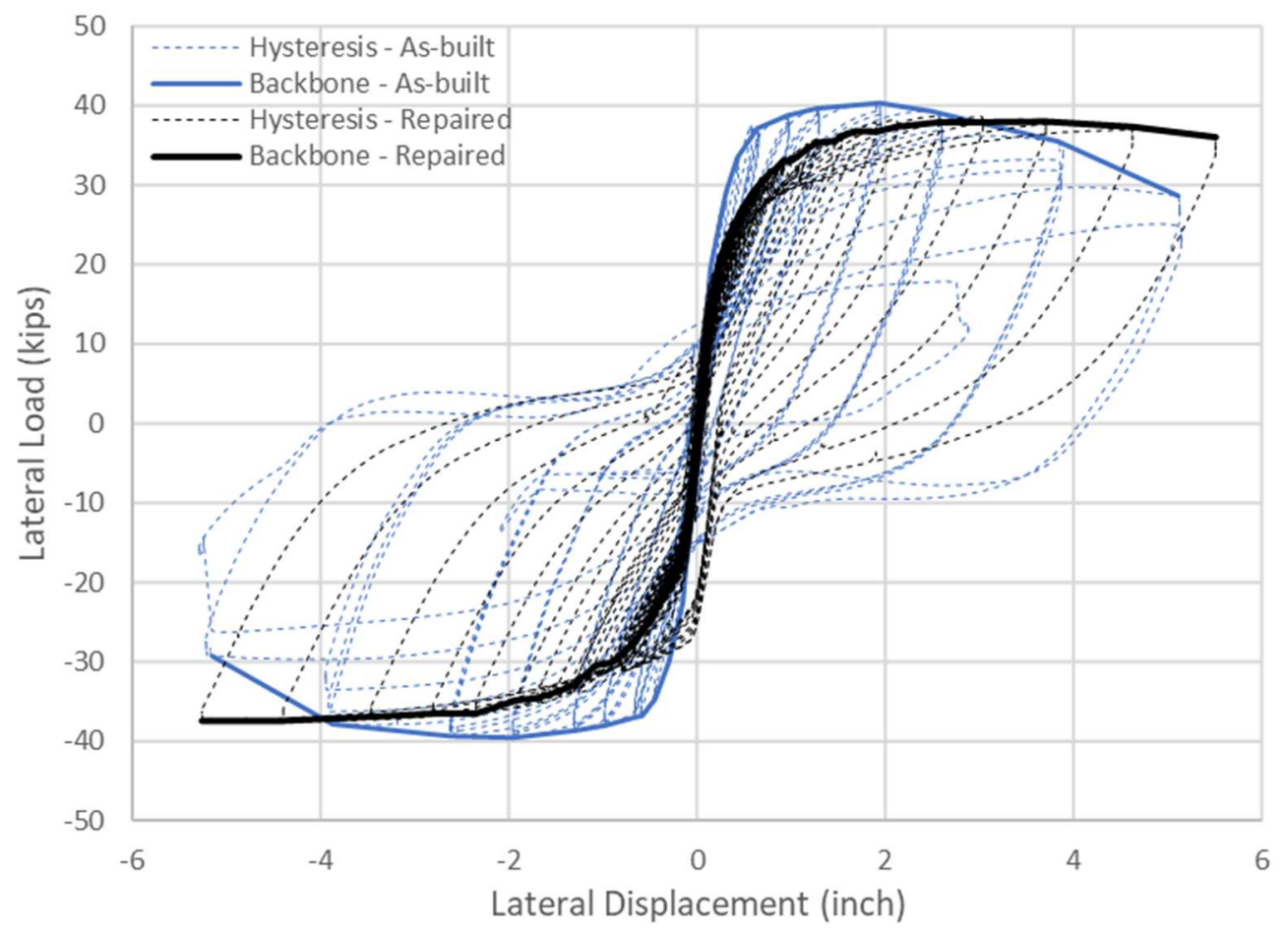

Figure 5.23: Test 4 Hysteresis

\subsubsection{Discussion}

The experimental program provided encouraging evidence to support the feasibility, adequacy, and benefits of the proposed repair methodology. This discussion correlates visual observations and measured data to evaluate the overall success of the design objectives. The objectives were to develop a practical post-earthquake repair methodology that (1) could be rapidly implemented following the CSZ earthquake, (2) incorporate low damage earthquake resilience for future shaking, (3) achieve restored or controlled strength. The following three subsections individually address the success of these objectives. 


\subsubsection{Rapid and Economic Deployment}

This methodology could potentially be adopted and necessary parts prepared prior to a major earthquake. The parts and components such as steel jackets, hold-downs, and UFPs, could be premanufactured and stockpiled for rapid access when needed. In that case, the time or labor of installation is the most important factor when evaluating the feasibility of rapid application.

The process of implementing and re-implementing the proposed repair methodology in the laboratory demonstrated the feasibility of rapid application and provided insight for efficient constructability. The proposed repair methodology was implemented on two damaged column specimens. The first specimen was repaired and tested once. The second specimen was repaired and tested three times by re-implementing the existing repair. Upon each successive implementation or re-implementation, the installation process became quicker. The first implementation was difficult due to fabrication tolerances. Some of the bolt holes in the UFPs did not align with the holes in the exterior hold-down leg. This was mainly due to slightly misshaped UFPs. Bending consistent geometries proved difficult but improved with experience. The addition of oversized holes and plate washers on the second repair greatly reduced the time and difficulty of installing the UFPs and hold-downs. With practice and refinement, the proposed repair methodology can be both feasible and rapid.

\subsubsection{Enhanced Resilience}

Visual observations suggest that this repair methodology successfully met the design objective of isolating inelastic deformations and damage to the easily replaceable ductile fuse hold-downs. Thus, enhancing resilience for future aftershocks and earthquakes. Visual 
observations from all four tests revealed very little damage to the original column and the footing remained completely undamaged throughout all four tests.

Conventional repair methods will shift damage to the area above the repair in future seismic events. The four tests showed that the proposed methodology does not shift damage to the area above the repair. In all four tests there were small flexural cracks above the repaired zone. These cracks were initiated during the as-built test and were lengthened during testing of the repaired column. Throughout all four tests, there were no residual gaps in the flexural cracks. The second specimen was repaired and tested three times and still, the zone above the repair showed no increase in damage. These observations suggest that inelastic strains did not occur and that the design objective was met.

\subsubsection{Restored or Controlled Strength}

The lateral load displacement plots in Figure 5.20 through Figure 5.23 show similar behavior and strength between the as-built column and the repaired column however, the repaired columns consistently underperformed the expected repair capacity in terms of lateral strength. This suggests that the proposed repair methodology is capable of achieving restored or controlled strength, but that the design methodology needs refinement. This section will quantify the success of achieving restored or controlled strength and then present suggestions for a refined design process.

Key metrics were calculated and compared to the as-built columns. These key metrics are effective stiffness, peak horizontal load, displacement at peak horizontal load and horizontal load degradation at final cycle and are tabulated in Table 5.3. While the design methodology directly aims to control strength, it is also important to consider 
stiffness. Effective initial stiffness was calculated by taking the load divided by displacement at the first peak or target displacement per the loading protocol. The average effective stiffness from all peaks at the first target displacement is reported in Table 5.3. The effective initial stiffness for Test 1 was within $2 \%$ of the as-built column. For the other tests, the effective initial stiffness varied by as much as $32 \%$ greater than as-built and $13 \%$ less than as-built.

Horizontal load at final cycle was calculated by taking the percent difference between peak horizontal load and horizontal load at the final cycle which occurred at approximately 5.4 inches of displacement at the top of the column. All four tests showed that the repaired columns had a significant reduction in horizontal load degradation at final cycle. The asbuild columns degraded an average of $26 \%$ while the repaired columns degraded an average of just $15 \%$ at final cycle. This suggests a reduction in degradation could be an added benefit of the low-damage repair methodology. The repaired columns remain undamaged whereas the as-built column experiences significant damage in the plastic hinge region such as concrete spalling, concrete crushing, rebar yielding and rebar buckling leading to strength degradation.

It is also important to compare the strength degradation between the four repaired tests. The average horizontal load degradation of the first two tests is $20 \%$ while the average over the last two tests is only $10 \%$. This difference could be due to the effects of hold-down leg separation which is discussed in section 5.5.1 and pictured in Figure 5.11. The addition of the hold-down rollers, which were added after Test 2 and described in section 5.5.1.3, prevent hold-down leg separation. In Test 2, the hold-down legs separated by as much as $3 / 4$ inch, while in Test 3 the hold-down rollers limit separation of the legs to $1 / 4^{\text {th }}$ inch. The 
maximum hold-down force, given by equation (2.2), is inversely proportional to the distance between legs and a $3 / 4$ inch separation results in a $18.7 \%$ reduction in theoretical hold-down force. It is also possible that hold-down leg separation effects can be observed in the measured data by comparing Test 2 and Test 3 . The UFP geometry remained constant between these two tests, however the displacement at peak horizontal load is 1.908 inches in Test 2 and 2.492 inches in Test 3. Monitoring separation with instrumentation while testing would help to better understand the effects of hold-down leg separation. The difference in displacement at peak horizontal load along with the difference in horizontal load degradation at final cycle, suggests that the hold-down rollers were successful in preserving hold-down force by retaining the outer leg of the hold-down through cyclic loading.

Table 5.3: Results Comparison

\begin{tabular}{ccccc}
\hline Test & $\begin{array}{c}\text { Effective Stiffness, } \\
\text { k (kips/inch) }\end{array}$ & $\begin{array}{c}\text { Peak Horz. } \\
\text { Load (kips) }\end{array}$ & $\begin{array}{c}\text { Displacement at } \\
\text { Peak Horz. Load } \\
\text { (in.) }\end{array}$ & $\begin{array}{c}\text { Horz. Load Degradation } \\
\text { at Final Cycle (\%) }\end{array}$ \\
\hline As-built 1 & 164 & 44.9 & 1.80 & 23 \\
Test 1 & 166 & 40.2 & 2.01 & 15 \\
As-built 2 & 144 & 40.3 & 1.94 & 29 \\
Test 2 & 190 & 31.6 & 1.91 & 25 \\
Test 3 & 130 & 30.5 & 2.49 & 13 \\
Test 4 & 122 & 38.6 & 2.49 & 7 \\
\hline
\end{tabular}

The design process and selection of UFP geometry was based on the static design process explained in section 4.3.1. Based on the assumptions and simplifications of the static design process, the expected peak horizontal load was predicted to overestimate the lateral strength. All four tests confirmed this prediction. The measured peak horizontal load 
in Test 1 was $13 \%$ less than the static design process predicted. The difference was larger in the next three tests: $35 \%$ in Test $2,37 \%$ in Test 3 , and $37 \%$ in Test 4.

The assumptions from the static design method are (1) the rocking point is at the edge of the column, (2) column curvature is negligible, and (3) the maximum expected hold-down forces are acting about the column in its undeformed state. When the rocking point is assumed to be a single point at the column edge, the compressive force or reaction in the concrete is assumed to act directly through the overturning point and have no effect on the overturning moment. In reality, the rocking point is located some distance inward from the column edge and might be described better as a neutral axis, where there is a compression block between the neutral axis and the column edge. In this case, the compression force does not act directly through the neutral axis and actually contributes to resisting overturning forces.

The hold-down resisting forces are also impacted by the location of the rocking point or neutral axis. If we consider the simple static analysis from section 4.3.1, but vary the rocking point location, we can plot the effects it has on expected peak horizontal load. In Figure 5.24, the $\mathrm{x}$-axis represents the location of the rocking point or neutral axis with respect to the column edge. At $\mathrm{x}=0$ inches, the plot shows the expected peak horizontal load assuming rocking occurs at the column edge. As that distance increases, the summation of lever arms between the hold-downs and the neutral axis decreases. The distance between the axial load and neutral axis also decreases. This results in a decrease in overturning moments and thus a decrease in expected peak horizontal load. Figure 5.24 also shows that this effects corner orientation and face orientation differently. As the rocking point moves inward from the column edge, the expected peak lateral load decreases 
faster for face orientation than for corner orientation. This is solely due to the position of hold-downs relative to the neutral axis.

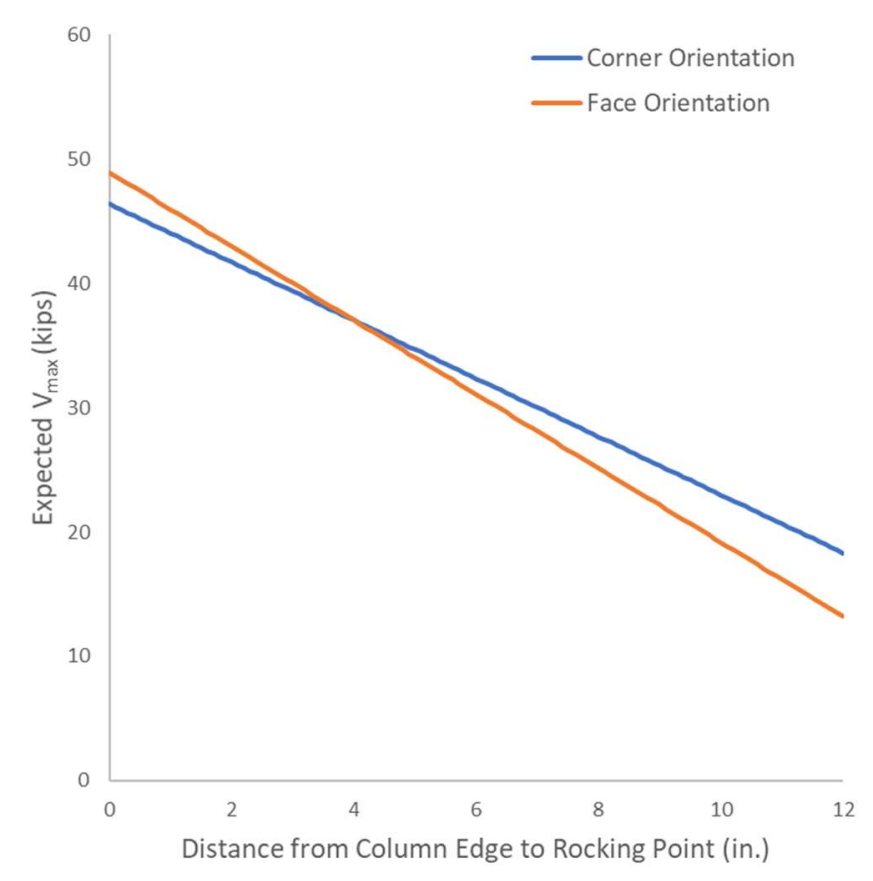

Figure 5.24: Effects of rocking point assumption

To remove this assumption from the design methodology, the actual neutral axis was calculated from the measured data. During testing, each hold-down was equipped with a LVDT to monitor vertical displacement. If we assume the principals of rigid body motion apply to the repair jacket, the four hold-down LVDTs can be used to calculate the actual neutral axis on the rotating column. Figure 5.25 shows the results of this calculation from Test 1. The dots represent the neutral axis distance from column edge at peak displacements, yellow dots are on push cycles when the axial load is increased, and grey dots are on pull cycles, when the axial load is decreased. As you would expect, the neutral axis is near the middle of the column at very small displacements, and it moves toward the 
edge as the column is pushed further. As column displacements become large, the neutral axis approaches a horizontal asymptote around three to four inches from the column edge.

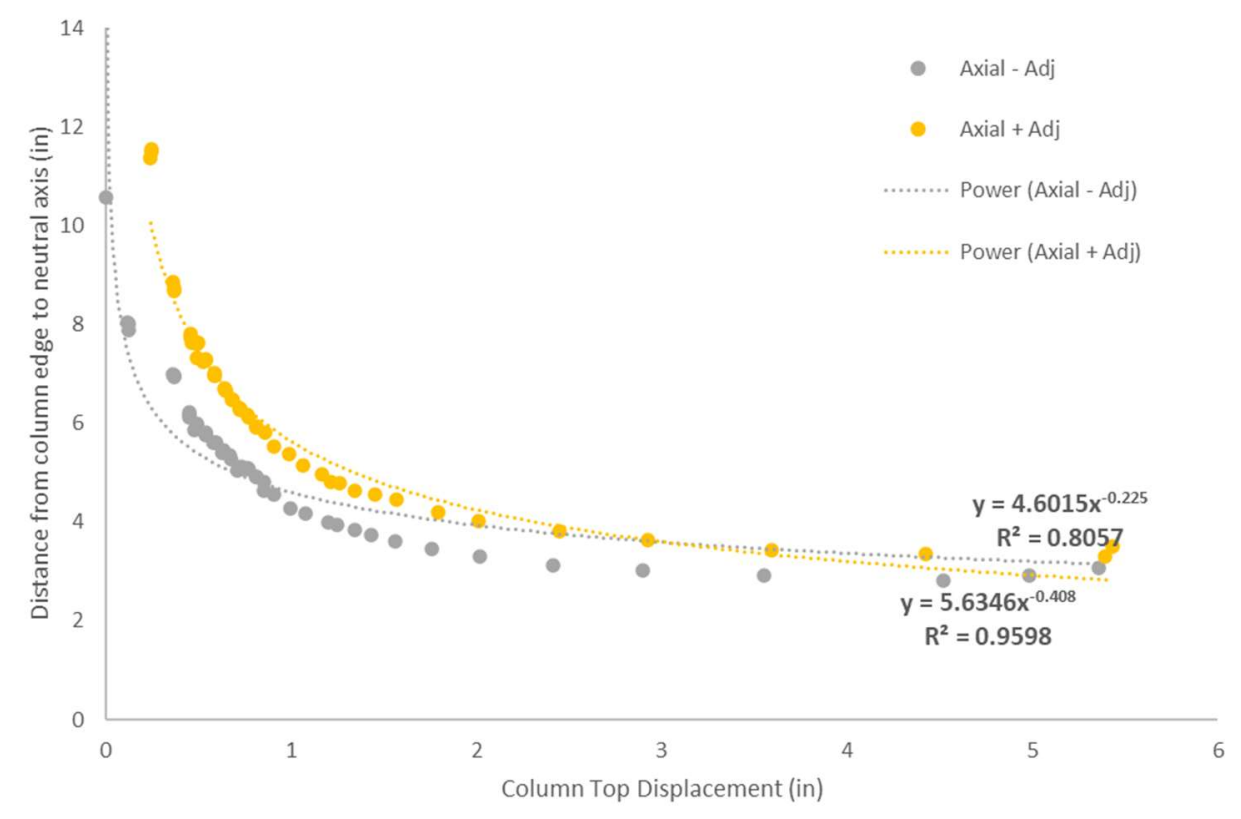

Figure 5.25: rocking point distance to edge of column, corner orientation

The actual rocking point and its effects on peak lateral load can be accounted for if the pushover analysis method from section 4.3.2 is used. This method also accounts for assumption (3) which states that the maximum expected hold-down forces are acting about the column in its undeformed state. In reality, the hold-downs exert no force on the column in its undeformed state. The hold-downs do not engage until the column has started rocking and there is vertical displacement at the hold-downs. The pushover analysis method assumes rigid body motion of the repaired column and calculates the hold-down force based on a bi-linear force-displacement relationship of the UFPs. The pushover analysis method also accounts for p-delta effects by reducing the lever arm between the axial load and the neutral axis and the column is displaced laterally. Figure 5.26 shows the results of 
the pushover analysis overlayed on top of the lateral load-displacement response from Test 1. The red line is a pushover analysis that assumes rocking occurs at the edge of the column, as described in section 4.3.2. The yellow line is a pushover analysis that is modified to account for the actual measured rocking points from Figure 5.25. These methods of analysis appear to predict the systems behavior more accurately than the static design method. For this repair, the static method predicted a peak horizontal load of 46 kips while the push over analysis predicted a peak horizontal load of 43 kips before accounting for the actual rocking point and 37 kips after accounting for the actual rocking point. The measured peak lateral load from this test was 40 kips.

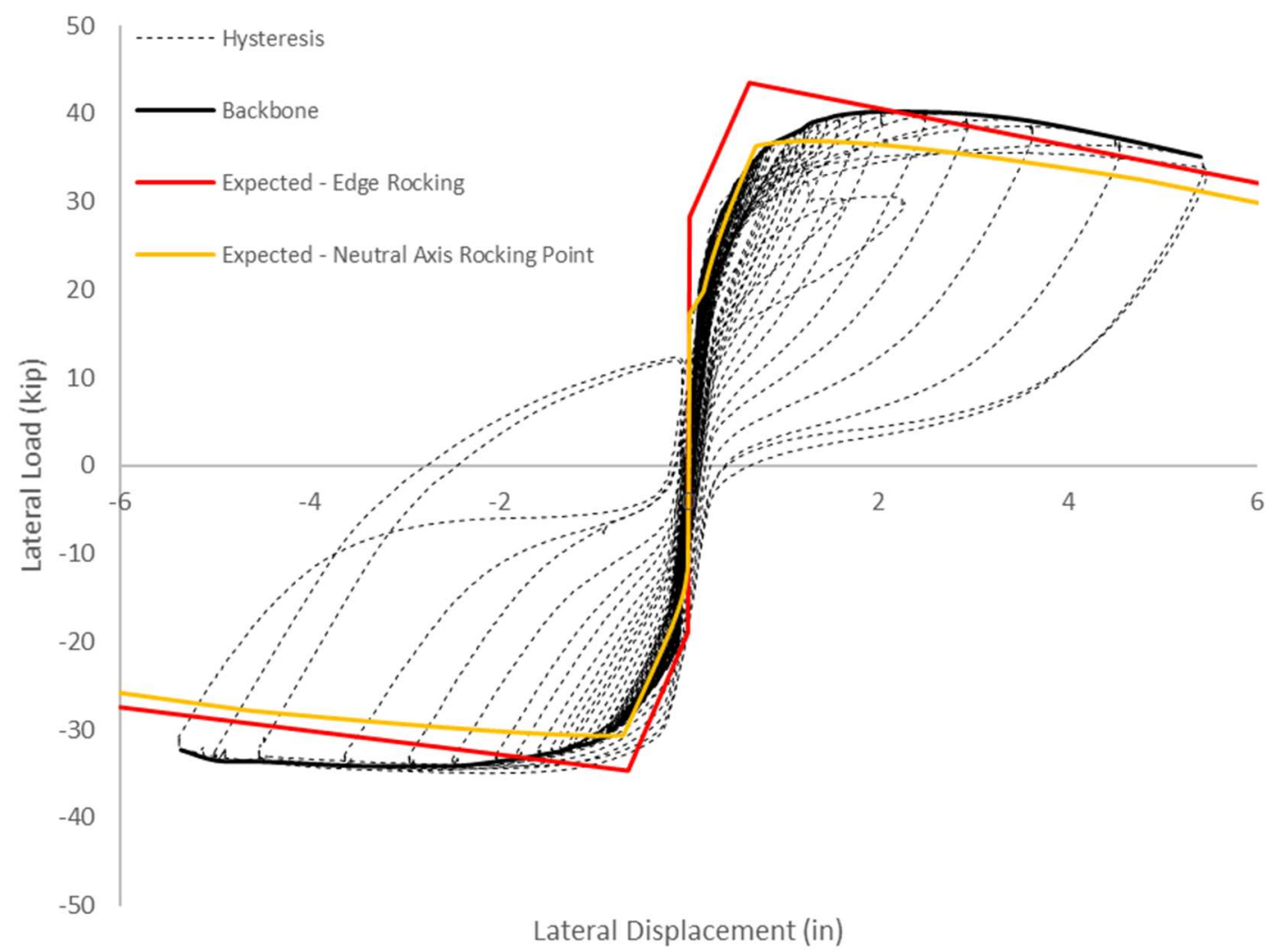

Figure 5.26: Refined design methodology 


\subsection{CONCLUSIONS}

The experiments validated the design goal of achieving restored or controlled strength, while isolating damage to replaceable ductile fuses and in turn, enhancing the columns resilience to aftershocks or future seismic events. The experiments have shown the potential of this methodology to rapidly repair earthquake damaged columns with a relatively generic approach.

The key takeaways from the experiments are as follows:

1. This study provided strong evidence to validate the design goal of achieving restored or controlled strength, however further testing and research is needed to predict the global behavior of the repair more accurately. This report presents three methodologies for predicting behavior: (1) the static method, (2) the pushover method, and (3) the pushover method adjusted with measured location of the neutral axis. The experimental results confirmed that static method consistently overpredicts the repaired peak lateral load. In order to achieve restored or controlled strength, a more detailed design process such as the pushover analysis should be used to size the holddowns.

2. The weld failure in Test 1 led to a critical improvement of the hold-downs. Exterior hold-down legs, along with the connection to the foundation, should be designed for the combination of uplift from the UFPs and flexural forces from the lateral drift of the exterior hold-down leg. Neglecting to account for flexural forces will greatly underestimate demand at the baseplate and anchors. A reduced section plastic hinge at the base of the hold-down leg can effectively be used to limit flexural forces. The 
expected UFP force plus the maximum expected moment from the reduced section plastic hinge will then govern the design of the weld, the base plate, and the anchors.

3. An additional benefit to the proposed repair methodology is reduced strength degradation at high drifts and during long duration cyclic loading. The experimental results from all four repair tests showed a significant reduction in strength degradation from the as-built state. Strength degradation can be additionally reduced with the application of hold-down rollers which work to prevent hold-down leg separation.

4. The experimental program demonstrated the feasibility of the proposed repair methodology to be rapidly implemented. The components should be fabricated with adequate tolerances for constructability. Oversized hole and plate washers on the exterior hold-down leg greatly reduced the installation time. Prior to the CSZ earthquake, the proposed repair methodology should be pre-manufactured and inventoried for rapid access in the aftermath of an earthquake. Earthquake preparation should include training and practice for workers to implement the repair methodology.

In conclusion, this study successfully demonstrated the development of a resilient repair methodology for earthquake damaged bridge columns that can be rapidly implemented following a damaging earthquake. 


\subsection{REFERENCES}

ACI Committee 374. (2013). ACI 374.2R-13 Guide for Testing Reinforced Concrete Structural Elements under Slowly Applied Simulated Seismic Loads. Farmington Hills, MI: American Concrete Institute.

Baird, A., Smith, T., Palermo, A., \& Pampanin, S. (2014). Experimental and numerical Study of U-shape Flexural Plate (UFP) dissipators. New Zealand Society for Earthquake Engineering 2014 Technical Conference and AGM.

Bazaez, R., \& Dusicka, P. (2014). Development of Cyclic Loading Protocol for Bridge Columns Considering Subduction Zone Mega Earthquakes. Proceedings of the 10th National Conference on Earthquake Engineering. Anchorage, Alaska: Earthquake Engineering Research Institute.

Bazaez, R., \& Dusicka, P. (2016, May). Cyclic Loading for RC Bridge Columns Considering Subduction Megathrust Earthquakes. Journal of Bridge Engineering, 21(5). doi:https://doi.org/10.1061/(ASCE)BE.1943-5592.0000891

Buckle, I., Friedland, I., Mander, J., Martin, G., Nutt, R., \& Power, M. (2006). Seismic Retrofitting Manual for Highway Structures: Part 1 - Bridges. U.S. Department of Transportation Federal Highway Administration.

Chancellor, N. B., Eatherton, M. R., Roke, D. A., \& Akbas, T. (2014). Self-Centering Seismic Lateral Force Resisting Systems: High Performance Structures for the City of Tomorrow. MDPI Journal of Buildings, 520-548.

D.E. Lehman, S. G. (2001). Repair of Earhtquake Damanged Bridge Columns. 98(2). 
Eatherton, M. R., Ma, X., Krawinkler, H., Mar, D., Billington, S., Hajjar, J. F., \& Deierlein, G. G. (2014). Design Concepts for Controlled Rocking of Self-Centering Steel-Braced Frames. Journal of Structural Engineering, 140(11).

He, R., Yang, Y., \& Sneed, L. H. (2015). Seismic Repair of Reinforced Concrete Bridge Columns: Review of Research Findings. Journal of Bridge Engineering, 04015015-1 04015015-13.

J. Stanton, M. E. (2014). A Pre-Tensioned, Rocking Bridge Bent for ABC in Seismic Regions. Anchorage, Alaska: Tenth U.S. National Conference on Earthquake Engineering.

Kelly, J. M., Skinner, R. I., \& Heine, A. J. (1972). Mechanisms of Energy Absorption in Special Devices for use in Earthquake Resistant Structures. Bulletin of the New Zealand Society for Earthquake Engineering, 5(3), 63-84.

Mashal, M., Palermo, A., \& Chegini, Z. (2014). Quasi-static cyclic tests of half-scale fully precast bridge bents incorporating emulative and post-tensioned low damage solutions. Second European Conference on Earthquake Engineering and Seismology. Istanbul.

Midorikawa, S., Miura, H., \& Si, H. (2012). Preliminary Analysis for Characteristics of Strong Fround Motion from Gigantic Earthquakes. 15th World Conference on Earthquake Engineering. Lisboa.

Murtuz, A. G., Dusicka, P., \& Schumacher, T. (2020). Seismic Performance Design Criteria for Bridge Bent Plastic Hinge Regions. Portland: Oregon Department of Transportation.

Palermo, A., \& Pampanin, S. (2005). Application of hybrid concept for an improved seismic ductile design of bridges. New Zealand Society for Earthquake Engineering Conference.

Palnikov, I. S. (2017). Design and Experimental Investigation of 500kV Current Transformer Seismic Retrofit Utilizing Structure Rocking. Portland: PDXScholar. 
Priestley, M. J., Seible, F., \& Calvi, G. M. (1996). Seismic Design and Retrofit of Bridges. John Wiley \& Sons, Inc.

Priestley, M., \& Park, R. (1987). Strength and ductility of concrete bridge columns under seismic loading. ACI Struct J, 61-76.

Smith, A. D. (2019). Test Setup Design and Cyclic Evaluation of Rocking CLT Wall and Floor Restoring Force Lateral System. Civil and Environmental Engineering. Portland:

PDXScholar. Retrieved from https://pdxscholar.library.pdx.edu/cengin_gradprojects/46

Zhao, X., Wu, Y.-F., Leung, A., \& Lam, H. F. (2011). Plastic hinge length in reinforced concrete flexural members. The Twelfth East Asia-Pacific Conference on Structural Engineering and Construction (pp. 1266-1273). Elsevier Ltd. 